\title{
Understanding factors influencing adverse sex ratios at birth and exploring what works to achieve balance: The situation in selected districts of Nepal
}

Mahesh Puri

Anand Tamang

Follow this and additional works at: https://knowledgecommons.popcouncil.org/departments_sbsr-pgy

Part of the Demography, Population, and Ecology Commons, Family, Life Course, and Society Commons, Gender and Sexuality Commons, and the International Public Health Commons How does access to this work benefit you? Let us know!

\section{Recommended Citation}

Puri, Mahesh and Anand Tamang. 2015. "Understanding factors influencing adverse sex ratios at birth and exploring what works to achieve balance: The situation in selected districts of Nepal." Kathmandu: CREHPA. 


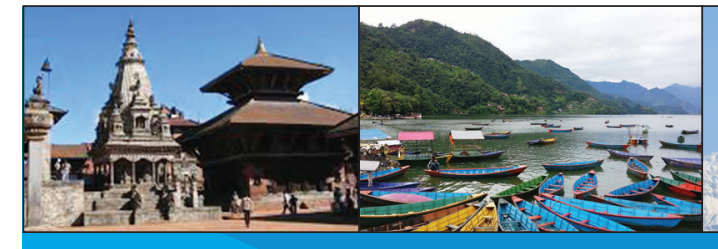

\section{UNDERSTANDING FACTORS}

INFLUENCING ADVERSE SEX RATIOS AT BIRTH AND EXPLORING WHAT WORKS TO ACHIEVE BALANCE: THE SITUATION IN SELECTED DISTRICTS OF NEPAL

NIV THN UKaid
(2) POPULATION COUNCIL

Ideas. Evidence. Impact. 


\section{क्पा}

Established in July 1994, Center for Research on Environment Health and Population Activities (CREHPA) is a not-for-profit research organization based in Kathmandu, Nepal. The organization conducts policy relevant research on population, reproductive and sexual health and rights including on gender-based violence in collaboration with government ministries, universities, bilateral, multi-lateral agencies and international non-governmental organizations. Results of policy research are disseminated widely and utilized for advocacy to influence law and policy decisions.

\section{CREHPA}

Kusunti-13, Lalitpur, Nepal

P.O. Box : 9626 , Kathmandu

Phone : 977-1-5546487, 5521717 Fax: 977-1-5522724

E-mail : crehpa@crehpa.org.np Web: www.crehpa.org.np

\section{NVL \\ ThN \\ UKaid}

This project has been funded by UKaid from the UK Government; however the views expressed do not necessarily reflect the UK Government's official policies.

\section{POPULATION} Ideas. Evidence. Impact.

The Population Council confronts critical health and development issues-from stopping the spread of HIV to improving reproductive health and ensuring that young people lead full and productive lives. Through biomedical, social science, and public health research in 50 countries, we work with our partners to deliver solutions that lead to more effective policies, programs, and technologies that improve lives around the world. Established in 1952 and headquartered in New York, the Council is a nongovernmental, nonprofit organization governed by an international board of trustees.

The information and views expressed in this report do not necessarily reflect the views of the Population Council.

Suggested Citation: Puri, M. and A. Tamang. 2015. Understanding factors influencing adverse sex ratios at birth and exploring what works to achieve balance: The situation in selected districts of Nepal. Kathmandu, Nepal: CREHPA. 


\section{UNDERSTANDING FACTORS INFLUENCING ADVERSE SEX RATIOS AT BIRTH AND EXPLORING WHAT WORKS TO ACHIEVE BALANCE: THE SITUATION IN SELECTED DISTRICTS OF NEPAL}

Mahesh Puri Anand Tamang 


\section{Abbreviations and Acronyms}

$\begin{array}{ll}\text { CBS } & \text { Central Bureau of Statistics } \\ \text { CEDAW } & \text { Convention on the Elimination of Discrimination against Women } \\ \text { CRC } & \text { Convention of Rights of Child } \\ \text { CREHPA } & \text { Center for Research on Environment Health and Population Activities } \\ \text { FCHV } & \text { Female Community Health Volunteer } \\ \text { GSP } & \text { Girls' Scholarship Programme } \\ \text { HDI } & \text { Human Development Index } \\ \text { MoHP } & \text { Ministry of Health and Population } \\ \text { NGO } & \text { Non-Governmental Organization } \\ \text { NHSSP } & \text { Nepal Health Sector Support Programme } \\ \text { PPS } & \text { Probability Proportional to Size } \\ \text { PSU } & \text { Primary Sampling Unit } \\ \text { SMC } & \text { School Management Committee } \\ \text { SRB } & \text { Sex Ratio at Birth } \\ \text { TV } & \text { Television } \\ \text { UN } & \text { United Nations } \\ \text { UNFPA } & \text { United Nations Population Fund } \\ \text { USG } & \text { Ultra-sonogram }\end{array}$




\section{Table of Contents}

Abbreviations and Acronyms iii

Table of Contents $\quad \mathrm{V}$

List of Tables vii

List of Figures

Acknowledgements $\quad$ xi

Executive Summary xiii

CHAPTER 1 INTRODUCTION 1

1.1 Rationale of the study 1

1.2 Objectives of the study 2

1.3 Background 2

1.4 Study design and methodology 5

1.5 Study instruments 7

1.6 Data collection and quality control 8

1.7 Data management and analysis 8

1.8 Ethical considerations 8

1.9 Challenges and limitations 9

1.10 Socio-demographic characteristics of respondents 9

$\begin{array}{lll}1.11 & \text { Report structure } & 11\end{array}$

CHAPTER 2 FACTORS UNDERLYING UNBALANCED SEX RATIOS 12

2.1 Women's perspectives 13

2.2 Stakeholder's perspectives on factors underlying unbalanced sex ratios at birth 19

CHAPTER 3 WHAT WORKS TO REDUCE GENDER-BIASED SEX SELECTION: PERSPECTIVES ON THE ENFORCEMENT OF THE LAW 25

3.1 Women's awareness of the abortion law and other laws protecting women 26

3.2 Women's perceptions about the extent of adherence to and enforcement of $\begin{array}{ll}\text { the Abortion Law } & 27\end{array}$

3.3 Women's attitudes about enforcement of the Abortion Law 28

3.4 Perspectives of districts level stakeholders 29

CHAPTER 4 WHAT WORKS TO REDUCE GENDER-BIASED SEX SELECTION: INITIATIVES TO ENHANCE THE STATUS OF THE GIRL CHILD THROUGH SCHOLARSHIPS, LEGAL AWARENESS AND GENDER EQUALITY PROGRAMMES

4.1 Gender focused programme: women's perspectives 33

4.2 Women's awareness on gender equality programmes 36

4.3 Perspectives of stakeholders on gender-focused programmes 37 
CHAPTER 5 FACTORS UNDERLYING DIFFERENCES BETWEEN KASKI AND TANAHUN

5.1 Perceived value of sons 40

5.2 Pressure to bear a son $\quad 40$

5.3 Disclosure of sex of the foetus and sex selective abortion 40

5.4 Access to health facilities and sex determination technology 41

5.5 Perceptions about factors underlying differences in the intensity of son preference 41

5.6 Exposure to health care providers and community mobilization activities 42

$\begin{array}{lll}5.7 & \text { Law enforcement } & 42\end{array}$

5.8 District level stakeholders' recommendations for addressing unbalanced SRB $\quad 43$

$\begin{array}{ll}\text { CHAPTER } 6 & 46\end{array}$

$\begin{array}{ll}\text { References } & 48\end{array}$

$\begin{array}{ll}\text { Annex 1: } & \text { A summary of programmes and interventions }\end{array}$

$\begin{array}{ll}\text { The Study Team } & 51\end{array}$ 


\section{List of Tables}

Table 1.1: Socio-demographic profile of selected study sites, Nepal

Table 1.2: The sample coverage: Household survey

Table 1.3: Number and category of district level stakeholders covered for in-depth interviews

Table 1.4: Selected background characteristics of women who had participated in the survey:

Kaski and Tanahun

Table 2.1: Percent distribution of women by ideal number of children and actual family size:

Kaski and Tanahun

Table 2.2: Indicators of son preference among women having two living children: Kaski and Tanahun

Table 2.3: Percentage of women reporting various attitudes relating to son preference:

Kaski and Tanahun

Table 2.4: Percentages of women reporting experience of ultrasonography during pregnancy, disclosure of the sex of the foetus, and acquaintance with others to whom sex of the foetus was disclosed: Kaski and Tanahun

Table 2.5: Percentage of women reporting experiences of personal disclosure of the sex of the foetus by parity and sex of previous child: Kaski and Tanahun

Table 2.6: Percentage of women who underwent an abortion by reasons for abortion: Kaski and Tanahun

Table 2.7: Percentage of women reporting opinions on the consequences of adverse sex ratio: Kaski and Tanahun

Table 3.1: Percentage of women reporting awareness of different laws protecting women: Kaski and Tanahun

Table 3.2: Percentage of women reporting awareness about laws that prevent sex selective abortion by sources of information: Kaski and Tanahun

Table 3.3: Percentage of women reporting that providers continue to violate the Abortion Law, and that raids and punishment of violators have taken place in their areas: Kaski and Tanahun

Table 3.4: Percentage of women reporting opinions on the law prohibiting sex selection and punishment of law violators: Kaski and Tanahun

Table 4.1: Percentage of women reporting names of scholarship for girls and amount of scholarship: Kaski and Tanahun 
Table 4.2: $\quad$ Percentage of women reporting perceived positive and negative aspects of the scholarships for girls: Kaski and Tanahun

Table 4.3: $\quad$ Percentage of women reporting exposure to gender equality programmes: Kaski and Tanahun

Table 4.4: Percentage of women reporting the sources of information that talks about not discriminating against daughters: Kaski and Tanahun

Table 4.5: Percentage of women reporting the sources of information that campaigns for saving the girl child: Kaski and Tanahun

Table 4.6: Programmes in the study districts to raise the value of girls and women as reported by stakeholders: Kaski and Tanahun 


\section{List of Figures}

Figure 2.1: Mean ideal number of children, children ever born and children surviving

Figure 2.2: Experience of induced abortion

Figure 2.3: Percentage of women reporting various attitudes towards gender-biased sex selection (\% of agreeing)

Figure 3.1: Percentage of women reporting awareness of legal provision concerning sex selective abortion

Figure 4.1: Percentage of women who had heard about free textbooks or school uniforms for girls and had received free textbooks for their daughters

Figure 4.2: Percentage of women who had heard about scholarship schemes for girls and whose received a daughter had scholarship

Figure 5.1: Percentage of women reporting experience of pressure from family members to have a son while pregnant

Figure 5.2: Percentage of women reporting relationship with family member who pressurised her to have a son while pregnant 


\section{Acknowledgements}

The successful completion of this important study is an outcome of the collaborative efforts of Centre for Research on Environment Health and Population Activities (CREHPA), Population Council- India and many other organizations and individuals. First of all, we would like to thank the Population Council for entrusting us with such an important piece of work. The study team wishes its sincere gratitude to Dr. Shireen Jejeebhoy (Population Council, India) for her input, technical advice, guidance and support throughout the study. Our sincere appreciation also goes to Dr. Rajib Acharya, (Population Council, India) for his contribution in the design and finalization of research tools and in providing feedbacks on the draft version of this study. We express our sincere gratitude to Dr. Melanie Frost (Oxford University, United Kingdom) for her excellent review and suggestions.

We would like to express our sincere thanks to the Local Development Office, District Education Office, District Public Health Office, Women and Children Development Office and District Police Office of both study districts- Kaski and Tanahun for their support during the data collection for this study.

Finally, the participation of district level stakeholders and women who received the study team with understanding and patience and shared their perceptions and personal experiences in this study are gratefully acknowledged. This study would not have been possible without their voluntary and enthusiastic participation.

The Study Team 


\section{Executive Summary}

In South Asian countries, strong son preference has led to serious discriminatory practices towards girls and women, with negative effects on their status, health and development. These gender disparities have resulted in a skewing of population and child sex ratios. Nepal has begun showing signs of skewed or disturbed sex ratios at birth in some districts of the Terai and hill regions-a reflection of persistent gender discrimination, combined with a preference for small numbers of children and the increasing availability of prenatal diagnostic technologies including ultrasonography (USG) since the 1980s and consequently an increase in the practice of gender-biased sex selection. While the Government of Nepal is committed to ensuring women's legal right to abortion under certain conditions, disclosure of the sex of the foetus and subsequent termination of pregnancies carrying a female foetus are prohibited by law.

In this scenario, district-level differences in sex ratios raise questions such as: what accounts for the worsening of the sex ratio at birth in some districts of Nepal, but not in neighboring districts? To what extent are USG and other prenatal diagnostic techniques misused in those districts? Our limited understanding of the answers to these questions poses a key challenge to our understanding of promising approaches that will halt or reverse trends in adverse sex ratios at birth in Nepal. The gap between policy and programme commitments and realities is the limited evidence on effective programme strategies that reduce couples' practice of sex selection in this country.

Recognizing these gaps in understanding, and with support from UKAid, the Population Council, India, and the Centre for Research, Environment, Health and Population Activities (CREHPA), Nepal, and led by the Council's India office, have undertaken a project that aims to shed light on the issue of gender-biased sex selection in India, Bangladesh, Pakistan and Nepal, and make evidence-based recommendations for actions that hold promise for responding to adverse sex ratios at birth in these settings.

In Nepal, two adjoining hill districts located in the western development region, namely, Kaski (where sex ratios are adverse) and Tanahun (where sex ratios are normal) were selected for study. This study adopted a mixed method design that included a population-based survey of 1,000 married women with at least two children, one of whom was aged 0-5 years; and 29 key informant interviews with stakeholders such as district-based public and private sector health care providers and programme implementers/managers.

Results show that several background characteristics of sampled women in the two districts were similar: their age distribution and religious affiliation, for example. Differences were however observed in terms of ethnicity/caste composition, level of education, household wealth, paid work, status of women and women's agency. Women in Kaski were better educated, were better off in terms of household wealth, and had greater freedom of movement and self-efficacy than women in Tanahun.

The three preconditions identified by Guilmoto (2011) as key in accounting for skewed sex ratios at birth, include: preference for small families, persistent strong son preference, and access to pre-natal diagnostic technology, all which were prevalent in both districts. For example, women in both Kaski and Tanahun expressed a desire for a small family size. Likewise, son preference as measured by three indictors (no sex preference on their ideal number of children, and desire to continue child bearing and family planning practice, respectively, by the sex composition of living children) was evident in both districts, but was slightly stronger among women in Kaski (particularly urban Kaski) than in Tanahun. Key informants from both districts reiterated the prevalence of son preference in their district, but confirmed that it was more pronounced in Kaski than in Tanahun.

More women in Kaski than Tanahun reported that they had experienced USG in at least one pregnancy to track the development of the foetus ( $82 \%$ versus $52 \%$ ), and more admitted that they had obtained information on sex of the foetus (42\% versus 32\%) during pregnancy. Women reporting disclosure of the sex of the foetus increased by parity, particularly in Kaski (from $11 \%$ in parity one to $29 \%$ at parity three). Similarly, significantly more women from Kaski than Tanahun reported that they or someone they knew had been told the sex of their foetus $(67 \%$ versus $40 \%$ ). In addition, women from Kaski demonstrated a greater inclination to have an induced abortion following sex determination than did those from Tanahun. It is highly likely that women would underreport sex selection in view of the illegality of the practice although the demand for disclosure of sex of foetus has increased in recent years as also confirmed by the key informants. 
In order to ascertain factors likely to have contributed to inter-district differences, we explored the extent to which differences emerged in terms of the spread of educational entitlements for girls, implementation and awareness of the laws relating to disclosure of the sex of the foetus, and implementation of and exposure to communication, advocacy and community mobilization activities. We also explored perspectives about the structural differences that set the two districts apart. Nearly all stakeholders from both the study districts mentioned that Kaski was a more developed district than was Tanahun, had better access to sex selection technology and people living in this district were better informed about sex selection procedures and the location of USG services than were those in Tanahun. Several stakeholders suggested that factors underlying normal or "balanced" sex ratios in Tanahun may therefore be its dominant rural population, its relative poverty and more limited purchasing power of its residents, the more limited number of diagnostic facilities and trained providers, and women's more limited access to available facilities.

As far as initiatives to implement the law were concerned, stakeholders from both the districts identified weak enforcement of the law on sex selective abortion and poor monitoring mechanisms as a reason for the proliferation of USG services, especially in Kaski. They suggested that neither raids nor prosecutions had taken place in their district or anywhere else in the country, and pointed to corruption within the system and the ability of powerful providers to avoid prosecution as key reasons. However, stakeholders from Tanahun reported that their district public health office played an active role in enforcing the law, monitoring facilities and equipment, and confronting violators.

With regard to entitlements for girls' education, findings suggest that school-based entitlements, including scholarships were accessed in both districts but more so in Tanahun than Kaski (37\% versus 18\%), the poorer of the two districts.

Differences were however observed in communication, advocacy and community mobilization activities focusing on raising the value of girls. Tanahun reported relatively better community-based gender-focused programmes promoting gender equality and the value of the girl child than Kaski. While somewhat more women from Kaski than Tanahun were exposed to media messages, more women from Tanahun than Kaski had been exposed to interpersonal communication delivered by frontline workers, NGO programmes and discourses by religious leaders.

To address the adverse sex ratio at birth (SRB), stakeholders made certain recommendations. These emphasized the need for measures to change public attitudes towards girl children; raise the value of girls; focus on girl's education and vocational skill training; ensure a daughter's right to parental property; and engage women more effectively in decision making bodies of the country. They stressed that such strategies should focus on quality formal education, social and financial skills, and offering economic support and incentives for girls and their families. They also called for greater media involvement to increase knowledge about the negative consequences of sex selective abortion. At the system and programme level, stakeholders recommended more effective enforcement of abortion laws that prohibit the disclosure of the sex of the foetus, and regular monitoring and supervision of facilities offering USG services.

\section{Way forward}

Our findings suggest that in the absence of direct interventions on this issue, there is a possibility of a worsening situation in Nepal with regard to the sex ratio at birth as access to prenatal diagnostic techniques proliferates to districts beyond Kaski. With regard to programme initiatives that hold promise, we may draw inferences from interdistrict differences, about the likely effectiveness of communication, advocacy and community mobilization efforts in the short term. In the long term, what is required are programmes which aim to empower girls, promote gender equality and improve girls' overall situations. Programmes must focus on keeping girls in school and ensure that they complete a secondary education, providing girl-friendly education to encourage school retention, and expand the reach of the universal scholarship scheme for girls. Other efforts adopted in neighboring countries, including conditional cash transfer schemes that provide benefits to parents when their daughter achieves immunization, education and other milestones, and remains unmarried until age 18 may also hold promise. 


\section{CHAPTER 1 \\ INTRODUCTION}

\section{Summary}

The goal of this study is to identify programmes and socio-cultural factors underlying disparities in sex ratios at birth in some parts of Nepal, by comparing the situation in districts with high and normal sex ratios at birth and among under- 5 children. Findings are expected to inform the design of programmes intended to raise the value of girls in general and counter the practice of gender-biased sex selection in particular. This study was conducted in two adjoining hill districts of the western development region of Nepal, namely, Kaski (where sex ratios are adverse) and Tanhaun (where sex ratios are normal). This study adopted a mixed method that included a population-based survey of 1,000 married women with at least two children, one of whom was aged 0-5 years; and 29 key informant interviews with district based public and private sector health care providers and programme implementers/managers. A total of 24 field researchers were involved in the data collection. Data were collected between October and November, 2014.

Some background characteristics such as age distribution and religion affiliation of surveyed women in the two districts were similar. Differences in characteristics were also observed. For example, caste/ethnicity distribution show that more women in Kaski than Tanahun belonged to upper caste group (Brahmin/Chhetri). In contrast, more women in Tanahun than Kaski belonged to the disadvantaged indigenous group (Janajatis). Similarly in educational attainment, women in Kaski were better educated than those in Tanahun. Comparatively, a higher percentage of women in Kaski than Tanahun were better off in terms of household wealth and general wellbeing. Similar differences were also observed in paid work status of women. Differences were also noticed in aspects of women's agency-a higher percentage of women in Kaski than Tanahun reported freedom of movement to go unescorted to a meeting or programme, or to visit friends and relatives outside their area of residence, and to express themselves freely to their husbands on household matters.

\subsection{Rationale of the study}

Gender-biased sex selection and its consequence on the sex ratios of population is an emerging issue in Nepal. Nepal has only recently legalized abortion, meaning that unlike in its neighbors India and China, the use of sex-selective abortion has not received much attention in either the research or policy context. However, in the wake of legalization and increasing availability of prenatal sex-determination technologies, the religious and socio-economic values given to sons, reduction in fertility, and pressure put on couples to have a son coupled with the lack of a focused policies and programmes to address gender discrimination (including sex selection), and the weak enforcement of the law relating to disclosure of the sex of the foetus, it is feared that the practice of gender-biased sex selection may increase in the future. Though very limited, studies indicate that the practice of sex selection is more prevalent among relatively rich, educated, urban women and in areas bordering with India (Frost et al, 2013; Lamichhane et al., 2011). However, more research is needed to validate this information.

In Nepal, notwithstanding commitments to gender equality and women's empowerment in the Interim Constitution and the National Plan of Action for Gender Equality and Women's Empowerment, there are hardly any focused programmes intended to raise the status of girls or address son preference and gender-biased sex selection. Although the law strictly prohibits the disclosure of the sex of the foetus and sex selective abortion, enforcement of such laws is unclear as revealed by anecdotal information. Likewise, while limited and not well coordinated, advocacy efforts have been implemented by NGOs and the mass media, their effect in raising awareness of the law, changing attitudes relating to son preference, and affecting practices related to gender-biased sex selection are not known. The issue of sex selection and its sequel on sex ratio imbalance among children 0-4 years in certain districts of Nepal is likely to pose an even greater challenge in the coming years when more Nepalese couples accept the advantages of a small family size. It is important, therefore, to better understand the causes of the skewed sex ratios in certain districts of the country, and understand the factors underlying skewed sex ratios in these districts compared to neighboring districts with similar characteristics in terms of ethnicity/caste, religion, education and economic status 
from the perspectives of women and various stakeholders, including health care providers and those engaged in enforcing laws or addressing female empowerment issues.

\subsection{Objectives of the study}

Since there is an indication from the Nepal Population Census that imbalanced sex ratios among children 0-4 years are apparent in some districts in the Terai and hill regions but not in others in the same region, the main objectives of the study are to identify programme and socio-cultural factors underlying disparities in sex ratios at birth or child sex ratio in some parts of Nepal and inform the design of programmes intended to raise the value of girls in general and counter the practice of gender-biased sex selection in particular. More specifically, the study is aimed at:

- Identifying factors underlying the worsening of the sex ratio at birth or sex ratio of children in some parts of Nepal;

- Understanding providers' and programme policy makers' perspectives about the practice of gender-biased sex selection; and

- Informing the design of programmes intended to raise the value of girls in general and counter the practice of gender-biased sex selection.

\subsection{Background}

Many Asian settings have long been characterized by wide gender disparities and a strong preference for sons, often manifested in terms of the greater investment in the health, nutrition and education of sons over daughters. These gender disparities have resulted in several settings, including South Asia, in a skewing of population and child sex ratios. Since the 1980 s, however, the increasing availability of prenatal diagnostic technologies has facilitated an increase in the occurrence of gender-biased sex selection. As a result, sex ratios at birth have become skewed, far beyond the normal ratio of 105 male births for 100 female births. Sex ratios at birth are most skewed in China (117.8 in 2011), Vietnam (111.2 in 2010), Azerbaijan (116.5 in 2011), Armenia (114.9 in 2010) and Georgia (113.6 in 2009-11) (UN, 2013; UNFPA, 2012). South Korea also exhibited a hugely skewed sex ratio at birth in the 1980s, but succeeded in reversing this trend, from a high of 116 in 1993-94 to 106 by 2009 (Kim, 2013; UN, 2013).

In South Asia too, sex ratios at birth are skewed: while Bangladesh and Nepal are showing signs of disturbed sex ratios at birth, with ratios of 109 in Bangladesh (NIPORT et al., 2013), 106 in Nepal (Central Bureau of Statistics, 2012), the situation in India is particularly adverse. India's sex ratio at birth today stands at 110 male births per 100 female births (Office of the Registrar General, India, 2013). While Pakistan's sex ratio at birth is normal (102.5), there are some settings (Sind, for example and some urban pockets) that are found to display a disturbed sex ratio at birth (NIPS and ICF International. 2013).

Since historic times, Nepal has been a patriarchal society. Women in Nepal face unequal power relations with their male counterparts and strong gender-based barriers to realizing their aspirations. Patriarchal values are deeply ingrained in the social and economic spheres of Nepali life which has led to the development of gender-biased institutions and structures, ideology, and social norms which continue to limit the progress of women. These strong biases against women are clearly depicted in the daily reality of son preference in society.

In Nepal, a son is preferred to a daughter for several reasons; carrying on family lineage, providing support to elderly parents and performing funeral rituals for deceased parents (Nanda et al., 2012; Subedi, 2011; Puri, 2010). Gender inequality remains prevalent across all religious, social, cultural, economic and political spheres of life. Due to deeply embedded patriarchal values in Nepali society, opportunities in terms of education, health, employment, decision making, and in other social and economic dimensions are limited for girls and women. In addition, gender-based violence is widely practiced and accepted across Nepal, controlling and confining women within the domestic sphere of home (MoHP, 2012).

Strong son preference can lead to an increased number of boys, and differential treatment of girls in terms of resource allocation, leading to female disadvantage in mortality and morbidity. According to the 2011 Census, among children below 10 years of age in Nepal, the number of male children exceeded female children by $2.2 \%$. In urban Nepal, 5.6\%more male than female children were reported as compared to $1.7 \%$ more male than female children in rural Nepal (CBS, 2012). Newborn females have a biological advantage in survival over newborn males and throughout the life course the same is expected if access to resources such as food and medical care is the 
same for males and females (Waldron, 1998). In Nepal, however, although more male neonates die than female (Male: 37 deaths per thousand live births, Female: 33 deaths per thousand live births) female post neonatal mortality (between the ages of 28 days and 1 year) is higher (19 per thousand live births) than the male post neonatal mortality rate (17 per thousand live births) (MoHP, 2012).

Strong son preference compounded by the availability of sex determination technology (e.g. ultra-sonogram) enables couples to resort to sex selective abortion which contributes to increased sex ratio at birth (SRB) and an imbalanced population sex ratio (Guilmoto, 2009). Ultra-sonogram (USG) has become more available over the past decade and costs around USD6 even in rural and remote areas of Nepal (NHSSP, 2013). The Government of Nepal is promoting at least two USG scans as a component of antenatal care (NHSSP, 2013). Fertility is rapidly declining in Nepal. In the past 15 years, the fertility of Nepali women has decreased by two children. On average, a woman during 1996 used to have 4.6 births but it decreased to 2.6 births per women in 2011 (MoHP, 2012).

Until recently, the maternal mortality ratio (281 per 100,000 live births) of Nepal was among the highest in the world (MoHP et al., 2007). Significant proportions of maternal deaths and life threatening gynaecological complications were attributed to unsafe abortions (Pradhan et al., 2010). In response to the increasing evidence of maternal deaths and injuries related to unsafe abortions, and to provide Nepali women with increased power to decide on their fertility choices, in 2002 the Government of Nepal amended the Muluki Ain 1959 (the main National Legal Code) which had earlier criminalized abortion, characterizing it as an offence against life (Ministry of Law, Justice and Parliamentary Affairs, 1997). This amendment led to the development of the National Safe Abortion Policy and Strategy 2002 which ensures access to safe abortion services under the following conditions: up to 12 weeks of gestation upon pregnant women's consent; up to 18 weeks of gestation if the pregnancy results from rape or incest; at any time during pregnancy if it threatens the life, physical or mental health of women or in the case of a deformed foetus with the advice of a medical practitioner and the pregnant woman's consent (MoHP, 2002). Furthermore, only certified providers based in certified clinics can perform the procedure. Termination of pregnancies which have indications of sex determination is legally prohibited (MoHP, 2002).

No separate law regarding preconception and prenatal diagnostic techniques has been enacted in Nepal. In the present Muluki Ain, which liberalized the old restrictive law on abortion, there is clause Number 28A that restricts the use of technology or any means to determine the sex of a foetus for the purpose of sex-selective abortion. The law states:

"No one shall commit or cause to be committed an act to identify (determine) the gender of the foetus for the purpose of abortion. A person who commits this offence shall be liable to the punishment of imprisonment for a term ranging from three months to six months."

According to the law, both the woman undergoing the sex determination test and the physician/medical personnel conducting such a test for the purpose of sex selection shall be imprisoned for a term ranging from three to six months. Moreover, if the woman undergoing the sex determination test is doing so as a result of family pressure, if it can be proved in the court of law, the family member who had put such a pressure on the woman and the medical personnel conducting the test to reveal the sex of the foetus are liable for imprisonment also. However, it is not stated either in the Muluki Ain or National Safe Abortion Policy and Strategy 2002 about the institutions responsible for enforcing the law and monitoring its implementation. To date, no criminal prosecution has been made in Nepal against the offence of sex determination test or sex selective abortion because of the lack of surveillance mechanisms (Lamichhane et al., 2011).

Access to technologies that can determine the sex of foetus, culture of strong preference for sons, expansion of safe abortion services, rapid decline in total fertility rates (MoHP et. al, 2007 and 2012) and recent reports of skewing sex ratio at birth in Nepal (CREHPA, 2007; Frost et al, 2013) has raised some concerns among researchers, policy makers and programme implementers. Considerable attention has been devoted to this problem because of its harmful effects to the children of the less-desired sex. Moreover, it can have unfavorable demographic and social consequences. For example, strong gender preference can lead to sex-selective abortions, and hence to skewed sex ratios (Guilmoto, 2009). Consequences of skewed sex ratio at birth in countries where the issue has been prevalent for long time are expected to be dire. Daughter preference is less observed around the globe and in countries where sons are preferred to daughter, and sex ratio at birth is highly skewed, consequences such as shortages of marriageable women, high rate of rape/incest, violence, abduction, trafficking and risky sexual behaviors has been documented (Hesketh and Xing, 2006; UNFPA, 2012; Bien et al., 2013). 
Limited studies that have focused on gender selection, differential in health care by gender, desired sex composition of children and contraceptive use have revealed that the son preference has been very strong in Nepal when compared to other countries around the world (Arnold et al, 1997; Leone et al, 2003; CREHPA, 2007; Jayaraman, et al. 2009; Frost et al, 2013; Bongaarts, 2013). Arnold (1997) using data from Nepal Fertility, Family Planning and Health Survey 1991 and 56 Demographic and Health Surveys from 44 other countries conducted during a 10 year period from 1986 to 1995 found that, among all countries, even at parity one, women from Nepal only showed preference for son ( $89 \%$ with a daughter as compared to $79 \%$ with a son wanted to bear another child). Son preference increased starkly by the second parity as more than three times as many women who had two daughters (77\%) wanted to continue child bearing as compared to women who had two sons (25\%). Similar patterns were observed as the parity increased.

Likewise, Leone et al. (2003) examined son preference and gender bias in Nepal using the data of Nepal Demographic and Health Survey, 1996. The study found strong son preference among Nepali women. Among 4,661 ever-married women aged 15-49 who had stopped child bearing, overall sex ratio at last birth which suggests the way families exercise preference for son was 146, indicating a tendency to stop child bearing when a son was born. Likewise, great disparity in contraception prevalence was observed as a result of son preference. Among 5,902 women with up to four children, the overall contraception prevalence was $25 \%$. If these women had had no desire for a son, the contraceptive prevalence rate would have soared to 33\%. (Leon et al, 2003).

Another study conducted among 2,644 married women of the age group 15-49 years, their husbands and motherin-laws in five districts; Dhanusa, Parsa, Kapilbastu, Gorkha, and Kathmandu showed that in the first pregnancy, the majority of the women (54\%) had no gender preference, $40 \%$ preferred sons, and only $6 \%$ preferred daughters (CREHPA, 2007). In general son preference was highest among mothers-in-law (52\%) followed by husbands (50\%) whereas daughter preference in the first pregnancy stood very low; at $4 \%$ and $3 \%$ respectively for husbands and mothers-in-law. Preference for sons was high in the Terai (low land) communities (51\%, 47\%, 42\% respectively for Yadav, Terai Dalit and Tharu) as compared to women of Hill communities (28\% for Hill Brahmin and Magars). Major reasons for son preference that were cited are: elderly parent support (79\%), economic value (67\% carrying family lineage (60\%) and funeral rituals (59\%). Some of the major reasons for not preferring daughters were that daughters go to the husband's home after marriage, and dowry, making women a perceived unproductive investment. The study also revealed that women face tremendous pressure from husbands (42\%) and mothers-in-law (41\%) to bear sons. Women who had daughters as their first children faced different forms of violence and deprivation. The same study also found that of the 2,504 ever-pregnant women, 222 had used some measures to influence the sex of their child to be male, which included observing religious rites, visiting shamans or consulting a doctor to find out if any medical measures could help them to bear male children in their next pregnancy. Another study by Brunson (2010) also showed that despite modest improvements in gender equality, level of education, and economic conditions, the practical knowledge that daughters will be lost to other lineages and households pressures couples who might otherwise be willing to invest in daughters to continue procreating until they produce a son (Burnson, 2010).

Another study by Fuse (2008) which measured gender preference attitudes using Demographic and Health Survey data from 40 countries including Nepal Demographic and Health Survey, 2006 found that among 10,363 women of reproductive age (15-49 years) from Nepal, 17\% did not have any gender preference, $52 \%$ wished that they had an equal number of sons and daughters, $29 \%$ preferred more sons and $1.6 \%$ preferred more daughters. Among all the 40 countries, women from Nepal stood at fifth position in terms of son preference and second (to Pakistan) when compared to its South Asian counterparts. Among all the 40 countries, Nepal showed least preference for daughters (1.6\%) among women, putting it at top of the rank in terms of low daughter preference. Similarly, another study that examined the extent of son preference-Nepal, India and Bangladesh found that found that the desire for another child decreased as parity increased and at any given parity, women with higher numbers of sons showed the least desire for another child. At parity one, $77 \%$ of the women with no sons and $64 \%$ of the women with one son desired for another child with a difference of $11 \%$. The desire increased starkly at parity two, with $51 \%$ of women with two daughters desiring another child compared to $6 \%$ of women with two sons. Similarly at parity three, $45 \%$ of women with three daughters wanted another child whereas only $1 \%$ women with three sons wanted more children (Jayaraman et. al., 2009).

This picture raises questions such as: what accounts for the worsening of the sex ratio at birth in some districts of Nepal, but not in neighboring districts? To what extent are ultrasound and other prenatal diagnostic techniques misused in those districts displaying adverse sex ratios? Our limited understanding of the answers to these 
questions poses a key challenge to our underlying of promising approaches to halting or reversing trends in adverse sex ratios at birth in Nepal. The gap between policy and programme commitments and realities is the limited evidence on effective programme strategies that reduce couples' practice of sex selection in this country.

To our knowledge, no separate Act or policy addressing the root causes of gender discrimination, son preference and conditional cash transfer programmes for every girl child is present in Nepal. No special programme exists for this, except a general programme that supports parents for the education of their daughters. Although the Interim Constitution of Nepal 2007 mentions that the State shall not discriminate against citizens on grounds of sex, religion, race, caste, tribe, sex, origin, language, a report in 2009 revealed that there are still several discriminatory provisions and schedules, mainly on nationality, marriage and family relations, sexual offences, and property rights, all of which counter the rights of women and the girl child. A bill to address these discriminatory provisions is drafted and waiting for Cabinet approval. Gender and social inclusion, gender mainstreaming and women's empowerment including gender-based budgeting have received prime importance in the national agenda, and the National Plan of Action for Gender Equality and Women's Empowerment have been implemented by the government since 2004. However, no focused programmes to address sex selection has been developed and implemented yet by the Government. Although the law strictly prohibits sex determination tests and sex selective abortion, enforcement of such laws is weak and unregulated. Nepal's efforts to address gender inequities and gender-biased sex selection and its effectiveness are presented in Annex 1.

Recognizing these gaps in understanding, and with support from UKAid, the Population Council's Bangladesh, India and Pakistan offices, and the Centre for Research, Environment, Health and Population Activities (CREHPA), Nepal, and led by the Council's India office, have undertaken a project that aims to shed light on the issue of genderbiased sex selection in these countries and make evidence based recommendations for actions that hold promise for responding to adverse sex ratios at birth in these settings. The project was implemented in two phases, an initial phase in which researchers reviewed and synthesized the available evidence on the situation and available programmes to counter gender-biased sex selection, and identified key research topics; and a more recent primary research phase in which researchers explored key emerging questions in each setting.

\subsection{Study design and methodology}

This study adopted a mixed method approach that included a population-based survey of married women with at least two children, one of whom was aged 0-5 years; and key informant interviews with district based public and private sector programme implementers/managers. In the survey, apart from soliciting their socio-economic and demographic characteristics (such as age, education, occupation, ethnicity and place of residence) of married women, they were asked about their marriages, birth histories, "wanted-ness" of each pregnancy, histories of termination or pregnancy loss, use of contraceptives between two births, use of USG during pregnancy, and whether the sex of foetus had been disclosed. Researchers also asked women about their preference about family size and composition, and attitude relating to son preference or daughter preference. The survey also asked women about their mobility, autonomy, awareness of the law related to abortion, exposure to advocacy and community mobilization efforts intended to change attitudes about sons and daughters and acceptability of gender-biased sex selection.

The in-depth interviews with district level health care providers (obstetricians and gynecologists, radiologists, nurses and others engaged in conducting USG and other prenatal diagnostics tests) and programme managers at government and NGO levels were conducted to assess their perceptions about son preference, the prevalence of gender-biased sex selection in their districts, demand for disclosure of the sex of foetus, the practices used by health care providers in disclosing the sex of the foetus, the extent of enforcing of the abortion law, reasons underlying unbalanced sex ratio in Kaski and normal/balances sex ratios in Tanahun. Any initiative that aimed at raising status of girls and changing community attitudes towards daughters in their districts were also probed. Challenges faced and recommendations for community mobilization, advocacy and communication programmes intended to change community attitudes towards daughters were also assessed.

\subsubsection{Study sites}

Two adjoining hill districts of the western development region, namely Kaski and Tanahun were chosen as the study sites. Kaski district represents a district with a high child sex ratio (113.9) and Tanhaun with a normal child sex ratio (101.8) (CBS, 2012). Kaski district covers an area of $2017 \mathrm{~km}^{2}$ and inhabits a population of 492,098 in 2011. 
Table 1.1: Socio-demographic profile of selected study sites, Nepal

\begin{tabular}{|c|c|c|c|}
\hline Indicator & Nepal & Kaski & Tanahun \\
\hline Population (2011) & $26,494,504$ & 492,098 & 322,288 \\
\hline Number of municipalities (2011) & 58 & 2 & 1 \\
\hline Village Development Committees & 3,915 & 43 & 46 \\
\hline Human Development rank/Index (HDI) (2013) & 138 & 0.576 & 0.506 \\
\hline Major ethnic groups & $\begin{array}{l}\text { Chhetri, Brahmin, } \\
\text { Magar, Tharu and } \\
\text { Tamang }\end{array}$ & $\begin{array}{l}\text { Brahmins, Gurungs, } \\
\text { Chhetris, Magars }\end{array}$ & $\begin{array}{l}\text { Brahmins, Gurungs, } \\
\text { Chhetris, Magars and } \\
\text { Newars }\end{array}$ \\
\hline
\end{tabular}

Sources: Central Bureau of Statistics (2012)-Nepal Population and Housing Census 2011-Major highlights, Kathmandu, Nepal; National Planning Commission/Government of Nepal/UNDP (2014)-Nepal Human Development Report 2014: Beyond Geography, Unlocking Human Potential. Kathmandu, Nepal

This district has two municipalities and 43 Village Development Committees, while Tanhaun district has geographical area of $1546 \mathrm{~km}^{2}$ and a population size of 322,288 in 2011. Tanahun has one municipality (Damoli) and 46 Village Development Committees. The Human Development Index ranged from 0.576 in Kaski to 0.506 in Tanahun in 2013. Ethnic profiles were largely similar, with major ethnic groups comprising Brahmins, Gurungs, Chhetris and Magars in both districts, and additionally, Newars in Tanahun.

\subsubsection{Study sample and sampling procedures}

The study interviewed 1,000 women (500 per district, 250 each from rural and urban areas) with at least two children, one of whom was born in the five years preceding the survey. The selection of married women fulfilling the above parity and age criteria was based on a multi-staged-stage cluster sampling technique.

In the first stage, a listing of all Village Development Committees and Municipalities of two study districts were listed separately in alphabetical order together with their household/population in each ward using data from the Population Census, 2011. A ward of a Village Development Committee was considered as a cluster and served as the Primary Sampling Unit (PSU). From the list of clusters, 20 clusters (10 from urban and 10 from rural) in each district were selected using the probability proportional to size to (PPS) method. Each cluster comprised at least 200 households in the urban areas and 150 households in the rural areas. The selection of urban and rural sampling units was done independently. Thus, a total of 40 clusters ( 20 from each district) were selected. This level of selection was made in Kathmandu. In cases of not having 150 households in sampled clusters, an adjoining ward/s of the same Village Development Committee was clubbed and treated as one sampling unit. In urban areas, if a selected cluster had more than 200 households, then the cluster was divided into segments containing at least 200 households and one segment was selected randomly.

In the second stage, the research team made door-to-door visits, and administered a short screening household questionnaire to the most knowledgeable adult person of the household and identified households having an eligible respondent fulfilling the study criteria. From the households containing eligible women, 25 respondents in each cluster were selected using the systematic random sampling method. If there was more than one eligible woman in a household, one respondent was randomly selected using the Kish table (Kish, 1949). When the respondent selected was not available, the interviewer made an appointment to return to conduct the interview. At least two additional visits were made before the respondent was considered not available for interview. In the case of non-availability of selected eligible respondents in any of the sampled households, additional households were sampled from the same list until the team completed 20 individual interviews in a cluster. Altogether, 5,012 households (2,518 in Kaski and 2,494 in Tanahun) were visited to interview 1,000 women. The overall response rate was 94\%, with a higher response rate in Kaski (97\%) than in Tanahun (91\%) (Table 1.2). 
Table 1.2: The sample coverage: Household survey

\begin{tabular}{lcccc}
\hline District and site & $\begin{array}{c}\text { Number of } \\
\text { households visited } \\
\text { and screened for } \\
\text { eligible women }\end{array}$ & $\begin{array}{c}\text { Number of married women with } \\
\text { at least two children, one of whom was } \\
\text { aged } \mathbf{0 - 5} \text { interviewed }\end{array}$ & $\begin{array}{c}\text { Response rate } \\
\text { (\%) }\end{array}$ \\
\cline { 3 - 4 } Kaski-Total & $\mathbf{2 , 5 1 8}$ & $\mathbf{5 1 7}$ & \\
Kaski-Rural & 1,224 & 256 & $\mathbf{5 0 0}$ & $\mathbf{9 6 . 7}$ \\
Kaski-Urban & 1,294 & 261 & 250 & 97.7 \\
Tanahun-Total & $\mathbf{2 , 4 9 4}$ & $\mathbf{5 4 7}$ & 250 & 95.8 \\
Tanahun-Rural & 1,230 & 280 & $\mathbf{5 0 0}$ & $\mathbf{9 1 . 4}$ \\
Tanahun Urban & 1,264 & 267 & 250 & 89.3 \\
Total (Kashi and Tanahum) & $\mathbf{5 , 0 1 2}$ & $\mathbf{1 , 0 6 4}$ & 250 & 93.6 \\
\hline
\end{tabular}

In the qualitative study, 29 in-depth interviews with district level stakeholders were carried out. Of them, 17 were programme implementers/managers (6 in Kaski and 11 in Tanahun) responsible for the implementation of a range of activities-programmes for girls, communication, community mobilization and advocacy, law enforcement-at government and NGO levels, and 12 were health care providers (six in each district) such as obstetricians and gynaecologists, radiologists, others engaged in conducting USG and other prenatal diagnostics test and nurses. A list of potential participants both for the health care providers and programme implementers (both governmental and non-governmental) was prepared andbased on these lists, the participants were selected purposively from government and private facilities/organizations. Of the total participants interviewed, 14 were females (four health providers and 10 programme implementers/managers) and 15 males (eight health care providers and seven programme implementers/managers). Participant's ages ranged between 25 and 59 years. Participants had a wide range of years of experience (ranging between one and 26 years) in programme design and implementation related to women and girls' empowerment or providing health care services including abortion and USG.

Table 1.3: Number and category of district level stakeholders covered for in-depth interviews

\begin{tabular}{lccc}
\hline Category of district level stakeholders & Kaski & Tanahun & Total \\
\hline $\begin{array}{l}\text { Heath care providers (radiologists, obstetricians, gynaecologists } \\
\text { and other abortion providers }\end{array}$ & 6 & 6 & 12 \\
$\begin{array}{l}\text { Programme implementers/managers-public (local development } \\
\text { officers, district development officers, public health office nurses, }\end{array}$ & & & \\
and district education officers) & 6 & 5 & 11 \\
Programme implementers/mangers-private and NGOs & 3 & 3 & 6 \\
Total number of participants interviewed in-depth & $\mathbf{1 5}$ & $\mathbf{1 4}$ & $\mathbf{2 9}$ \\
\hline
\end{tabular}

\subsection{Study instruments}

The following four sets of study instruments were developed and used in the study:

- Screening questionnaire for heads of the households

- Structured individual interview questionnaire for women

- In-depth interview guidelines for health care providers

- In-depth interview guidelines for programme implementers/mangers 
All the research instruments were developed in English and translated into Nepali language. English questionnaires were designed in close consultation with the Population Council, India. Pre-testing of the questionnaires was carried out with 16 women, screened from 67 households and revised based on the results of the pre-test.

A structured questionnaire was administered to the eligible woman for obtaining data. A key informant interview guide was also prepared and used to conduct key informant interviews.

\subsection{Data collection and quality control}

A team of 24 interviewers (all female) and 6 supervisors (all female) were involved in the data collection. These members are university graduates and experienced in collecting information on sensitive issues. They received five days of intensive training on cluster level sampling, ethical aspects, and on questionnaire administration. Altogether, six teams-each team comprising of one field supervisor and four enumerators-were formed to cover the two study districts.

In-depth interviews with health care providers and programme implementers/managers were carried out by the field supervisors or one of the core study team members. All in-depth interviews were audio-recorded with informed consent of the participants.

The field researchers were closely supervised by the core team members in order to ensure the quality of their work. During data collection, the core team members visited the field teams and conducted random and spot checking of randomly selected interviewees. During the fieldwork, regular communications over the phone were scheduled. Data was collected between October and November, 2014.

\subsection{Data management and analysis}

All completed questionnaires were manually edited and coded before being entered into a special computer package -CSPro 6.0. Open ended questions were scrutinized and coded. Data was entered twice by different data entry clerks to check and minimize data entry problems. A number of quality check mechanisms such as range and consistency checks were carried by developing computer programming. A Data Management Officer closely monitored the work of data entry clerks and randomly checked entered data every day. Quantitative data was analyzed using Statistical Package for Social Sciences 20. A descriptive analysis was carried out. The central focus of the analysis was to compare the situation in two contrasting study districts on factors underlying the disparities in sex ratios. Depending on the nature of data, researchers carried out either Chi square test or T-test to measure the difference between Kaski and Tanahun, Kaski urban and Tanahun urban and Kaski rural and Tanhaun rural areas.

With regard to qualitative data, all audio tapes and field notes of in-depth interviews were expanded, transcribed word by word and translated into English. A thematic analysis approach was used. In view of the time and resources, the textual data was analyzed manually. After carefully reading the transcripts, the findings were summarized in grid tables according to key themes and analysis given. Information on the qualitative data was used to complement and supplement the quantitative results.

\subsection{Ethical considerations}

The researchers recognize that the survey has some ethical concerns. The major challenges are the safety and confidentiality of participants. Therefore, the study was conducted with full respect of ethical and safety considerations. The following measures were adopted to protect both the respondents and the research team and to ensure privacy and confidentiality of the interviewees.

- The study maintained ethical guidelines developed by the World Health Organization on studying sensitive issues throughout the study and beyond.

- Participants were fully informed about the nature of the study, research objectives, confidentiality of the data, and full consent for their participation in the study was obtained. The informed consent form was written in simple Nepali language. This was read aloud to the respondents and a written consent (thumb print if illiterate) was obtained. 
- During the introduction, respondents were told that they could skip any question they did not wish to answer. At the end of interview they were given the opportunity to make comments or ask any questions to the interviewers.

- Individual interviews were conducted in a private and convenient location for the respondent. No one but the interviewer and the respondent were present during the interview. Interviewers were instructed to terminate or change the subject of discussion if an interview was interrupted by anyone.

- Protecting confidentiality is essential to ensuring the respondent's privacy and safety, as well as data quality. Therefore, all researchers had received strict instruction about the importance of maintaining confidentiality. This was stressed during the training to the research team.

- In the questionnaire/transcription no names were recorded; instead, an individual code number was assigned to link the interviews with the corresponding respondent. No individual data was disseminated. In presenting any quotation from in-depth interviews in the dissemination or report, no personal identifiers were used.

The protocol for this study was approved by the Institutional Review Board of the Population Council and the Nepal Health Research Council.

\subsection{Challenges and limitations}

Fieldwork coincided with peak harvesting time, which limited access to target populations. Team members had to walk to most of the villages, resulting in extra time spent travelling to villages. Scheduling appointments with district level stakeholders, particularly health care providers, was a major challenge.

As with any research, there are limitations both to data collection and interpretation. We have grouped these into three main areas: first, the cross-sectional nature of the data limits the ability to establish temporality or causality in many of the observed relationships. Second, due to the purposeful selection of study districts, findings may not be generalized to a wider population. Third, although efforts have been made to ensure the reliability and validity of responses, the possibility of under- or over reporting of sex selection abortion or related indicators cannot be entirely ruled out given the patterns of social stigma and fear of retribution associated with sex selective abortion or use of USG.

\subsection{Socio-demographic characteristics of respondents}

Few background characteristics of women in the two districts were similar (Table 1.4). For example, over half of women fall in the age group of 20-29 in both the districts, with mean age of about 29 years. The large majority of women from both districts were Hindus (85-90\%), followed by Buddhists.

Differences in some characteristics were also observed. For example, caste/ethnicity distribution show that more women in Kaski than Tanahun belonged to an upper caste group (Brahmin/Chhetri). In contrast, more women in Tanahun than Kaski belonged to a disadvantaged indigenous group (Janajatis).

Differences were also observed in educational attainment of women. Women in Kaski were better educated than Tanahun. For example, more women in Kaski than Tanahun had 12 or more years of education (14\% versus $7 \%$ ). Comparatively, a higher percentage of women in Kaski than Tanahun were better off in terms of household wealth wellbeing ( $26 \%$ versus $14 \%$ in highest category). Similar differences were also observed in paid work status of women. Comparatively, a higher percentage of women in Kaski than Tanahun reported having worked for wages in the year preceding the interviews (35\% versus $24 \%$ ).

Differences were also noticed in aspects of women's agency, measured in terms of reported decision making authority, freedom of movement to visit various places unescorted, and ability to express opinions to husbands. Though no major difference was observed in decision making in studied districts, significantly, a higher percentage of women in Kaski than Tanahun reported freedom of movement to go unescorted to a meeting or programme, to visit friends or relatives outside the area of residence (80\% versus $70 \%)$, and to express themselves freely to their husbands on household matters (79\% versus $72 \%$ ). 
Table 1.4: Selected background characteristics of women who had participated in the survey: Kaski and Tanahun

\begin{tabular}{|c|c|c|c|c|c|c|}
\hline \multirow[t]{2}{*}{ Characteristics } & \multicolumn{2}{|c|}{ Urban } & \multicolumn{2}{|c|}{ Rural } & \multicolumn{2}{|c|}{ Total } \\
\hline & Kaski & Tanahun & Kaski & Tanahun & Kaski & Tanahun \\
\hline \multicolumn{7}{|l|}{ Current age (years) ${ }^{\text {ns }}$} \\
\hline $18-19$ & 0.4 & 0.4 & 1.6 & 0.8 & 1.0 & 0.6 \\
\hline $20-24$ & 18.4 & 20.4 & 18.0 & 23.6 & 18.2 & 22.0 \\
\hline $25-29$ & 42.4 & 36.8 & 40.0 & 36.8 & 41.2 & 36.8 \\
\hline $30-34$ & 27.2 & 28.8 & 28.4 & 22.4 & 27.8 & 25.6 \\
\hline 35 and above & 11.6 & 13.6 & 12.0 & 16.4 & 11.8 & 15.0 \\
\hline Mean age in years ${ }^{\text {ns }}$ & 28.7 & 28.9 & 28.5 & 28.6 & 28.6 & 28.8 \\
\hline \multicolumn{7}{|l|}{ Religion $^{\text {ns }}$} \\
\hline Hindu & 90.0 & 90.8 & 80.0 & 88.4 & 85.0 & 89.6 \\
\hline Muslim & 1.2 & 1.2 & 5.6 & 0.0 & 3.4 & 0.6 \\
\hline Christian & 1.6 & 3.6 & 2.0 & 1.2 & 1.8 & 2.4 \\
\hline Buddhist & 7.2 & 4.4 & 12.4 & 10.4 & 9.8 & 7.4 \\
\hline \multicolumn{7}{|l|}{ Caste/ethnicity ${ }^{\text {ns }}$} \\
\hline Dalits (untouchables) & 18.4 & 14.4 & 30.0 & 18.8 & 24.2 & 16.6 \\
\hline Disadvantaged indigenous group (Janajatis) & 18.4 & 25.6 & 10.0 & 42.8 & 14.2 & 34.2 \\
\hline Religious minority & 1.2 & 1.2 & 5.6 & 0.0 & 3.4 & 0.6 \\
\hline Disadvantaged non-Dalit Teraicaste group & 0.4 & 0.4 & 0.0 & 0.0 & 0.2 & 0.2 \\
\hline $\begin{array}{l}\text { Relatively advantaged indigenous group } \\
\text { (Janajatis) }\end{array}$ & 11.6 & 23.6 & 17.6 & 17.2 & 14.6 & 20.4 \\
\hline Upper caste group & 50.0 & 34.8 & 36.8 & 21.2 & 43.4 & 28.0 \\
\hline Years of schooling & $* *$ & & $* * *$ & & $* * *$ & \\
\hline None/ non- formal education & 10.4 & 12.4 & 13.6 & 28.0 & 12.0 & 20.2 \\
\hline $1-7$ years of schooling & 30.4 & 42.4 & 40.0 & 47.6 & 35.2 & 45.0 \\
\hline $8-11$ years of schooling & 40.0 & 34.8 & 37.6 & 20.4 & 38.8 & 27.6 \\
\hline 12 or above & 19.2 & 10.4 & 8.8 & 4.0 & 14.0 & 7.2 \\
\hline Median years of schooling completed & 9.0 & 7.0 & 7.0 & 4.0 & 8.0 & 6.0 \\
\hline Wealth wellbeing (Quintile) & $* * *$ & & $* * *$ & & $* * *$ & \\
\hline Lowest & 0.8 & 17.6 & 10.4 & 51.2 & 5.6 & 34.4 \\
\hline Second & 6.4 & 14.0 & 33.6 & 24.8 & 20.0 & 19.4 \\
\hline Middle & 20.8 & 18.4 & 30.4 & 11.6 & 25.6 & 15.0 \\
\hline Fourth & 29.6 & 25.6 & 16.8 & 8.0 & 23.2 & 16.8 \\
\hline Highest & 42.4 & 24.4 & 8.8 & 4.4 & 25.6 & 14.4 \\
\hline \multicolumn{7}{|l|}{ Wage work status } \\
\hline Engaged in any paid work in last 12 months & $34.8^{*}$ & 24.8 & $34.4^{* *}$ & 22.8 & $34.6^{* * *}$ & 23.8 \\
\hline
\end{tabular}




\begin{tabular}{|c|c|c|c|c|c|c|}
\hline \multirow[t]{2}{*}{ Characteristics } & \multicolumn{2}{|c|}{ Urban } & \multicolumn{2}{|c|}{ Rural } & \multicolumn{2}{|c|}{ Total } \\
\hline & Kaski & Tanahun & Kaski & Tanahun & Kaski & Tanahun \\
\hline \multicolumn{7}{|l|}{ Women's agency } \\
\hline $\begin{array}{l}\text { Decision making }{ }^{\text {ns: }} \\
\text { Makes independent decisions on at least one } \\
\text { of the following: how to spend money, which } \\
\text { school to send children, and facility in which } \\
\text { she delivered }\end{array}$ & 52.0 & 54.0 & 50.8 & 49.2 & 51.4 & 51.6 \\
\hline $\begin{array}{l}\text { Freedom of movement: } \\
\text { Is allowed to go unescorted to all three of } \\
\text { the following: a meeting/programme, to visit } \\
\text { a relative outside the tole/village, to an } \\
\text { entertainment show/mela }\end{array}$ & 79.6 & 76.0 & $80.8^{* * *}$ & 64.0 & $80.2^{* * *}$ & 70.0 \\
\hline $\begin{array}{l}\text { Self-efficacy: } \\
\text { Never finds it difficult to express opinions to } \\
\text { husband on working outside the home, going } \\
\text { out unescorted, or education and care of } \\
\text { children }\end{array}$ & 77.6 & 72.4 & $81.2^{* *}$ & 70.8 & $79.4^{\star *}$ & 71.6 \\
\hline Number of women & 250 & 250 & 250 & 250 & 500 & 500 \\
\hline
\end{tabular}

\subsection{Report structure}

This study report is divided into six chapters. This first chapter introduces the study and its methodology and characteristics of the study population. Chapter 2 assesses factors underlying unbalanced sex ratios. Chapter 3 discusses about what works to reduce gender-biased sex selection. Initiatives to enhance the status of females are assessed in Chapter 4. Chapter 5 assesses factors underlying differences between Kaski and Tanahun. Finally, a summary and recommendations are presented in Chapter 6. 


\section{CHAPTER 2 \\ FACTORS UNDERLYING UNBALANCED SEX RATIOS}

\section{Summary}

The three preconditions identified by Guilmoto as key in accounting for skewed sex ratios at birth, namely preference for small families, persistent strong son preference, and access to pre-natal diagnostic technology was higher in Kaski, than in Tanahun. Though small family size is widely prevalent in both districts, son preference as measured by the three indictors used in this study (no sex preference on their ideal number of children, desire to continue child bearing by the sex composition of living children and family planning behavior)-was slightly stronger among women in Kaski (particularly urban Kaski) than in Tanahun.

Though attitudes towards son preference were stronger among women in both districts, it was more pronounced among women in Kaski than in Tanahun. For example, $72 \%$ of women in Kaski thought that a son is essential to continue the family lineage compared with $63 \%$ women in Tanahun. Whereas, a considerable proportion of women in both districts believed that having a son determines a woman's status in her family (34\% verses $27 \%$ ). Key informants reiterated that son preference remains strong due to the well-known reasons demonstrated by several previous studies. However, most key informants, particularly health care providers from Tanahun believed that son preference has been weakening in their districts due to extensive awareness programmes and increased levels of education.

More women in Kaski than Tanahun reported the use of USG (82\% versus 52\%). About $42 \%$ of women in Kaski compared with 32\% women in Tanahun reported seeking information on the sex of the foetus at least for one pregnancy. More women from urban than rural areas reported seeking information on the sex of the foetus in both districts. Misuse of technology was reported by a higher proportion of women in Kaski than in Tanahun. For example, $37 \%$ of women in Kaski, compared with $27 \%$ in Tanahun reported that their provider had disclosed the sex of foetus to them, and once again, more urban than rural women reported so. In addition, there was a fairly systematic increase in percentage of women reporting disclosure of the sex of the foetus by parity. This was particularly more pronounced in Kaski where the percentage increased from $11 \%$ in parity one to $29 \%$ at parity three. Similarly, significantly more women from Kaski than Tanahun reported that they or someone they knew had been told the sex of their foetus (67\% versus $40 \%$ ). Thirteen percent of women from Kaski compared to about $10 \%$ of those in Tanahun reported experiences of an induced abortion. Of them, $13 \%$ of women reported sex selection was the reason for an abortion. Key informants strongly agreed that the misuse of technologiesboth disclosure of the sex of the foetus and termination of pregnancies carrying a female foetus-persisted in both districts. They believed that the demand for disclosure of sex of foetuses has increased in recent years. Easy access to technology, advancement of new technology to detect the sex of foetus and patriarchal culture were the main reasons for increasing demand for the disclosure of the sex of foetus. They also opined that the demand and access to USG was higher in Kaski than Tanahun.

This chapter explores factors underlying unbalanced sex ratios in the two study districts based on the survey and textual data drawn from women and key informants. From the survey of women with two or more children (one of whom was aged 0-5 years at the time of the survey), researchers focus on each of the three preconditions identified by Guilmoto (2009) as key in accounting for skewed sex ratios at birth, namely: preference for small families, persistent strong son preference, and access to pre-natal diagnostic technology. We followed this discussion with the perspectives of district level stakeholders relating to two of these three preconditions, namely persistent strong son preference, and access to pre-natal diagnostic technology. 


\subsection{Women's perspectives}

\subsubsection{Family size preference}

The two child norm is well established in study districts, with $81-87 \%$ of women in the two districts expressing a preference for two children, and no more than $11 \%$ reporting a preference for more than two children (4-10\%) or just one child (5-11\%). With regard to sex composition of the children desired, most women expressed a desire for one son (92-95\%) and one daughter (95-97\%).

Figure 2.1: Mean ideal number of children, children ever born and children surviving

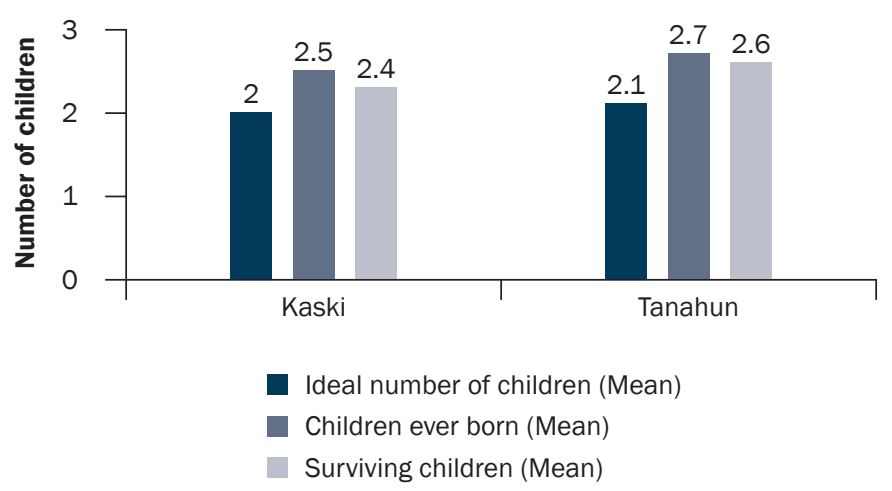

Differences in mean ideal number of children desired, children ever born and surviving children is slightly more pronounced in Tanahun than in Kaski (Figure 2.1). Comparatively, more women in Kaski than Tanahun considered one child to be ideal for a family. Similarly, a higher percentage of women residing in urban Kaski than urban Tanahun considered one child to be ideal ( $11 \%$ versus $4 \%$ ). Though our sample comprised of women with two or more children, one of whom was aged 0-5 years at the time of survey, actual family size reported was small. Indeed, the majority of women reported just two children (57-76\%). Comparatively, a lower percentage of women in Kaski than Tanahun reported 3 or more surviving children ( $7 \%$ versus 13\%). (Table 2.1 )

\subsubsection{Son preference}

A second pre-condition for skewed sex ratios at birth is the extent of son preference expressed by women and their families. This study measured the extent of son preference in several ways. First, using a direct question posed to assess the number of sons and daughters a woman considered ideal, we calculated the proportion of women who had two living children and did not express a preference for sons over daughters when asked about their ideal number of sons and daughters. A second indicator of son preference was the extent to which women's desire to continue childbearing depended on the sex composition of her living children. In order to measure this, we compared among those who had two living children, the proportion of women with two sons wanting no more children with the proportion of women with two daughters wanting no more children. Clearly, if there were no preference for sons versus daughters, the ratio of these two responses would be 1.0, and the higher the value of the ratio, the stronger the son preference. Finally, since we know son preference affects the family planning behavior of couples, we examined the extent to which women's use of contraception was associated with the sex composition of their living children. A simple indicator was constructed to measure this-we compared, among those who had two living children, the proportion of women with two sons currently using contraception with the proportion of women with two daughters using contraception. As above, if there were no preference for the sex of children, the ratio of these two quantities would be 1.0, and the higher the value of the ratio, the stronger the son preference.

Findings suggest that son preference, as measured by these three indicators, was moderate in both districts. Some difference was also observed among women between urban and rural areas (Table 2.2).

The second and third indicators show some preference for sons in both districts. No marked inter-district differences are apparent in son preference as assessed by these two measures. For example, a woman's desire for no more children, as measured by the ratio of those with two sons versus two daughters expressing a desire for no more children, was slightly stronger in Kaski than in Tanahun. This picture was similar in the urban area. Women in rural Kaski than in Tanahun have a slightly strong son preference. Women's use of contraception also shows that those from Kaski who had two sons and no daughters were slightly more likely to use it than their counterparts in Tanahun (Table 2.2).

In this survey, we also assessed women's attitudes about having sons and daughters, and again, it is clear that though son preference is prevalent in both districts, it is more pronounced among women in Kaski than Tanahun 
Table 2.1: Percent distribution of women by ideal number of children and actual family size: Kaski and Tanahun

\begin{tabular}{|c|c|c|c|c|c|c|}
\hline \multirow[t]{2}{*}{ Family preference } & \multicolumn{2}{|c|}{ Urban } & \multicolumn{2}{|c|}{ Rural } & \multicolumn{2}{|c|}{ Total } \\
\hline & Kaski & Tanahun & Kaski & Tanahun & Kaski & Tanahun \\
\hline Ideal number of children & ** & & * & & $* * *$ & \\
\hline 1 & 11.2 & 4.4 & 6.4 & 5.2 & 8.8 & 4.8 \\
\hline 2 & 85.2 & 86.0 & 87.6 & 81.2 & 86.4 & 83.6 \\
\hline 3 or more & 2.4 & 7.6 & 5.2 & 11.6 & 3.8 & 9.6 \\
\hline Up to god/no numeric response/not want & 1.2 & 2.0 & 0.8 & 2.0 & 1.0 & 2.0 \\
\hline Mean ideal number of children ${ }^{+n s}$ & 1.9 & 2.0 & 2.0 & 2.1 & 2.0 & 2.1 \\
\hline \multicolumn{7}{|l|}{ Preferred sex of the children } \\
\hline \multicolumn{7}{|l|}{ Number of sons ${ }^{\text {ns }}$} \\
\hline 1 & 96.1 & 94.7 & 94.0 & 88.4 & 95.0 & 91.6 \\
\hline 2 & 3.4 & 5.3 & 5.1 & 4.3 & 4.3 & 8.4 \\
\hline \multicolumn{7}{|l|}{ Number of daughters ${ }^{\text {ns }}$} \\
\hline 1 & 97.0 & 95.6 & 97.7 & 94.8 & 97.3 & 95.2 \\
\hline 2 & 3.0 & 3.9 & 2.3 & 5.2 & 2.7 & 4.5 \\
\hline Mean number of children ever born & 2.4 & 2.5 & 2.5 & $2.9^{* * *}$ & 2.5 & 2.7 \\
\hline Number of surviving children & & & ** & & $* * *$ & \\
\hline 2 & 76.0 & 70.4 & 70.8 & 56.8 & 73.4 & 63.6 \\
\hline 3 & 20.4 & 21.2 & 19.2 & 25.2 & 19.8 & 23.2 \\
\hline 4 or more & 3.6 & 8.4 & 10.0 & 18.0 & 6.8 & 13.2 \\
\hline Mean number of surviving children & 2.3 & 2.4 & 2.4 & 2.7 & 2.4 & 2.6 \\
\hline \multicolumn{7}{|l|}{ Desire for additional children ${ }^{++}$ns } \\
\hline Don't want more children & 93.2 & 94.4 & 92.8 & 90.8 & 93.0 & 92.6 \\
\hline Want additional children & 6.0 & 5.6 & 6.8 & 8.4 & 6.4 & 7.0 \\
\hline It depends & 0.8 & 0.0 & 0.4 & 0.8 & 0.6 & 0.4 \\
\hline Number of women & 250 & 250 & 250 & 250 & 500 & 500 \\
\hline
\end{tabular}

Note: ${ }^{*}{ }^{* *},{ }^{* *}$ indicate that differences between Kaski and Tanahun, Kaski urban and Tanahun urban and Kaski rural and Tanahun rural are significant at $p<.05, p<.01$ and $p<0.001$, respectively; ${ }^{+}$Those women who reported up to god/no numeric response in the ideal number of children they were excluded to calculate the mean value; ${ }^{++}$Sterilized women are assumed to want no more children; ns: not significant.

Table 2.2: Indicators of son preference among women having two living children: Kaski and Tanahun

\begin{tabular}{|c|c|c|c|c|c|c|}
\hline & \multicolumn{2}{|c|}{ Urban } & \multicolumn{2}{|c|}{ Rural } & \multicolumn{2}{|c|}{ Total } \\
\hline & Kaski & Tanahun & Kaski & Tanahun & Kaski & Tanahun \\
\hline $\begin{array}{l}\text { Percentage who expressed no preference for the } \\
\text { sex of their children }\end{array}$ & $15.8^{* * *}$ & 5.8 & 14.5 & 8.5 & $15.2^{* * *}$ & 7.0 \\
\hline $\begin{array}{l}\text { Wanted no more children among those with two } \\
\text { sons versus two daughters (ratio) }\end{array}$ & 1.14 & 1.14 & $1.26^{\star \star *}$ & 1.09 & 1.20 & 1.12 \\
\hline $\begin{array}{l}\text { Currently using contraception among those with } \\
2 \text { sons versus } 2 \text { daughters (ratio) }\end{array}$ & $1.29^{*}$ & 1.19 & 1.26 & 1.18 & $1.30^{* *}$ & 1.17 \\
\hline Number of women with two living children & 177 & 171 & 166 & 130 & 343 & 301 \\
\hline
\end{tabular}

Note: ${ }^{*},{ }^{* *},{ }^{* *}$ indicate that differences between Kaski and Tanahun, Kaski urban and Tanahun urban and Kaski rural and Tanahun rural are significant at $p<.05, p<.01$ and $p<0.001$, respectively. 
(Table 2.3). For example, a higher percentage of women in Kaski than Tanahun thought that a son is essential to continue the family lineage ( $72 \%$ versus $63 \%$ ). Similarly, a considerable proportion of women in both districts believed that having son determines a woman's status in her family (24-42\%) and that a family without a son receives less respect in society than other families (8-16\%). About one in 10 women in both districts thought that a woman with only daughters is unfortunate. Women in rural areas of each district were more likely than their urban counterparts to display attitudes suggesting strong son preference, and inter-district differences were somewhat narrow in most cases except in two instances. In rural areas, for example, women from Kaski were significantly more likely than their counterparts from Tanahun to believe that a son is essential to continue the family lineage, and that the presence of a son determines the status of the mother in the family. In contrast, significantly fewer urban women from Kaski than Tanahun believed that the presence of a son affected the status of women in the community. Comparatively, a significantly higher proportion of women from Kaski than Tanahun believed that women are forced to continue having children until a son is born (85\% versus $70 \%$ ) (Table 2.3 ).

An index was created that summed up women's responses on these four indicators of son preference. Findings suggest that women reported attitudes reflecting son preference on an average of 1.1-1.5 of the first four statements overall; attitudes were more likely to reflect stronger son preference among women from Kaski than Tanahun (Table 2.3).

Table 2.3: Percentage of women reporting various attitudes relating to son preference: Kaski and Tanahun

\begin{tabular}{|c|c|c|c|c|c|c|}
\hline \multirow[t]{2}{*}{ Son preference } & \multicolumn{2}{|c|}{ Urban } & \multicolumn{2}{|c|}{ Rural } & \multicolumn{2}{|c|}{ Total } \\
\hline & Kaski & Tanahun & Kaski & Tanahun & Kaski & Tanahun \\
\hline \multicolumn{7}{|l|}{$\%$ of women agreeing that } \\
\hline $\begin{array}{l}\text { It is important to have sons because only they } \\
\text { can continue the family lineage }\end{array}$ & 64.4 & 58.0 & $78.8^{* *}$ & 68.4 & $71.6^{* *}$ & 63.2 \\
\hline $\begin{array}{l}\text { It is important to have sons because having a son } \\
\text { determines a woman's status in the family }\end{array}$ & 27.2 & 30.4 & $41.6^{* * *}$ & 24.4 & $34.4^{*}$ & 27.4 \\
\hline $\begin{array}{l}\text { Only a son can help a family gain social status in } \\
\text { their community }\end{array}$ & 8.8 & $14.4^{*}$ & 14.0 & 15.6 & 11.4 & 15.0 \\
\hline A woman with only daughters is unfortunate ns & 6.4 & 7.6 & 10.8 & 11.2 & 8.6 & 9.4 \\
\hline Index of women reporting various attitudes $(0-4)$ & 1.07 & 1.10 & $1.45^{* *}$ & 1.20 & 1.26 & 1.15 \\
\hline Cronbach's alpha & 0.64 & 0.63 & 0.62 & 0.62 & 0.62 & 0.62 \\
\hline $\begin{array}{l}\text { Women are forced to continue having children } \\
\text { until a son is born }\end{array}$ & $82.0^{* * *}$ & 68.4 & $87.0^{* * *}$ & 71.2 & $84.8^{* * *}$ & 69.8 \\
\hline Number of women & 250 & 250 & 250 & 250 & 500 & 500 \\
\hline
\end{tabular}

\subsubsection{Access to technology enabling disclosure of the sex of the foetus}

The third precondition for unbalanced sex ratios at birth is the use of technologies to detect the sex of the foetus and selectively terminate pregnancies carrying a female foetus. In Nepal, the most commonly used method of detecting the sex of the foetus is USG. While USG is used by large proportions of women for monitoring the growth and development of the foetus, disclosure of the sex of the foetus is not permitted under the abortion law in Nepal. However, some providers do disclose such information to women and families, resulting in the subsequent abortion of female foetuses.

In this section, we explore women's access to technologies enabling disclosure of the sex of the foetus, the extent of termination of pregnancies carrying female foetuses and attitudes about the acceptability of gender-biased sex selection. 


\subsubsection{Use of USG and disclosure of the sex of the foetus}

Several questions were posed to assess the extent to which women reported disclosure of the sex of a foetus during any of their pregnancies. For each pregnancy, first we asked whether or not USG was performed, and specifically, whether the doctor had disclosed the sex of the foetus to them during the procedure. Secondly, a direct and general question was posed, that asked whether the respondent had ever received information about the sex of the foetus. And finally, recognizing that women may be unwilling or uncomfortable about revealing, in a direct face-toface situation, that they had violated the law, researchers also enquired about disclosure of the sex of the foetus indirectly, in an anonymous (but linked) format. With this, at the end of the interview, women were handed a card and were asked to mark a tick if the sex of any foetus had been disclosed to them after USG or any other prenatal diagnostic test, and a cross if not. They were also told to place the card in an envelope provided by the interviewer, seal it, and return it to the interviewer. The interviewer did not observe this part of the interview but informed the respondent that we would be able to link the response on the card with other responses made in the main body of the interview. In addition, we also enquired about the respondent's acquaintance with a friend or relative or someone in the community, respectively, who had received information on the sex of their foetus.

Findings showed that the use of USG during pregnancy for any reason (foetal growth monitoring, screening for abnormalities of the foetus, sex determination, etc.) was common in both districts. Results clearly show that more women in Kaski than Tanahun reported the use of this technology (82\% versus 52\%). In both districts, more women in urban areas than rural reported the use of USG, probably due to the easier access to this technology in urban areas ( $88 \%$ vs. $76 \%$ in Kaski; $63 \%$ vs. $41 \%$ in Tanahun). In face-to-face interviews a higher percentage of women in Kaski (37\%) than in Tanahun (27\%) admitted to seeking information on the sex of their foetus. When responses made in the face-to-face format were supplemented by those made in the anonymous format, percentages increased: about $42 \%$ of women in Kaski reported seeking information on the sex of the foetus compared with $32 \%$ of women in Tanahun. Rural-urban differences were clearly evident with more women from urban than rural areas reporting disclosure of sex of the foetus after an ultrasound. Even those who reported that their friend or family member had done so (57\% in Kaski and 35\% in Tanahun), or someone in their village, town or ward had done so (67\% vs. $40 \%$ ) was much higher in Kaski than in Tanahun. Clearly, seeking to know the sex of the foetus was quite common in both districts, but more so in Kaski than Tanahun, and more so among urban than rural women (Table 2.4).

Findings also suggest that doctors did not hesitate about providing women who underwent USG information about the sex of their foetus. Indeed, as many as 37\% of women in Kaski, and $27 \%$ of those in Tanahun reported that the doctor had supplied this information to them, and once again, more urban than rural women (40\% versus 35\% in Kaski; 31\% versus 22\% in Tanahun) reported that they had been informed about the sex of their foetus by their provider. While it is difficult from this survey to gauge the gestational age at which this information was supplied, and whether women who obtained this information would be eligible for legal termination of pregnancy, we note that it is illegal to disclose the sex of the foetus to women. We also note that there was no noticeable difference (discordance) in reports about disclosure of the sex of the foetus through face-to-face and confidential reporting (concealed envelope) methods used (Table 2.4).

We also assessed disclosure of sex of foetus by women's parity. The results show that there is a fairly systematic increase in percentage of women reporting disclosure of the sex of the foetus by parity (as birth order increases)and increases are particularly notable among women whose previous child was a daughter; again this pattern is more evident in Kaski than in Tanahun after the birth of daughter. This was particularly more pronounced in Kaski where percentage increased from $10.6 \%$ in parity 1 to $29 \%$ at parity three. A similar pattern was observed in rural and urban areas of the district. In contrast, in Tanahun, increases were not as pronounced as Kaski (Table 2.5).

\subsubsection{Experience of induced abortion}

In response to a question about their experience of induced abortion, 13\% of women from Kaski, compared to about 10\% of those in Tanahun, reported life time experience of an induced abortion (Figure 2.2). Percentages were particularly high among women from urban Kaski (17\%) and lowest among those in rural Tanahun (8\%). Experience of multiple induced abortions was also reported by about $5 \%$ in Kaski and about $2 \%$ in Tanahun (not shown in Figure 2.2). Numbers are small and findings are thus presented at district level only. Therefore, this data must be interpreted cautiously. 
Table 2.4: Percentages of women reporting experience of ultrasonography during pregnancy, disclosure of the sex of the foetus, and acquaintance with others to whom sex of the foetus was disclosed: Kaski and Tanahun

\begin{tabular}{|c|c|c|c|c|c|c|}
\hline \multirow[t]{2}{*}{ Sex selection practices } & \multicolumn{2}{|c|}{ Urban } & \multicolumn{2}{|c|}{ Rural } & \multicolumn{2}{|c|}{ Total } \\
\hline & Kaski & Tanahun & Kaski & Tanahun & Kaski & Tanahun \\
\hline Had at least one USG during any pregnancy & $88.4^{* * *}$ & 62.8 & $76.0^{* * *}$ & 41.2 & $82.2^{* * *}$ & 52 \\
\hline $\begin{array}{l}\text { Ever obtained information about the sex of the } \\
\text { foteus (any pregnancy, direct question) }\end{array}$ & $38.8^{*}$ & 31.2 & $35.2^{* \star}$ & 22.8 & $37.0^{\star * *}$ & 27 \\
\hline $\begin{array}{l}\text { Ever obtained information about the sex of foetus } \\
\text { (any pregnancy, anonymous) }\end{array}$ & $42.4^{* *}$ & 31.6 & $35.6^{* \star *}$ & 20.8 & $39.0^{* * *}$ & 26.2 \\
\hline $\begin{array}{l}\text { Ever obtained information about the sex of any } \\
\text { foetus, (any pregnancy, reported in face-to-face or } \\
\text { anonymous format) }\end{array}$ & 46 & 38.4 & $37.6^{* * *}$ & 24.8 & $41.8^{* \star *}$ & 31.6 \\
\hline $\begin{array}{l}\text { Knows that friends/family members have } \\
\text { undergone USG for sex detection }\end{array}$ & $60.4^{* *}$ & 46.4 & $53.2^{* \star \star}$ & 24 & $56.8^{* \star *}$ & 35.2 \\
\hline $\begin{array}{l}\text { Knows someone in village, town or ward who has } \\
\text { undertaken USG to detect the sex of the foetus }\end{array}$ & $70.0^{* * *}$ & 48 & $63.6^{* * *}$ & 31.6 & $66.8^{* * *}$ & 39.8 \\
\hline Disclosure of sex of the foetus by the providers & & & & & & \\
\hline Provider disclosed the sex of the foetus & $39.6^{*}$ & 30.8 & $35.2^{* *}$ & 22.4 & $37.4^{* * *}$ & 26.6 \\
\hline Number of women & 250 & 250 & 250 & 250 & 500 & 500 \\
\hline
\end{tabular}

Note: ${ }^{*}{ }^{* \star},{ }^{* \star *}$ indicate that differences between Kaski and Tanahun, Kaski urban and Tanahun urban and Kaski rural and Tanahun rural are significant at $p<.05, p<.01$ and $p<0.001$, respectively.

Table 2.5: Percentage of women reporting experiences of personal disclosure of the sex of the foetus by parity and sex of previous child: Kaski and Tanahun

\begin{tabular}{|c|c|c|c|c|c|c|}
\hline \multirow[t]{2}{*}{ Sex selection practices } & \multicolumn{2}{|c|}{ Urban } & \multicolumn{2}{|c|}{ Rural } & \multicolumn{2}{|c|}{ Total } \\
\hline & Kaski & Tanahun & Kaski & Tanahun & Kaski & Tanahun \\
\hline \multicolumn{7}{|c|}{ Doctor disclosed the sex of the foetus by children ever born and sex combination of previous children (Number of women) } \\
\hline $1^{\text {st }}$ parity & $\begin{array}{r}11.6 \\
(250)\end{array}$ & $\begin{array}{r}8.0 \\
(250)\end{array}$ & $\begin{array}{r}9.6 \\
(250)\end{array}$ & $\begin{array}{r}5.2 \\
(250\end{array}$ & $\begin{array}{c}10.6^{*} \\
(500)\end{array}$ & $\begin{array}{r}6.6 \\
(500)\end{array}$ \\
\hline $2^{\text {nd }}$ parity & $\begin{array}{c}26.8^{*} \\
(250)\end{array}$ & $\begin{array}{r}17.6 \\
(250)\end{array}$ & $\begin{array}{l}21.2^{*} \\
(250)\end{array}$ & $\begin{array}{r}13.2 \\
(250)\end{array}$ & $\begin{array}{l}24.0^{* * *} \\
(500)\end{array}$ & $\begin{array}{r}15.4 \\
(500)\end{array}$ \\
\hline $1^{\text {st }}$ child-son & $\begin{array}{r}19.3 \\
(114)\end{array}$ & $\begin{array}{r}15.0 \\
(113)\end{array}$ & $\begin{array}{r}19.2 \\
(120)\end{array}$ & $\begin{array}{r}13.6 \\
(103)\end{array}$ & $\begin{array}{l}19.2^{* * *} \\
(234)\end{array}$ & $\begin{array}{r}14.4 \\
(216)\end{array}$ \\
\hline $1^{\text {st }}$ child-daughter & $\begin{array}{c}33.1^{*} \\
(136)\end{array}$ & $\begin{array}{r}19.7 \\
(137)\end{array}$ & $\begin{array}{c}23.1^{*} \\
(130)\end{array}$ & $\begin{array}{r}12.9 \\
(147)\end{array}$ & $\begin{array}{l}28.2^{* * *} \\
(266)\end{array}$ & $\begin{array}{r}16.2 \\
(284)\end{array}$ \\
\hline $3^{\text {rd }}$ parityns & $\begin{array}{r}34.3 \\
(70)\end{array}$ & $\begin{array}{r}25.3 \\
(79)\end{array}$ & $\begin{array}{r}25.0 \\
(84)\end{array}$ & $\begin{array}{r}14.3 \\
(119)\end{array}$ & $\begin{array}{r}29.2 \\
(154)\end{array}$ & $\begin{array}{r}18.7 \\
(198)\end{array}$ \\
\hline $2^{\text {nd }}$ child-son & $\begin{array}{r}14.8 \\
(27)\end{array}$ & $\begin{array}{r}18.5 \\
(27)\end{array}$ & $\begin{array}{r}22.6 \\
(31)\end{array}$ & $\begin{array}{l}10.0 \\
(40)\end{array}$ & $\begin{array}{l}19.0 \\
(58)\end{array}$ & $\begin{array}{r}13.4 \\
(67)\end{array}$ \\
\hline $2^{\text {nd }}$ child-daughter & $\begin{array}{r}46.5 \\
(43)\end{array}$ & $\begin{array}{r}28.8 \\
(52)\end{array}$ & $\begin{array}{r}26.4 \\
(53)\end{array}$ & $\begin{array}{r}16.5 \\
(79)\end{array}$ & $\begin{array}{r}35.4 \\
(96)\end{array}$ & $\begin{array}{r}21.4 \\
(131)\end{array}$ \\
\hline
\end{tabular}

Note: ${ }^{*}{ }^{* *},{ }^{* * *}$ indicate that differences between Kaski and Tanahun, Kaski urban and Tanahun urban and Kaski rural and Tanahun rural are significant at $p<.05, p<.01$ and $p<0.001$, respectively; Number within the parentheses denotes denominator; ${ }^{n s:}$ not significant. 
Figure 2.2: Experience of induced abortion

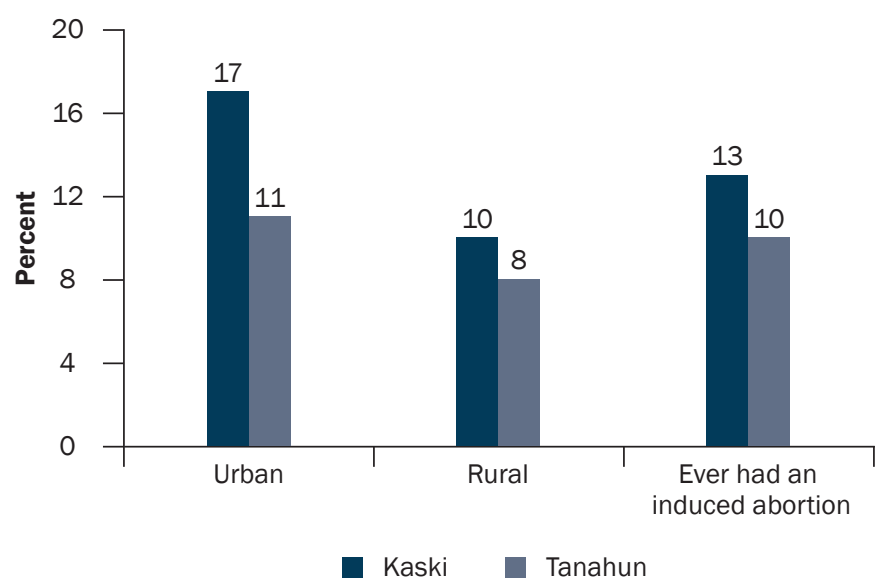

Reported reasons for induced abortion were mainly related to mistimed or unwanted pregnancy. For example, $70 \%$ of woman in Kaski and $52 \%$ in Tanahun reported a mistimed pregnancy as the reasons for abortion and $48-65 \%$ an unwanted pregnancy. Contraceptive failure was cited as the reason for induced abortion by $16 \%$ of women from Kaski, compared to just $2 \%$ of those from Tanahun. A substantial percentage of women who had undergone an induced abortion reported that they had done so for sex selection (13\% in Kaski and 12\% in Tanahun). Comparatively, a higher percentage of women from urban areas than rural in both districts reported sex selection as the reasons for abortion (Table not shown).

Of the entire sample (1,000 women), in the facetoface interview, only nine women from Kaski (3.6\%)

and six women from Tanahun (2.4\%) reported that they had undergone a sex selective abortion. Due to the lack of similar data, this figure cannot be compared with any other previous studies in Nepal. However, due to sensitive nature of information we cannot rule out the possibility of underreporting. For example, when asked about their friends and relatives, a significantly higher percentage of women from Kaski (31.4\%) than in Tanahun (15.4\%) reported that someone they knew had undergone a sex selective abortion (Table 2.6).

\subsubsection{Attitudes toward disclosure of the sex of the foetus}

The large majority of the respondents in both Kaski (76\%) and Tanahun (69\%) perceived that there is nothing wrong in knowing the sex of the foetus. The majority was also confident that nobody is ever punished for seeking information on the sex of the foetus, although more women from Kaski than Tanahun reported such confidence (87\% vs. 66\%) Figure 2.3 ).

Table 2.6: Percentage of women who underwent an abortion by reasons for abortion: Kaski and Tanahun

\begin{tabular}{|c|c|c|}
\hline Reasons for abortion ${ }^{+}$ & Kaski & Tanahun \\
\hline Did not want another child at that time/last child was too young & 70.1 & 52.1 \\
\hline Did not want another child at all & 47.8 & 64.6 \\
\hline Husband did not want the child & 1.5 & 12.5 \\
\hline Was too young/old & 0.0 & 6.3 \\
\hline Contraceptive failure & 16.4 & 2.1 \\
\hline Foetus was a female & 13.4 & 12.5 \\
\hline Medical reasons (Doctor advised, concerns about mother's health) & 9.0 & 8.3 \\
\hline Number of women who ever had an induced abortion & 67 & 48 \\
\hline Percentage of women who knows someone who had an induced abortion (relatives, friends) & $31.2^{* * *}$ & 15.4 \\
\hline $\begin{array}{l}\text { Percentage of women who ever had sex selective abortion combined (self, friends } \\
\text { and relatives) }\end{array}$ & $31.4^{* * *}$ & 16.0 \\
\hline Number of women & 500 & 500 \\
\hline
\end{tabular}

Note: ${ }^{* * \star}$ indicate that differences between Kaski and Tanahun, are significant at $p<0.001 ;{ }^{+}$Percentage total may exceed 100 due to multiple responses. 
Considerable minorities believed that discriminatory or gender-biased sex selection (particularly abortion of female foetus) was acceptable if a family already has children of a particular sex. For example, $14-17 \%$ of women from the two districts justified abortion of a female foetus. Finally, when asked if it was acceptable for a family with two or more daughters to undergo a sex determination test and abort the female foetus instead of bringing up an additional daughter, two fifths of the respondents in Tanahun (40\%) and a quarter of the respondents in Kaski (25\%) gave an affirmative response. This clearly suggests that in the prevailing patriarchal social structure, with the availability of technology, there is a likelihood of increased use of gender-biased sex selection and abortion of female foetuses among families having two or more daughters.

Figure 2.3: Percentage of women reporting various attitudes towards gender-biased sex selection (\% of agreeing)

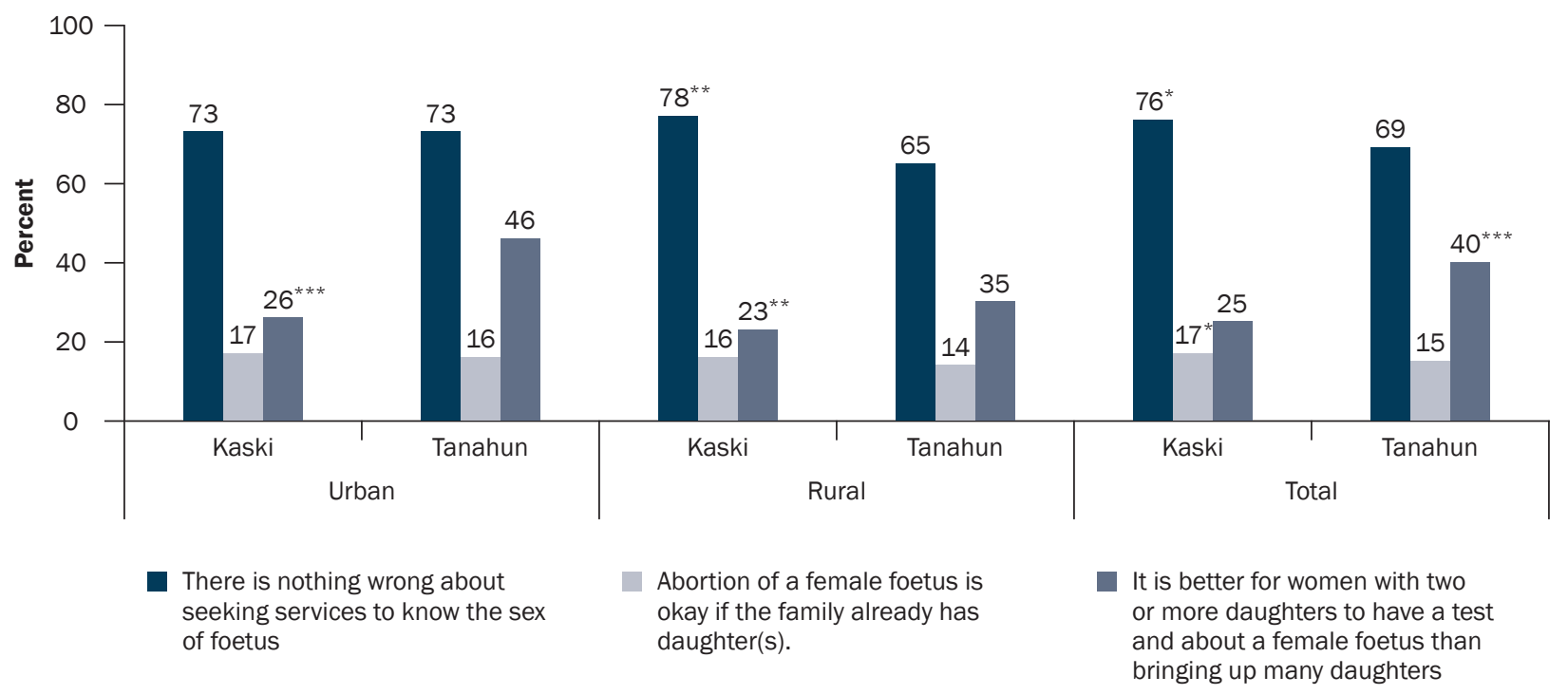

Note: ${ }^{*},{ }^{* *},{ }^{* * *}$ indicate that differences between Kaski and Tanahun, Kaski urban and Tanahun urban and Kaski rural and Tanahun rural are significant at $p<.05, p<.01$ and $p<0.001$, respectively.

\subsubsection{Perceptions on consequences of adverse sex ratio}

Our study also solicited the opinion of women about various negative consequences of gender-biased sex selection after 20 years. The data revealed that large proportions of women were aware of these consequences in both districts, but notably Kaski. For example, 93\% of women from Kaski, compared to 86\% of those from Tanahun agreed that there would not be enough girls for boys to marry. Similarly, 95\% of women from Kaski and $81 \%$ of those from Tanahun thought that there would be a rise in crime, and $89 \%$ and $79 \%$, respectively, believed that violence against women would increase. At the same time, large proportions believed that dowry amounts for girls would become smaller (65\% versus $53 \%$ ) and women's status would improve (61\% versus $54 \%)$. In contrast to inter-district differences, rural-urban differences were mild (Table 2.7).

\subsection{Stakeholder's perspectives on factors underlying unbalanced sex ratios at birth}

As described in Chapter 1, two types of districts level stakeholders (health care providers and programme implementers) were interviewed in-depth in our study. We explored stakeholders' perspectives about the implementation of the abortion law at the district level and its effectiveness; advocacy and community mobilization efforts in their districts; and any initiative to raise the status of girl and its effectiveness. We also asked their perceptions about underlying reasons for difference in sex ratio of boys to girls between two districts and negative consequences of gender-biased sex selection.

In this section, we explore the perspectives of district level stakeholders on the persistence of son preference, demand for disclosure of sex of the foetus, health providers' practice and discriminatory sex selection. 
Table 2.7: Percentage of women reporting opinions on the consequences of adverse sex ratio: Kaski and Tanahun

\begin{tabular}{lcccccc}
\hline Consequences of adverse sex ratio & \multicolumn{2}{c}{ Urban } & \multicolumn{2}{c}{ Rural } & \multicolumn{2}{c}{ Total } \\
\cline { 2 - 6 } & Kaski & Tanahun & Kaski & Tanahun & Kaski & Tanahun \\
\hline $\begin{array}{l}\text { If more boys are born, after 20 years there will } \\
\text { not be enough girls for our boys to marry }\end{array}$ & $92.4^{*}$ & 86.4 & $94.4^{* *}$ & 85.6 & $93.4^{* * *}$ & 86.0 \\
$\begin{array}{l}\text { If more boys are born, after 20 years, there will } \\
\text { be a shortage of women and crime will increase }\end{array}$ & $95.2^{* * *}$ & 80.8 & $94.8^{* * *}$ & 80.4 & $95.0^{* * *}$ & 80.6 \\
$\begin{array}{l}\text { If more boys are born, after 20 years, there will } \\
\text { be more violence against women and girls }\end{array}$ & $89.2^{* *}$ & 78.0 & $88.8^{* *}$ & 79.2 & $89.0^{* * *}$ & 78.6 \\
$\begin{array}{l}\text { If more boys are born, after 20 years, dowry } \\
\text { amounts for girls will be smaller }\end{array}$ & $69.2^{* * *}$ & 50.0 & 60.8 & 55.6 & $65.0^{* * *}$ & 52.8 \\
$\begin{array}{l}\text { If more boys are born, after 20 years, there will } \\
\text { be a great improvement in women's status }\end{array}$ & $67.2^{* *}$ & 54.0 & 55.6 & 54.8 & 61.4 & 54.4 \\
Number of women & $\mathbf{2 5 0}$ & $\mathbf{2 5 0}$ & $\mathbf{2 5 0}$ & $\mathbf{2 5 0}$ & $\mathbf{5 0 0}$ & $\mathbf{5 0 0}$ \\
\hline
\end{tabular}

Note: $* \star \star *, * *$ indicate that differences between Kaski and Tanahun, Kaski urban and Tanahun urban and Kaski rural and Tanahun rural are significant at $p<.05, p<.01$ and $p<0.001$, respectively.

\subsubsection{Stakeholders' perceptions of son preference}

All the district level stakeholders (12 health care providers, and 17 programme implementers) in both districts reported persistence of son preference in their districts. They reiterated the well-known reasons demonstrated by several studies on son preference, namely, sons as supporters to parents in their old age, performers of last rites for their parents (to secure a place in heaven), their ability to inherit family's property, their role in carrying family lineage and ensuring social status in the community. Some stakeholders also believed that having a son secures a woman's married life as this avoids the possibility of marrying another woman by her husband. In contrast, daughters were perceived as being obliged to leave home once married and that they provide little support for their parents. Moreover, many stakeholders described various discriminations and violence against women that surrounds the birth of a son or a daughter.

"Our society is patriarchal. Here all the rituals are done by the son after his parent's death, so people need a son. If you cannot bear sons then you cannot go to heaven, so women should give birth to sons. Sons will be the supporters in old age. Who will look after the property if there is no son? Also, sons are the ones who continue the family lineage. These are the reasons that people love sons more." (Female, programme implementer, age 42, Kaski, ID 22)

"In our society, parental property (Aansha) and family lineage (Bansa) belong to males. Therefore to secure these two things, the birth of a son is important and it is mandatory to have a son. This is the reason why women have to go for prenatal diagnostic tests and abort female foetuses if there is girl." (Female, programme implementer, age 50, Kaski, ID 15)

"As we know our country has a male dominated society. We have always been dependent on males. If there are no sons in our family we feel insecure, we fear who will take all the responsibilities of the family. Having sons provides respect in society, continues the family surname. These are the reasons we value sons more than daughters." (Male, health care provider, age 52, Kaski, ID 17)

"Until you have a son your married life is not secured. Earlier, it was believed that if you have two sons then your house will be secured but now it has been reduced to one son." (Female, health care provider, age 47, Kaski, ID 23)

"This is due to the society and tradition here in Nepal where people have the mentality that daughters goes off after marrying and will not be in touch after marriage. Whereas for sons, there is a belief that they stay attached until they grow old and look after their parents. This is our culture and we cannot blame them, it is the fault of our culture." (Male, health care provider, age 40, Tanahu, ID 06) 
"You have already known about our culture (laughing..) There is a saying that "If a son is born then a Goat (Khasi) is slaughtered to celebrate. But if a daughter is born then a pumpkin (Pharsi)." (Female, programme implementer, age 48, Kaski, ID 24)

"Here in our Kaski district, two sister-in-laws have delivery at the same time. The elder one gives birth to a daughter and the younger one delivers a son. The elder one gets the leftover rice and water mixed milk, but at the same time the younger one gets the fresh foods and good and pure milk, also she gets extra care from the family." (Female, programme implementer, age 42, Kaski, ID 22)

"One of the reasons is our male dominated culture. The center of power lies with male members. Usually, decision making power is under the control of males. For instance, you can think about money. It is always with males. As the parental property is transferred only to their sons, the power also gets transferred accordingly. That's why people are attracted to have a son to protect their powers." (Male, health care providers, age 37, Tanahun, ID 08)

"People prefer sons because they are the permanent member of their family. Daughters leave their parents after marriage. Some people also perceive that it is only the son to protect their generation-their blood. The daughters are not perceived with such value in our society. This has affected the concept of son preference". (Male, health care providers, age 27, Tanahun, ID 09)

"People believe that it is only their son who can continue their family. Moreover, the daughter is considered as a subject than can bring risk and insecurity to their family. If their daughter is out of the house alone, especially in the evening, parents feel her to be unsafe. Besides the innocence of daughters, if anybody misbehaved towards her, it results in dishonor to the family. Hence, people prefer sons." (Female, health care provider, age 25, Tanahun, ID 07)

"It is a consequence of our patriarchal thought. We are still captive of beliefs like we should get a drop of water from our son before we die. This belief motivates us to prefer sons." (Male, programme implementer, age 31, Tanahun, ID 14)

We also explored with stakeholders whether son preference has been weakening or becoming stronger in their districts and what young couples think about this issue. Most stakeholders believed that son preference has been weakening in their districts, particularly due to extensive awareness programmes and increased level of education. This belief was more commonly mentioned by the health care providers from Tanahun than Kaski who argued that daughters (and females) in their district have started carrying out final death rituals and local government has prioritised programmes that aimed to protect women's rights and empower women. In contrast, few programme implementers (four out of 17) and few health care providers (two out of 12) thought that son preference has been stronger among young couples in their districts. One of the stakeholders of Tanahun even mentioned about the craze of parents in Kaski district to enrol their sons in the British Gorkhas (Army) and hence they yearn for sons not daughters.

"Son preference has been weakening in this district. These days, at least educated families and urban people don't care about it (whether son or daughter). This practice is not found and cared about much. Around $60-70 \%$ in rural areas and $10-15 \%$ or $20 \%$ still exist but the trend has decreased. I feel it is due to education..... they started thinking that a son and a daughter are equal. They become proud of what their children have done and it follows when you see other people's daughters." (Male, health care provider, age 40, Tanahun, ID 06)

"Recently I heard the news that women are participating in the funeral procession and last death rites are performed by daughters. This kind practice is being developed in society. There is a change in thinking now. I have encountered many couples who are interested in having girls. Boys usually move away from the family, sometimes abroad so that parents prefer girls rather than boys. People think that the daughter loves them more than the son." (Male, health care provider, age 59, Kaski, ID 16)

"It is because of our Nepal Government who changes the law and gives priorities to women. Here in Tanahun, I have seen daughters doing funeral processes. I have seen two to three cases." (Male, health care provider, age 37, Tanahun, ID 08) 
"It is increasing nowadays. As the facility is increasing the demand is also increasing. In the past people don't have the facilities, but now people came to hospital for deliveries and also want to know about the foetus's sex." (Female, health care provider, age 40, Kaski, ID 21)

"The prevalence of son preference has not decreased. Still, people are not thinking beyond the traditional beliefs towards sons. Rare evidence, like one out of a hundred couples who are happy with only a daughter do not indicate a reduction of such practices." (Female, programme implementer, age 40, Kaski, ID 18)

"People have dual characters. They verbally would say that they do not discriminate against their daughters. But in practice, they prefer sons-especially at religious and ritual occasions. It shows that they have a hidden interest for sons." (Male, programme implementer, age 31, Tanahun, ID 14)

\subsubsection{Stakeholder's views on disclosure of the sex of the foetus}

Almost all health care providers acknowledged that most women continue to seek information on the sex of the foetus. Most of the health care providers believed that there was no major difference by women's caste/ethnicity, religion and economic status in seeking information on the sex of foetus. At the same time, few health care providers, particularly from Tanahun, said that women belonging to untouchable and higher caste groups than other groups were more likely to seek information on the sex of foetus. Some of the health care providers from both districts also perceived that those women whose first child was daughter were more likely than their counterparts to go for sex determination test.

"Yes, most of the women request me to disclose the sex of foetus; they offer more money for that. Usually 26-27 weeks pregnant women came for ANC checkups from Damauli hospital (Tanahun) and do video $x$-ray, after knowing the gender of the child one of the women resorted to abortion at 26-27 weeks of pregnancy, so after that event I don't tell them now. Mostly they are from Dalit, Chhettri and Brahmin castes, who are the most likely to ask such questions (sex of foetus). Gurung andMagars don't ask much. Dalits say that sons will be with them till the end and Brahmins say sons are needed for funerals after death." (Male, health care provider, age 37, Tanahun, ID 08)

With regards to providers practice on disclosures of sex of the foetus, almost all health care providers (10 out of 12) acknowledged that some providers disclose the sex of the foetus around 18-30 weeks. They stated that client's pressure, easy access to technology, weak enforcement of laws, lack of monitoring of health facilities and monetary benefits to the providers were main reasons for disclosing the sex of foetus. They also stated that they disclose the sex of the foetus after six months of pregnancy so that women were less likely to go for abortion.

"There are different reasons for the providers to disclose the sex of the foetus. Of course, the most common reason is clients' pressure. Service seekers pressurize us to disclose the sex of the foetus. The service providers would not disclose the sex if they did not get such pressure. Next thing is our value. People trust us only when we can satisfy them. If we did not disclose, they would not trust us. Maybe it is related to the incomes of the service providers. When they disclose, they get good amounts of money. The other thing is that there is a high unhealthy competition among providers in the market. They have to satisfy their clients to remain in competition. So, they disclose it." (Male, health care provider, age 27, Tanahun, ID 09)

"We have to provide service to more than 70 patients every day. Almost all the women and the visitors ask to disclose the sex of foetus. We should not and can't show our anger for their request. We can't be annoyed with all. That might be a reason why we tell them the sex of the foetus at later period of their pregnancy; to say, it is after 20 weeks". (Male, health care provider, age 39, Kaski, ID 19)

In terms of accessibility to USG, the health care providers said that there are fewer diagnostic centres in Tanahun than Kaski, and likewise, no approved service centres for second trimester abortions in Tanahun. They reiterated that the women from Tanahun who want to know the sex of the foetus need to travel to another district, either to Kaski or Chitwan, whereas women from Kaski can get this service in their home district. In addition, health care providers from Tanahun viewed that due to lack of skilled doctors and good health services, it was difficult to identify the sex of the foetus, whereas the opinion given by respondents from Kaski was not the same. Health care providers from Kaski said that it was easy for women to identify the sex of the foetus as compared to Tanahun due to various reasons: easy access to facilities, access to information about facilities, urbanization, people are economically 
sound, doctors easily disclose the sex of foetus when they get better payment. Only one provider from Kaski said that service charges were expensive and doctors are not flexible in terms of disclosing the sex of the foetus.

"There is no sex determination here (Tanahun). Most of the women go to Pokhara (Kaski) where they do the ultrasound after the 13th week of pregnancy and if they have doubts they go again after two weeks. I have heard that they go to Pokahara (Kaski) and Bharatpur (Chitwan) for this service. They identify the sex there and if it is a female child, they also abort there." (Male, health care provider, age 40, Tanahun, ID 06)

"I think it is not difficult for women to select the sex of th foetus in Kaski. There are various centers to provide services with video $x$-ray and the number of radiologists is also high. Women have more choice to seek services. They can access services from different centers. So, refusal ofone center can't stop women getting the service. There is good access in this district." (Male, health care provider, age 52, Kaski, ID 17)

Most of the health care providers (eight out of 12) stated that the demand for disclosure of sex of the foetus has increased in recent years. Easy access to technology, advancement of new technology to detect the sex of the foetus, and patriarchal and traditional beliefs were the main reasons for the increasing demand for the disclosure of sex of foetuses.

"The demand for disclosure hasincreased. If you think of a decade ago, there was a limited number of service centers for USG. I think there was not any center in Tanahun 10 years ago. But now, the number of service centers and service providers has little not as in Kaski. It has enlarged the concern of the general public on sex selection. As a consequence of all these factors, the demand for disclosure of the sex of the foetus has increased in recent years." (Male, health care provider, age 27, Tanahun, ID 09)

"As a consequence of our patriarchal society, the demand for disclosure of the sex of foetuses has increased. People believe that having a son in a family contributes towards their honor in society. People also perceive that sons are supposed to earn for the family. Likewise, the demand for disclosure of the sex is also related to a concept that sons are needed for continuation of their generation." (Male, health care provider, age 52, Kaski, ID 17)

We also explored with programme implementers about how easily service providers disclose the sex of the foetus to women. Most of the programme implementers (12 out 17) believed that service providers easily disclose the sex of the foetus. They mentioned that both the doctors and radiologists verbally disclose the sex of foetus. Few respondents (three out of 17) from Kaski reported that providers disclosed the sex of foetus in written form or by drawing a picture to inform their clients.

"If we request the providers to tell us the sex of the foetus, they won't disclose it at first. They might send women to the counter (to their administrative assistants) where we might have to bargain (for their fee) with them. I think they might ask us to add money for the disclosure. Then, the doctor might tell it verbally only if we could assure them about the confidentiality of their work and the disclosure. We might have to commit to them that we won't leak the issue out. I don't think such practice exists in government facilities. It is only in private service centers." (Male, programme implementer, age 31, Tanahun, ID 14)

"One of my relatives is a radiologist. I know his way to disclose the sex. He draws a sign to refer to the sex of the foetus. He draws ' + ' to denote female and ' $O$ ' to denote male in each report. But if a woman does not understand the sign, he does not say it verbally." (Male, programme implementer, age 35, Kaski, ID 28)

When we asked stakeholders what women would do after knowing the sex of foetus, almost all health care providers and programme implementers from both districts said that women resort to abortion if they are carrying a female foetus.

"I have an example of sex selection. One of my friends had a good professional status. She had two daughters. During her third pregnancy, she was threatened by her family to be sent away from her home if she delivered another daughter. So, she did USG to select the sex. She came to know that it was a son. So, she continued the pregnancy. But, when we generalize such cases, the female foetuses are aborted." (Female, programme implementers, age 31, Tanahun, ID 12)

"When women or their families come to know that the sex of the foetus is female, they abort it. In the context of Kaski, people go to a private hospital for sex selective abortion, though they have to higher fee 
may not be approved for second trimester abortion". (Female, programme implementers, age 46, Kaski, ID 27)

“We don't have a center for second trimester abortion in Tanahun district. In case women wanted to abort the female foetus after disclosure of the sex, they have to go to Gandaki zonal hospital (Kaski). So, due to limited access to service centers, women continue their pregnancy regardless of the sex in this district (Tanahun)." (Male, health care provider, age 38, Tanahun, ID 04)

Moreover, all stakeholders reported that no specific programme is in place to raise awareness about sex selective abortion among health care providers in both study districts.

"I have not heard about any programme to sensitize health service providers about the issue of sex selection. We, health service providers, have studied the legal and illegal condition in our academic courses. I have not heard any other specific programmes about the issue." (Female, health care provider, age 22, Kaski, ID 20)

"There are not any organized programmes on the issue of sex selection. The service providers get some information about the laws and specific rules during their education and other trainings. So, I don't think that there are any specific programmes in this district." (Female, health care provider, age 25, Tanahun, ID 07) 


\section{CHAPTER 3}

\section{WHAT WORKS TO REDUCE \\ GENDER-BIASED SEX SELECTION: PERSPECTIVES ON THE ENFORCEMENT OF THE LAW}

\section{Summary}

Although most women had heard of the abortion law (63\% Kaski and $46 \%$ in Tanahun), their knowledge about legal provisions for prohibiting disclosure of the sex of the foetus and sex selective abortion was limited in both districts (43\% in Kaski and 35\% in Tanahun). Moreover, only slightly above one in four women in both districts were aware that a person seeking disclosures of the sex of the foetus as well as the person conducting such a test may be jailed. Radio, television and newspapers remained the major sources of information about legal provisions that prevent sex selective abortion ( $87 \%$ in Kaski, $76 \%$ in Tanahun). Comparatively, exposure to these media channels was higher among women in Kaski (87\%) than in Tanahun (76\%).

In terms of adherence to and enforcement of the abortion law, more women in Kaski than in Tanahun (54\% versus 39\%) reported that providers do reveal the sex of foetus. Moreover, hardly any women-just 3-6\%-reported that they had heard about any action taken against a provider, such asa raid on those providers for revealing the sex of foetus or doctors being prosecuted or a clinic being closed for advertising sex determination services.

Most women-92\% from Kaski and 87\% from Tanahun-approved the law that prohibits sex selective abortion, indicating that without such a law there would be shortages of girls for marriage. The rural-urban differences in the responses were marginal. Almost all respondents, irrespective of district and rural-urban residence, also believed that the law was fair because girls had a right to be born (97-99\%). A large percentage of women in both districts opined that the person either seeking sex detection or disclosing the sex of the foetus should be punished/sentenced to imprisonment (68\% in Kaski and 66\% in Tanahun).

Almost all stakeholders presumed that their colleagues were aware of the legal provision regarding disclosing the sex of foetus and sex selective abortion. Only those few health care providers who were new in the job and received education from abroad expressed their ignorance about this legal provision. Except one from Tanahun, all the health care providers believed that there was no monitoring mechanism in place to control gender-biased sex selection in their districts. In line with women's views, key informants reported that nobody has been ever been imprisoned or held guilty for sex selection despite the law. The programme implementers, especially from Tanahun mentioned that the law is implemented through various awareness and advocacy programmes. They also reported that different committees formed at the village level support legal processes for such cases. Programme implementers also reported the active presence of one stop crisis centers, and civil watchdog groups in Tanahun but not in Kaski. According to the programme implementers, monitoring mechanisms in Kaski were virtually non-existent whereas in Tanahun few mentioned the existence of monitoring mechanisms. Programme implementers from Tanahun viewed that their district public health office is quite alert regarding sex selection practice when compared to Kaski.

As described in Chapter 1, in 2002, the Country Code of Nepal (Muulki Ain) was amended to grant all women the right to terminate a pregnancy up to 12 weeks' gestation on demand, up to 18 weeks if the pregnancy is due to rape or incest, and at any gestational age-if the woman is advised by a doctor that the pregnancy poses a danger to her life or physical or mental health, or in cases of foetal abnormality or impairment with the advice of a medical practitioner and the pregnant woman's consent. However, the law prohibits abortions done without the consent of 
pregnant women, abortion on the basis of sex selection, and abortions performed outside the legally permissible criteria. It also imposes punishment, by way of fines and imprisonment, on providers and families of pregnant women found to have violated the law. Despite these provisions in the laws, violations, particularly discriminatory sex selective abortion persist in the country.

In this chapter, we discuss the perceptions and experiences of women, and district level stakeholders about the enforcement of the law. Specifically, we explored the extent of awareness of various laws for women that aimed to protect and empower women, adherence, enforcement and effectiveness of such laws particularly laws related to disclosure of sex of the foetus and gender selective abortion.

\subsection{Women's awareness of the abortion law and other laws protecting women}

Women were asked about their knowledge about legal provisions for various social issues such as child marriage, dowry practice, right to property, abortion and gender-biased sex selection. Findings presented in Table 3.1 suggest that large percentages of women were aware of the child marriage law, laws about domestic violence, property rights for women, divorce and separation, and even the law prohibiting the dowry system. Percentages of women who were aware of these laws ranged from $60 \%$ to $87 \%$ in Kaski, and from $46 \%$ to $76 \%$ in Tanahun.

A large percentage of women were also aware about the abortion law: $63 \%$ of those from Kaski and $46 \%$ of those from Tanahun. In both districts, awareness among urban women considerably exceeded that of women from rural areas. However, women's knowledge about legal provisions for preventing sex selective abortion was limited in both the districts (35\% in Tanahun; 43\% in Kaski), with more women from urban than rural areas reporting such awareness (51\% versus 35\% in Kaski; $44 \%$ versus 26\% in Tanahun) (Table 3.1).

Radio, television and newspapers remained the major sources of information about legal provisions that prevent sex selective abortion (87\% in Kaski, $76 \%$ in Tanahun). Comparatively, exposure to these media channels was higher among women in Kaski (87\%) than in Tanahun (76\%). On the other hand, a higher percentage of women in Tanahun (41\%) than in Kaski (26\%) identified health providers as sources of information on sex selection prevention. Likewise, women in Tanahun (19\%) were more exposed to community level meetings conducted on the issue of sex selective abortion than in Kaski (4\%). Other sources, reported by more than $10 \%$ of women included, in Kaski, hoarding boards and advertisements (15\%) and family members, relatives, neighbors and friends (14\%), and in Tanahun, meetings (19\%) and family members, relatives, neighbors and friends (34\%). It was noted that more women in Tanahun than in Kaski reported both formal and informal sources of information (Table 3.2).

Women's knowledge about specific aspects of abortion laws was very limited. For example, only slightly above one in four women in both districts were aware that a person seeking disclosure of the sex of the foetus and the person conducting such a test may be jailed (Figure 3.1).

Table 3.1: Percentage of women reporting awareness of different laws protecting women: Kaski and Tanahun

\begin{tabular}{|c|c|c|c|c|c|c|}
\hline \multirow[t]{2}{*}{ Types of laws protecting women } & \multicolumn{2}{|c|}{ Urban } & \multicolumn{2}{|c|}{ Rural } & \multicolumn{2}{|c|}{ Total } \\
\hline & Kaski & Tanahun & Kaski & Tanahun & Kaski & Tanahun \\
\hline Prohibition of child marriage & 88.8 & 83.2 & $83.6^{* * *}$ & 60.0 & $86.2^{* * *}$ & 71.6 \\
\hline Women's right to inherit parental property & 71.6 & 63.6 & $60.0^{*}$ & 50.0 & $65.8^{* *}$ & 56.8 \\
\hline Prohibition of payment of dowry & $66.0^{* * *}$ & 52.0 & $54.8^{* * *}$ & 39.2 & $60.4^{* \star *}$ & 45.6 \\
\hline Domestic violence against women and girls & $92.0^{* * *}$ & 78.8 & $81.2^{*}$ & 73.2 & $86.6^{* * *}$ & 76.0 \\
\hline Laws on divorce and separation & $94.0^{* \star *}$ & 82.0 & $85.2^{* \star *}$ & 66.8 & $89.6^{* \star *}$ & 74.4 \\
\hline Abortion rights (women have right to seek abortion) & $68.0^{* *}$ & 56.0 & $57.2^{* * *}$ & 36.0 & $62.6^{* * *}$ & 46.0 \\
\hline $\begin{array}{l}\text { Law prohibiting disclosure of the sex of foetus and } \\
\text { sex selective abortion }\end{array}$ & 51.2 & 44.4 & $34.8^{*}$ & 26.0 & $43.0^{*}$ & 35.2 \\
\hline Number of women & 250 & 250 & 250 & 250 & 500 & 500 \\
\hline
\end{tabular}

Note: ${ }^{*},{ }^{* \star},{ }^{* * *}$ indicate that differences between Kaski and Tanahun, Kaski urban and Tanahun urban and Kaski rural and Tanahun rural are significant at $p<.05, p<.01$ and $p<0.001$, respectively. 
Table 3.2: Percentage of women reporting awareness about laws that prevent sex selective abortion by sources of information: Kaski and Tanahun

\begin{tabular}{|c|c|c|c|c|c|c|}
\hline \multirow[t]{2}{*}{ Sources of awareness ${ }^{+}$} & \multicolumn{2}{|c|}{ Urban } & \multicolumn{2}{|c|}{ Rural } & \multicolumn{2}{|c|}{ Total } \\
\hline & Kaski & Tanahun & Kaski & Tanahun & Kaski & Tanahun \\
\hline Radio/Television/Newspaper & $88.3^{* *}$ & 73.9 & 85.1 & 78.5 & $87.0^{* *}$ & 75.6 \\
\hline Health provider & 26.6 & $45.0^{* * *}$ & 26.4 & 35.4 & 26.5 & $41.5^{* * *}$ \\
\hline Meeting & 1.6 & $16.2^{* * *}$ & 8.0 & $24.6^{* *}$ & 4.2 & $19.3^{* * *}$ \\
\hline Hoarding boards/Advertisements in health facility & $16.4^{* * *}$ & 9.0 & 12.6 & 9.2 & 14.9 & 9.1 \\
\hline Family members/Relatives/Neighbors/Friends & 14.8 & $31.5^{* * *}$ & 11.5 & $38.5^{* \star *}$ & 13.5 & $34.1^{* * *}$ \\
\hline Others & 3.9 & 5.4 & 3.4 & 3.1 & 3.7 & 4.5 \\
\hline Number of women & 128 & 111 & 87 & 65 & 215 & 176 \\
\hline
\end{tabular}

Note: ${ }^{* *},{ }^{* * *}$ indicate that differences between Kaski and Tanahun, Kaski urban and Tanahun urban and Kaski rural and Tanahun rural are significant at $p<.01$ and $p<0.001$, respectively. ${ }^{+}$Percentage total may exceed 100 due to multiple responses.

Figure 3.1: Percentage of women reporting awareness of legal provision concerning sex selective abortion

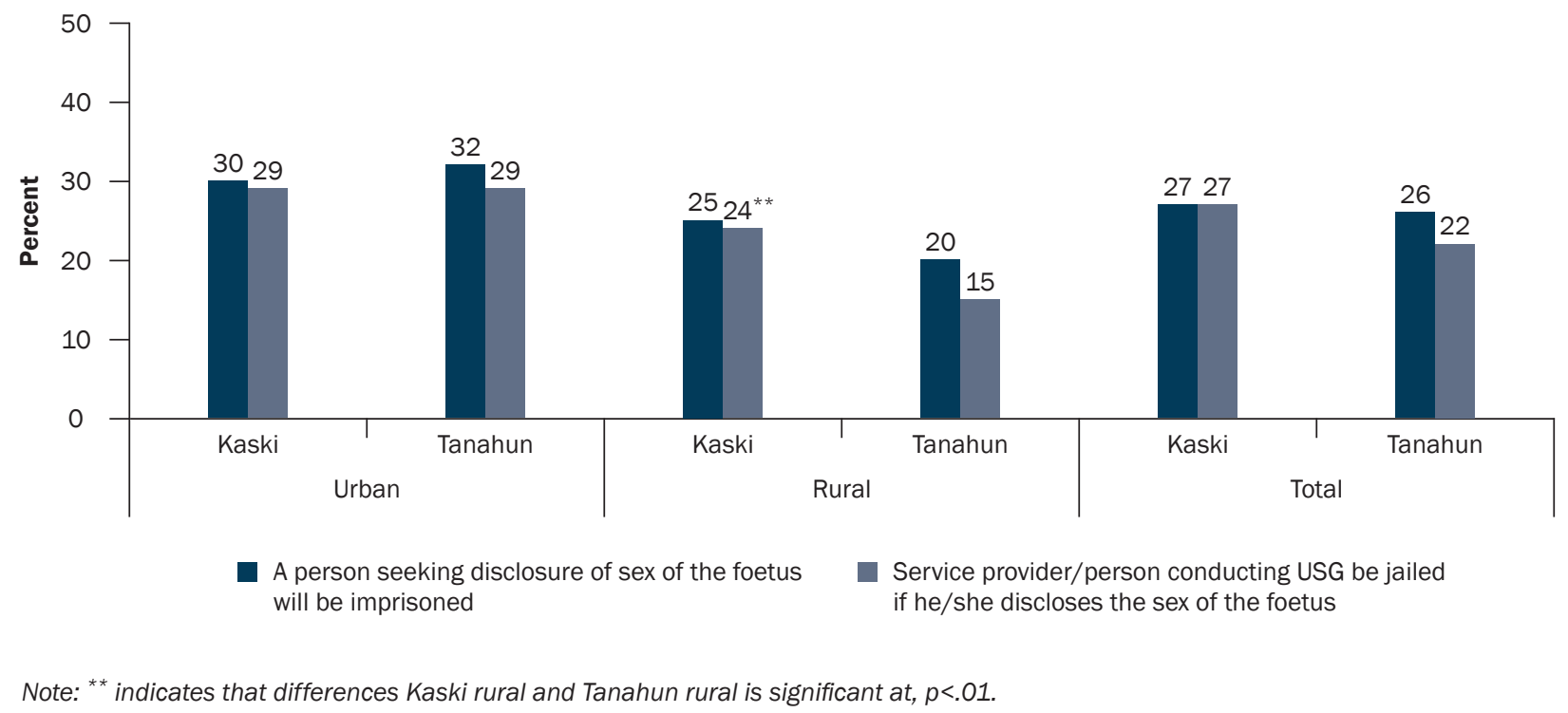

\subsection{Women's perceptions about the extent of adherence to and enforcement of the Abortion Law}

The present survey further solicited women's perceptions regarding the enforcement and adherence to the Abortion Law. Results show that not a single woman was able to articulate the kind of punishment that accompanies such a crime (not shown in table below). More women in Kaski than in Tanahun (54\% versus 39\%) reported that providers do reveal the sex of the foetus. Moreover, hardly any woman-just 3-6\%-reported that they had heard of any action taken against a provider, such as, for example, a raid on those providers for revealing the sex of foetus, doctors being prosecuted or a clinic being closed for advertising sex determination services. Although the percentages are small, relatively a higher percentage of women in Kaski than in Tanahun had heard that providers are being prosecuted for revealing the sex of the foetus or advertising the sex determination test services (Table 3.3). 
Table 3.3: Percentage of women reporting that providers continue to violate the Abortion Law, and that raids and punishment of violators have taken place in their areas: Kaski and Tanahun

\begin{tabular}{|c|c|c|c|c|c|c|}
\hline \multirow[t]{2}{*}{ Awareness indicators } & \multicolumn{2}{|c|}{ Urban } & \multicolumn{2}{|c|}{ Rural } & \multicolumn{2}{|c|}{ Total } \\
\hline & Kaski & Tanahun & Kaski & Tanahun & Kaski & Tanahun \\
\hline $\begin{array}{l}\text { Aware that some health care providers do reveal } \\
\text { the sex of the foetus }\end{array}$ & $54.0^{* *}$ & 44.0 & $53.2^{* \star *}$ & 34.0 & $53.6^{\star * *}$ & 39.0 \\
\hline $\begin{array}{l}\text { Ever heard about a doctor being prosecuted } \\
\text { or a clinic being closed for advertising sex } \\
\text { determination services or revealing the sex of the }_{\text {foetus }}^{\text {ns }}\end{array}$ & 8.4 & 9.6 & 5.2 & 5.2 & 6.8 & 7.4 \\
\hline $\begin{array}{l}\text { Heard about raids on some doctors in Kaski or } \\
\text { Tanahun for revealing the sex of the foetus }\end{array}$ & 6.4 & 3.2 & 6.0 & 3.6 & $6.2^{*}$ & 3.4 \\
\hline $\begin{array}{l}\text { Seen a sign saying particular facility does not } \\
\text { provide sex determination test }\end{array}$ & 13.2 & 15.6 & $16.0^{*}$ & 8.8 & 14.6 & 12.2 \\
\hline Heard about both (provider prosecuted and raid) & $4.0^{*}$ & 0.8 & $3.2^{*}$ & 0.4 & $3.6^{* * *}$ & 0.6 \\
\hline Number of women & 250 & 250 & 250 & 250 & 500 & 500 \\
\hline
\end{tabular}

Note: ${ }^{*},{ }^{* *},{ }^{* * *}$ indicate that differences between Kaski and Tanahun, Kaski urban and Tanahun urban and Kaski rural and Tanahun rural are significant at $p<.05, p<.01$ and $p<0.001$, respectively; ns:not significant.

\subsection{Women's attitudes about enforcement of the Abortion Law}

Most women-92\% from Kaski and 87\% from Tanahun-approved the law that prohibits sex selective abortion, indicating that without such a law there would be shortages of girls for marriage. The rural-urban differences in the responses were marginal. Almost all respondents, irrespective of district and rural-urban residence, also believed that the law was fair because girls had a right to be born (97-99\%).

A large percentage of women in both districts opined that the person either seeking sex detection or disclosing the sex of the foetus should be punished/sentenced to imprisonment (68\% in Kaski and 66\% in Tanahun). They also felt that service providers like doctors and radiologists conducting USG could be put behind bars if they disclosed the sex of the foetus (62-63\%). Less than a quarter of the women from both districts perceived that the fear of raids would deter providers (23-24\%) or families (22-23\%) from conducting and seeking these services. Half of women from Kaski (50\%) as compared to one third in Tanahun (34\%) disagreed that the law should allow sex selection of couples with two or more daughters but no son (Table 3.4).

Table 3.4: Percentage of women reporting opinions on the law prohibiting sex selection and punishment of law violators: Kaski and Tanahun

\begin{tabular}{|c|c|c|c|c|c|c|}
\hline \multirow{2}{*}{$\begin{array}{l}\text { Perceptions on law prohibiting sex selection } \\
\text { and punishment of law violators }\end{array}$} & \multicolumn{2}{|c|}{ Urban } & \multicolumn{2}{|c|}{ Rural } & \multicolumn{2}{|c|}{ Total } \\
\hline & Kaski & Tanahun & Kaski & Tanahun & Kaski & Tanahun \\
\hline $\begin{array}{l}\text { Such a law is important otherwise there will not } \\
\text { be enough girls for marriage }\end{array}$ & 90.0 & 84.0 & 94.8 & 89.6 & 92.4 & 86.8 \\
\hline $\begin{array}{l}\text { The law is fair because the girls have a right to } \\
\text { be born }{ }^{\text {ns }}\end{array}$ & 97.2 & 96.8 & 100.0 & 98.0 & 98.6 & 97.4 \\
\hline $\begin{array}{l}\text { People who disclose/ask for the sex of the foetus } \\
\text { should be punished }\end{array}$ & 68.4 & 66.8 & 68.0 & 64.8 & 68.2 & 65.8 \\
\hline $\begin{array}{l}\text { Health provider/doctor/person conducting USG } \\
\text { who disclose the sex of the foetus should be } \\
\text { punished }\end{array}$ & 56.3 & 65.8 & $70.1^{*}$ & 56.9 & 61.9 & 62.5 \\
\hline
\end{tabular}


Table 3.4: (Cont'd)

\begin{tabular}{|c|c|c|c|c|c|c|}
\hline \multirow{2}{*}{$\begin{array}{l}\text { Perceptions on law prohibiting sex selection } \\
\text { and punishment of law violators }\end{array}$} & \multicolumn{2}{|c|}{ Urban } & \multicolumn{2}{|c|}{ Rural } & \multicolumn{2}{|c|}{ Total } \\
\hline & Kaski & Tanahun & Kaski & Tanahun & Kaski & Tanahun \\
\hline $\begin{array}{l}\text { Disagreed that the law should allow sex selection } \\
\text { of couples with two or more daughters but no son }\end{array}$ & $47.2^{* * *}$ & 30.8 & $52.4^{* * *}$ & 38.0 & $49.8^{* * *}$ & 34.4 \\
\hline $\begin{array}{l}\text { Doctors will stop this practice because they fear } \\
\text { the raids }\end{array}$ & $15.2^{* * *}$ & 22.4 & 30.8 & 25.6 & 23.0 & 24.0 \\
\hline $\begin{array}{l}\text { Think that people will stop asking doctors to } \\
\text { reveal the sex of the foetus because of the raids }\end{array}$ & $14.4^{* *}$ & 21.2 & 28.8 & 24.8 & 21.6 & 23.0 \\
\hline $\begin{array}{l}\text { Think that the law is not effective as nobody is } \\
\text { jailed for practicing sex selection }\end{array}$ & $92.4^{* * *}$ & 69.2 & $90.8^{* * *}$ & 64.8 & $91.6^{* * *}$ & 67.0 \\
\hline Number of women & 250 & 250 & 250 & 250 & 500 & 500 \\
\hline
\end{tabular}

Note: ${ }^{*}{ }^{* \star},{ }^{* \star}$ indicate that differences between Kaski and Tanahun, Kaski urban and Tanahun urban and Kaski rural and Tanahun

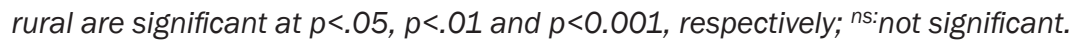

\subsection{Perspectives of districts level stakeholders}

We explored district level stakeholder's experiences with regard to implementation of the Abortion Law and their perceptions about the effectiveness of law enforcement. Since we had interviewed two broad range of stakeholders and their opinions differed to some extent on these issues, we present the findings by two types of stakeholdershealth care providers and programme implementers.

\subsubsection{Health care provider's awareness about the Abortion Law}

Almost all the health care providers presumed that their colleagues were aware about the legal provision regarding disclosing the sex of the foetus and sex selective abortion. Only those few health care providers (two out of 12) who were new in the job and received education from abroad expressed their ignorance about this legal provision. Health care providers also perceived that those who had not received training in providing abortion services and not received government approval for the same were unaware about the provision of abortion laws on sex selection. For example:

"All providers are aware about the abortion law. We discuss about the law, and other related rules and regulations during Comprehensive Abortion Care training. So, all service providers are informed." (Male, health care provider, age 30,Tanahun, ID 11)

"Service providers are well informed. As we are working in this area, we need to have information about this. I think all providers have knowledge on the legal provisions." (Female, health care provider, age 22, Kaski, ID 20)

"We have found some service providers who are uninformed. Especially those who studied in less reputed institutions and in other countries are not following the laws and ethics. We talk about it among our colleagues as well. Those providers who did not receive training on comprehensive abortion care are less informed about the legal provisions." (Male, health care provider, age 40, Tanahu, ID 06)

"I think some doctors who are new in this field and studied in foreign countries are less informed. Maybe it is only among the new doctors. Other experienced doctors are well informed." (Female, health care provider, age 25, Tanahun, ID 07)

\subsubsection{Perception of health care providers on enforcing abortion laws}

All the health care providers, except one from Tanahun, believed that there was no monitoring mechanism in place to control gender-biased sex selection in their districts. The single respondent who claimed that monitoring mechanisms exist in the district asserted that they carry out regular monitoring and supervisions of both government and private facilities particularly where there are facilities for conducting USG. 
"There is no good monitoring and supervision system in place to control sex selective abortion. If there were such mechanisms, the demand for sex selection would not increase. The practice would certainly decline. People are willing to do anything when they want to know the sex of the foetus. Since there is no strong and transparent law in our country, it has made the practice grow." (Male, health care provider, age 52, Kaski, ID 17)

"Monitoring and supervision are carried out by the government agencies like the district health office in this district. We are not limited to annual monitoring but we conduct such monitoring when we feel the need. We also monitor the types of infrastructure and equipment that the providers are using in their facility as these helps us to determine their services. We monitor both government and private facilities. We ask if they are using an ultra-sonogram equipment and if they use it, we use an indirect channel to know whether they use the technology for sex selection." (Female, health care provider, age 25, Tanahun, ID 07).

However, most of the health care providers acknowledged that more supervision and monitoring of health facilities and diagnostics centers are needed to ensure that the providers adhere to the existing law on sex selection. For example, one health care provider said:

"We need to increase the supervision and monitoring of health service centers. I think we can identify the service providers and centers disclosing the sex of the foetus through an indirect mechanism like we can get information from the clients of the suspected facilities. I don't think any service providers would reveal themselves that they provide sex determination tests, but we can obtain the facts from the clients." (Female, health care provider, age 25, Tanahun, ID 07).

It is to be noted that in both the districts, it was mentioned that there is a lack of proper evidence of sex selection and nobody has ever been imprisoned or accountable for sex selection despite the law. It was mentioned that the cases may come up if any complication or mishaps occurs but in the absence of such cases it would be very difficult to penalize a facility or the provider for the act.

"No. I have not heard about any case of raids or punishment in this district. It is not only in this district, I have not heard a case throughout the country." (Male, health care provider, age 38, Tanahun, ID 04)

"There is no any system to enforce the law and punish the violators. If there were strong mechanisms to monitor and control such activities, the demand for sex selection would not have increased." (Male, health care provider, age 52, Kaski, ID 17)

"The basic thing is that we need to have a strong guideline to monitor the activities. It does not mean that there is no authority to monitor but the problem is that the authorities do not work when they are supposed to." (Male, health care provider, age 59, Kaski, ID 16)

"The government should seal (close down) the service centers where radiologists provide sex selection services. Those must be closed. The providers should receive punishment. I am in a favor of prosecuting the providers who violate the laws. But, it is not in place. This is the main problem." (Male, health care provider, age 40, Tanahun, ID 06)

\subsubsection{Programme implementer awareness of the Abortion Law}

Most of the programme implementers in both the districts mentioned that they are aware about law on abortion. The programme implementers, especially from Tanahun mentioned that law is implemented through various awareness and advocacy programme. They also reported that different committees formed for child protection, gender based violence, anti-trafficking at village development committee level that supports legal process for such cases. Programme implementers also reported active presence of one stop crisis center, and civil watchdog group in Tanahun but not in Kaski.

According to the programme implementers, monitoring mechanism in Kaski was virtually non-existent whereas in Tanahun a few mentioned about the existence of a monitoring mechanism. Programme implementers from Tanahun viewed that their district public health office is quite alert regarding sex selection practice as compared to Kaski office: 
"There is paralegal committee in this district. The lawyers organize awareness programmes in the communities about the legal provisions. People are afraid to disclose the sex of the foetus and carry out sex selective abortion. So, we can assume that the law is enforced through their behaviors." (Female, programme implementer, age 50, Tanahun, ID 10)

"There is a law and service providers are aware about it but it is not enforced in this district. If it was enforced, we would not have imbalance sex ratio at birth. Providers are greedy for money... people are ready to do everything to earn money, that's why we are having this problem". (Female, programme implementer, age 32, Kaski, ID 26)

\subsubsection{Perception of programme implementers on enforcing abortion laws}

Most of the programme implementers considered that there was no effective enforcement of laws against genderbiased sex selective abortion. Comparatively, a higher number of programme implementers in Tanahun (six out of eight) than in Kaski (two out of nine) believed that there was no enforcement of the Abortion Law in their districts. Difficulty collecting evidence for legal action, lack of willingness and accountability, lack of collaboration and coordination between concerned agencies, and financial constraints were the main reasons for poor regulatory measures against sex selection.

"The most important thing is that there is no strong law in our country. Moreover, the existing law is not practical and not enforced either. The authority should take action to enforce the laws. Due to weakness of responsible authorities, the violators are beyond the control of law." (Male, programme implementer, age 32, Tanahu, ID 13)

"It is very difficult to find evidence of violations of the law. It is not possible to get proof that the abortion was done after sex selection. Just in case any violation is reported to authorities, the doctors can do everything to make decisions in their favor. That would be related to their business, their profession and their status. That's why the law is not enforced effectively over here." (Male, programme implementer, age 35, Kaski, ID 28)

"Even the government cannot file a case if there is not any evidence. If it was possible, there would be many people imprisoned by now. But there is no one in jail for sex selection and sex selective abortion." (Male, programme implementer, age 31, Tanahun, ID 14)

"High numbers of illegal abortions indicates the lack of effective enforcement of the abortion law. It is very clear that the law is not enforced effectively." (Female, programme implementer, age 48, Kaski, ID 24)

"I have heard from some pregnant women that they know the sex of their foetus. How would they know if radiologists did not disclose the sex of the foetus? I'd like to repeat that there is law in our country, but it is not enforced in practice. Since the issue of sex selection is a very private matter, the law can't control it. In addition, it is not possible to get written evidence to prosecute. It makes it difficult for enforcement." (Female, programme implementer,age 46, Kaski, ID 29) 


\section{CHAPTER 4}

\section{WHAT WORKS TO REDUCE}

GENDER-BIASED SEX SELECTION:

INITIATIVES TO ENHANCE THE STATUS

OF THE GIRL CHILD THROUGH

SCHOLARSHIPS, LEGAL AWARENESS

AND GENDER EQUALITY PROGRAMMES

\section{Summary}

Despite the introduction of several schemes and scholarships for girls and for children from disadvantaged communities, primary education enrolment of children from disadvantaged communities has been far from satisfactory in the country. In the present survey, although women's knowledge on girls' entitlements to free text books, school uniforms and scholarships for girls was quite widespread in both the study districts, less than a third of the women from both the study areas who had at least one daughter aged 6 years and above reported that their daughters had received free text books. Likewise, a little over one third of the women in Tanahun (37\%) and a quarter in Kaski (25\%) reported that their daughters had received scholarships. Comparatively, more women from rural areas than urban areas of both districts reported that their daughters had received a scholarship. The large majority of women who were aware of the scholarships for girls felt that it helped parents defray the costs of rearing a daughter and allowed girls to complete their educations. The negative features of the scholarship as expressed by the majority of the women in both the districts pertained to the (limited) amount of the scholarship, the fact that not everyone benefits and too much paper work among other things.

Women's exposure to messages against discrimination of daughters was very high in both districts but a limited proportion of them had heard of messages or campaigns about saving the girl child. It was much lower in Kaski $(28 \%)$ than in Tanahun (43\%). Awareness about any meeting or campaign discouraging women from seeking sex determination was low. Comparatively, a higher percentage of women from Tanahun than in Kaski were knowledgeable about such campaigns held in their villages. Only one quarter of respondents in both the study areas (24\%) admitted that they had seen/read messages on what information doctors can and cannot provide to women who undergo USG.

The district based stakeholders in both the districts claimed that their districts have been implementing scholarship programmes and programmes aimed at making schools girl-friendly (i.e. distribution of sanitary pads, construction of separate toilets for girls, etc.), adolescent-friendly health services and programmes aimed at preventing violence against girls/adolescents). In addition, budgetary provisions for women and children, and reservation policy were also mentioned as relevant programmes.

The Interim Constitution of Nepal of 2007 (Nepal Law Commission, 2007) has various provisions that support gender equality. It recognizes women as a marginalized group and ensures women get special treatment from the state. The country has already ratified Convention on the Elimination of Discrimination against Women (CEDAW) and Convention of Rights of Child (CRC) to provide equal rights to sons and daughters, irrespective of their caste, religion, economic status and gender. The Children's Act (1992) and Regulations (1995) of Nepal directly negates any form of discrimination between girls and boys. A Comprehensive National Plan of Action on children (2004-2014) which covers the period from 2004 to 2014, serves as a guiding policy document for the Government to review, harmonize and improve the legal framework to ensure rights of the children in line with the founding principles of 
the Convention on the Rights of the Child, the best interest of the child, non-discrimination, survival, growth and development and child participation. The National Plan of Action aims for the progressive realization of the rights of children and women through improved survival, development, protection and participation enshrined in the framework of CRC, the CEDAW, the Millennium Declaration, and the Millennium Declaration Goals. The details of these provisions and initiatives are explained in the literature review report that preceded this main study report.

In the education sector, the Government of Nepal, under Education for All: National Plan of Action 2001-2015, provides free education in government schools as well as in community managed schools only for all children (boys and girls) up to 10th grade. In addition, it has introduced a number of schemes and scholarships for girls only (up to 10th grade) and for children (both boys and girls) belonging to Dalit and disadvantaged communities. In recent years, it increased investment in the education budget which has doubled in the last five years (from Rs. 27 billion in 2007/8 to NRs. 64 billion in 2011/12). Despite this, primary education enrolment of children from disadvantaged communities was far from the desired amount. Only 38\% of children from indigenous communities, $20 \%$ of Dalits and a mere $1 \%$ of disabled children are believed to be enrolled in primary schools (Gautam, 2013).

To our knowledge, no focused policy or programme has been developed by the Government to address the imbalances in sex ratios at birth in Nepal. It may be due to the fact that the issue of imbalance in sex ratio at birth is a new phenomenon in the country and population level changes in demography have not yet been observed. A few awareness raising and advocacy initiatives against sex selection have been recently introduced but no impact evaluation of such activities have been carried out. Unfortunately, unlike in India, Nepal does not have conditional cash transfer programmes to motivate more equal opportunities for girls in Nepal.

In this chapter, we analyzed women's levels of awareness about and perceived value accorded by them on selected gender focused initiatives aimed at enhancing the status of women and girl children. Questions were asked to all women if they were aware of the provisions made by the government to distribute free text books, uniforms and scholarships to girls attending school and whether or not their daughters received these items/incentives. We had also asked respondents if they value the girls' scholarships intended to retain girls in school until secondary school and to prevent child marriage and other discriminatory practices against the girl child. In the subsequent sections of this chapter, women's perceptions regarding ways to stop discriminatory practices against daughters and their knowledge and exposure to advocacy and community mobilization initiatives as well as the perceptions of stakeholders on gender-focused programmes and effectiveness of these programmes will be discussed.

\subsection{Gender focused programme: women's perspectives}

\subsubsection{Women's awareness about free textbooks}

Women's knowledge on girls' entitlements to free textbooks and school uniforms was widespread in both the study districts, although it is important to note that one-quarter of women from Kaski and one fifth of women from Tanahun had not heard about these entitlements. Those who were aware about these entitlements and had at least one daughter of age 6 years or over were asked whether their daughters had ever received a free text book. Despite the fact that all girls enrolled in government schools as well as in community managed schools studying up to 10th grade are entitled to get free textbooks, it was dismaying to find that less than a third of the women with an eligible daughter (6 years and above) from both the study areas (27\% in Kaski and 31\% in Tanahun) reported that their daughters had received free textbooks (Figure 4.1). It may be due to the fact that a significant proportion of respondents' daughters are studying at places other than government or community managed schools which this study did not capture.

\subsubsection{Women's awareness about scholarships for girls}

Knowledge about scholarships for girls was widespread among women in the study districts. Approximately $90 \%$ of women in Tanahun and 82\% of those in Kaski were aware of the scholarship programme for girls (Figure 4.2). Most women, however, were unaware about the details of the scholarship schemes, including the type (name), amount and duration of the scholarship etc. Only one woman could recall the name of the scholarship scheme called the Dalit Scholarship; not a single respondent could name the Chhatra Chatrabriti programme (Girls Scholarship Programme) specifically intended for girls in the districts (Table not shown). 
Figure 4.1: Percentage of women who had heard about free textbooks or school uniforms for girls and had received free textbooks for their daughters

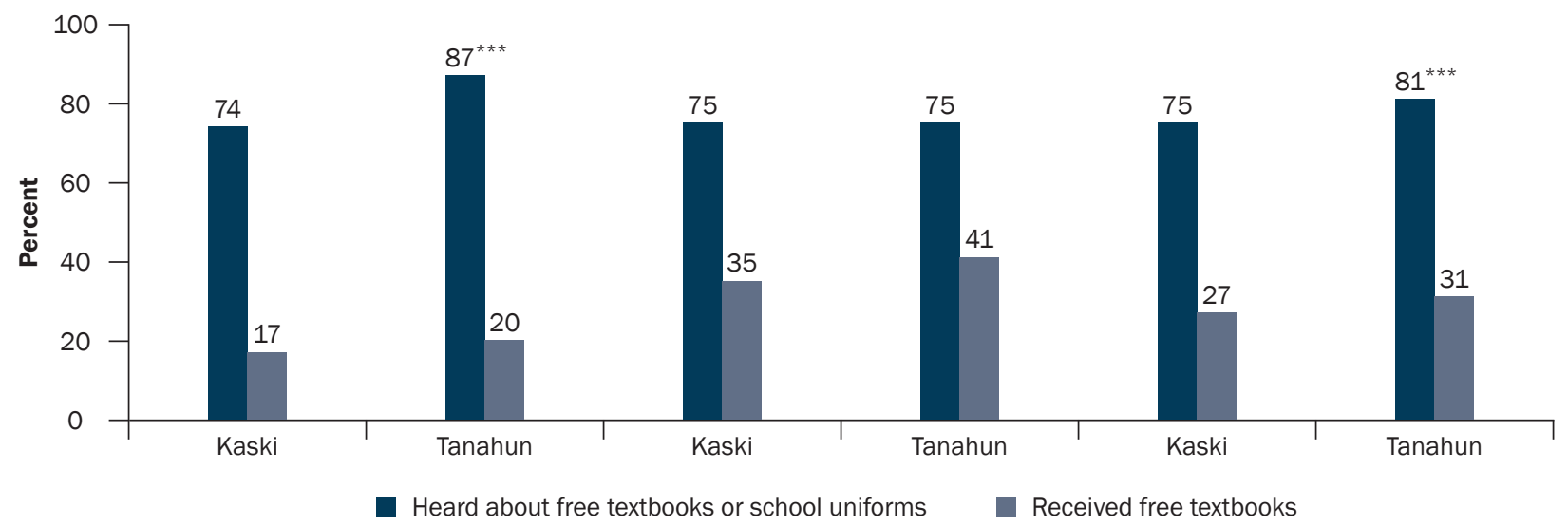

Note: ${ }^{* *}$ indicate that differences between Kaski and Tanahun, Kaski urban and Tanahun urban and Kaski rural and Tanhaun rural are significant at $p<0.001$.

As mentioned earlier, only girls studying in government schools as well as in community managed schools are entitled scholarships up to 10th grade, in addition to free education and free textbooks. In the present study, the percentage of women reporting that their daughter had received the scholarship was low. Comparatively, however, a higher percentage of women with an eligible daughter (6 years and above) in Tanahun (37\%) than in Kaski (25\%) reported that their daughter had received the scholarship. More women from rural areas than urban areas of both districts reported that their daughters had received a scholarship (Figure 4.2). It is important to note that the present survey did not solicit information about the type of school their daughters were enrolled at.

Nearly half of the women who knew about scholarships in Kaski (49\%) as against two-fifths in Tanahun (39\%) were unaware about the scholarship amount a girl receives in a year. Lack of awareness about the scholarship value was much higher among rural women in both the districts (Table 4.1).

Figure 4.2: Percentage of women who had heard about scholarship schemes for girls and whose received a daughter had scholarship

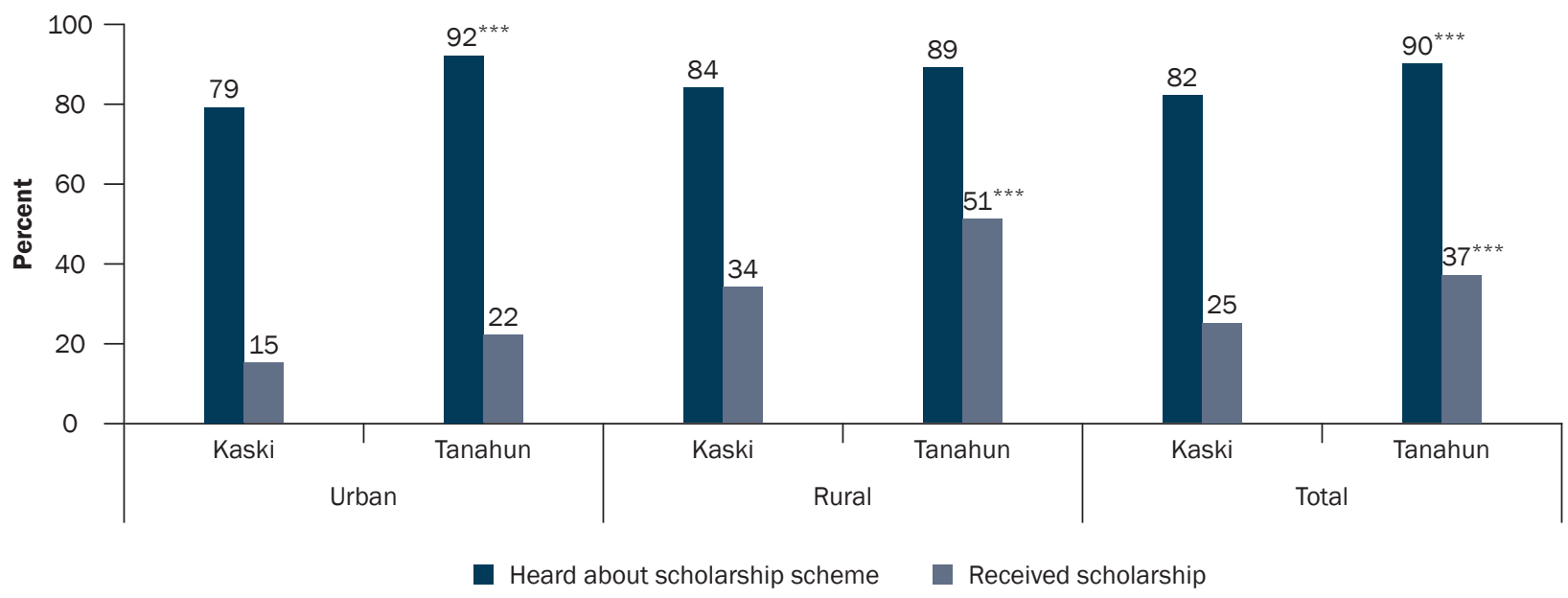

Note: ${ }^{* *},{ }^{* * *}$ indicate that differences between Kaski and Tanahun, Kaski urban and Tanahun urban and Kaski rural and Tanahun rural are significant at $p<.01$ and $p<0.001$, respectively. 
Table 4.1: Percentage of women reporting names of scholarship for girls and amount of scholarship: Kaski and Tanahun

\begin{tabular}{|c|c|c|c|c|c|c|}
\hline \multirow[t]{2}{*}{ Names of scholarship ${ }^{+n s}$} & \multicolumn{2}{|c|}{ Urban } & \multicolumn{2}{|c|}{ Rural } & \multicolumn{2}{|c|}{ Total } \\
\hline & Kaski & Tanahun & Kaski & Tanahun & Kaski & Tanahun \\
\hline Dalit scholarship & 7.1 & 13.0 & 15.2 & 12.6 & 11.3 & 12.8 \\
\hline Don't know scholarship names & 92.9 & 87.0 & 84.8 & 87.4 & 88.7 & 87.2 \\
\hline \multicolumn{7}{|l|}{$\begin{array}{l}\text { Amount of money (in NRs) a girl gets under this } \\
\text { scholarship in a year }\end{array}$} \\
\hline Less than 500 & 13.7 & 25.2 & 42.2 & 58.6 & 28.4 & 41.6 \\
\hline $500-1000$ & 11.2 & 13.0 & 10.4 & 11.7 & 10.8 & 12.4 \\
\hline 1000 and more & 11.2 & 10.4 & 11.4 & 4.1 & 11.3 & 7.3 \\
\hline Don't know scholarship amount & 64.0 & 51.3 & 36.0 & 25.7 & 49.5 & 38.7 \\
\hline Number of women who had heard of scholarship & 197 & 230 & 211 & 222 & 408 & 452 \\
\hline
\end{tabular}

Note: ${ }^{+}$Percentage total may exceed 100 due to multiple responses; ${ }^{\text {ns: }}$ not significant.

\subsubsection{Women's perceived values of scholarship for girls}

The large majority of women ( $71 \%$ in Kaski and $80 \%$ in Tanahun) who were aware of the scholarships for girls felt that it helped parents defray the costs of rearing a daughter and allowed girls to complete their education (Table 4.2). District-wise differences were mixed: more women from Kaski than Tanahun agreed that schemes helped defray the costs of rearing a daughter ( $46 \%$ versus 36\%), whereas, more women from Tanahun than Kaski believed that the scholarship programmes enabled girls to complete their education ( $28 \%$ versus $19 \%$ ); and helped parents financially ( $80 \%$ versus $71 \%$ ). Others reported that it helped girls to educate themselves (19\% versus $28 \%$ ). Rural-urban differences were also evident in a number of cases, with rural women more likely than their urban counterparts to appreciate the financial incentives (scholarships). The negative features of the scholarship, as expressed by the

Table 4.2: Percentage of women reporting perceived positive and negative aspects of the scholarships for girls: Kaski and Tanahun

\begin{tabular}{|c|c|c|c|c|c|c|}
\hline & \multicolumn{2}{|l|}{ Urban } & \multirow{2}{*}{$\begin{array}{l}\text { Rural } \\
\text { Kaski }\end{array}$} & \multicolumn{3}{|c|}{ Total } \\
\hline & Kaski & Tanahun & & Tanahun & Kaski & Tanahun \\
\hline \multicolumn{7}{|l|}{ Positive aspects of the scholarship for girls } \\
\hline Helps defray the expenses related to girls & 38.1 & 39.3 & 54.5 & 33.3 & 46.6 & 36.4 \\
\hline Helps parents & 71.1 & 80.3 & 71.6 & 80.2 & 71.3 & 80.3 \\
\hline Supports in buying uniform, copy, books, pencil, bags & 19.3 & 24.5 & 18.0 & 29.7 & 18.6 & 27.1 \\
\hline Enables girls to complete their education & 18.3 & 33.2 & 19.4 & 22.5 & 18.9 & 27.9 \\
\hline Supports in girls' snacks/meals & 0.0 & 0.0 & 0.0 & 0.9 & 0.0 & 0.4 \\
\hline \multicolumn{7}{|l|}{ Negative aspects of the scholarships for girls } \\
\hline The amount of money is too little & 41.6 & 36.5 & 43.6 & 32.4 & 42.6 & 34.5 \\
\hline Too much paperwork for too little money & 6.6 & 15.2 & 2.8 & 8.6 & 4.7 & 11.9 \\
\hline Not everyone benefits from it & 14.2 & 16.1 & 14.7 & 17.6 & 14.5 & 16.8 \\
\hline Economic status of the family is overlooked & 5.6 & 3.9 & 7.1 & 3.2 & 6.4 & 3.5 \\
\hline Scholarship is provided based on caste and ethnicity & 2.5 & 7.8 & 4.3 & 5.4 & 3.4 & 6.6 \\
\hline Others & 5.6 & 13.0 & 10.0 & 3.2 & 7.8 & 8.2 \\
\hline Nothing is disliked & 37.6 & 34.8 & 33.2 & 47.7 & 35.3 & 41.2 \\
\hline Number of women & 197 & 230 & 211 & 222 & 408 & 452 \\
\hline
\end{tabular}

Note: ${ }^{+}$Percentage total may exceed 100 due to multiple responses 
majority of the women in both the districts, pertained to: the (limited) amount of the scholarships, the fact that not everyone benefits, too much paperwork, etc. There was no apparent difference in citing these responses by women from the two districts.

\subsection{Women's awareness on gender equality programmes}

The large majority of the women in both Kaski (85\%) and Tanahun (74\%) had heard the messages against discrimination of daughters. In contrast, exposure to messages or campaigns about saving the girl child is low, and much lower in Kaski (28\%) than in Tanahun (43\%). Even in Tanahun, a higher percentage of urban women (57\%) than rural women (30\%) are exposed to the messages/campaigns indicating that the campaigns are more concentrated in urban areas.

Comparatively, a higher proportion of women from Tanahun than in Kaski reported that a health worker had talked to them about the importance of gender equality between a boy and a girl (35\% in Kaksi and $42.8 \%$ in Tanahun). Although low, a significantly higher percentage of women from Tanahun than in Kaski reported meeting or campaign held in their villages that aimed to discourage couples from seeking sex of the foetus.

Only one quarter of respondents in both the study areas (24\%) admitted that they had seen/read message on what information doctors can and cannot provide to women who undergo USG. Likewise, very few (less than 14\%) of the respondents reported that civil society organization representatives had ever talked to them about treating all children alike.

A low percentage of women in both the districts reported obtaining information from NGOs (11\% from Kaski; $13 \%$ from Tanahun) and from religious leaders (14\% and 18\%, respectively) (Table 4.3).

Table 4.3: Percentage of women reporting exposure to gender equality programmes: Kaski and Tanahun

\begin{tabular}{|c|c|c|c|c|c|c|}
\hline & \multicolumn{2}{|c|}{ Urban } & \multicolumn{2}{|c|}{ Rural } & \multicolumn{2}{|c|}{ Total } \\
\hline & Kaski & Tanahun & Kaski & Tanahun & Kaski & Tanahun \\
\hline $\begin{array}{l}\text { Heard something about non-discrimination against } \\
\text { daughters }\end{array}$ & 84.4 & 79.2 & $85.6^{* * *}$ & 69.6 & $85.0^{* * *}$ & 74.4 \\
\hline $\begin{array}{l}\text { Heard about campaigns or messages about saving } \\
\text { the girl child }\end{array}$ & 30.3 & $56.6^{* *}$ & 25.7 & 27.0 & 28.0 & $42.7^{* * *}$ \\
\hline $\begin{array}{l}\text { Meeting/campaign held in the village/ward } \\
\text { discouraging couples from seeking disclosure of sex } \\
\text { of the foetus from health providers }\end{array}$ & 2.8 & $10.8^{* * *}$ & 5.6 & 5.6 & 4.2 & $8.2^{* *}$ \\
\hline Religious leader talked about saving the girl child & 12.8 & $26.8^{* * *}$ & 15.2 & 10.0 & 14.0 & $18.4^{*}$ \\
\hline $\begin{array}{l}\text { Read/seen a message about what doctors can } \\
\text { and can't give information on foetus to woman } \\
\text { undergoing USG }\end{array}$ & 27.2 & $35.6^{*}$ & $20.8^{*}$ & 12.8 & 24.0 & 24.2 \\
\hline $\begin{array}{l}\text { Health worker discussed treating sons and } \\
\text { daughters alike }\end{array}$ & 37.6 & $53.2^{* * *}$ & 32.4 & 32.4 & 35.0 & $42.8^{* *}$ \\
\hline NGO talked about treating sons and daughters alike & 10.8 & $18.4^{*}$ & 10.4 & 8.4 & 10.6 & 13.4 \\
\hline
\end{tabular}

Note: ${ }^{*}{ }^{* *},{ }^{* *}$ indicate that differences between Kaski and Tanahun, Kaski urban and Tanahun urban and Kaski rural and Tanahun rural are significant at $p<.05, p<.01$ and $p<0.001$, respectively.

Those who had received information about not discriminating against daughters, discouraging abortion of female foetuses, and campaigning for saving the girl child were asked about the source of information separately. The results are presented in Table 4.4-4.5. As can been seen from the Tables, television, radio and newspapers formed the three main sources of information and advocacy that discourage discrimination against daughters, genderbiased sex selective abortion and saving the girl child in the study districts. Other sources of information were health care providers and female community health volunteers. 
Table 4.4: Percentage of women reporting the sources of information that talks about not discriminating against daughters: Kaski and Tanahun

\begin{tabular}{lcccccc}
\hline $\begin{array}{l}\text { Source of message discouraging } \\
\text { discrimination against daughters }\end{array}$ & \multicolumn{2}{c}{ Urban } & \multicolumn{2}{c}{ Rural $^{+}$} & \multicolumn{2}{c}{ Total $^{\text {Tanahu }}$} \\
\cline { 2 - 7 } & $\begin{array}{c}\text { Kaski } \\
\text { (\%) }\end{array}$ & $\begin{array}{c}\text { Tanahu } \\
\text { (\%) }\end{array}$ & $\begin{array}{c}\text { Kaski } \\
\text { (\%) }\end{array}$ & $\begin{array}{c}\text { Kaski } \\
\text { (\%) }\end{array}$ & $\begin{array}{c}\text { Tanahu } \\
\text { (\%) }\end{array}$ \\
\hline Television & 96.7 & 87.9 & 86.9 & 67.2 & 91.8 & 78.2 \\
Radio & 46.0 & 65.2 & 70.6 & 72.4 & 58.4 & 68.5 \\
Newspapers & 52.6 & 43.9 & 32.7 & 28.7 & 42.6 & 36.8 \\
Health provider/FCHV & 8.1 & 26.3 & 5.6 & 20.7 & 6.8 & 23.7 \\
Meeting & 1.9 & 17.7 & 2.8 & 23.0 & 2.4 & 20.2 \\
Family members/Friends & 1.9 & 5.6 & 5.6 & 7.5 & 3.8 & 6.5 \\
Advertisement in health facility & 1.9 & 3.0 & 1.4 & 8.6 & 1.6 & 5.6 \\
Neighbors & 2.4 & 4.0 & 1.4 & 5.2 & 1.9 & 4.6 \\
Hoarding board & 6.2 & 0.5 & 1.4 & 2.3 & 3.8 & 1.3 \\
Others & 2.4 & 3.0 & 0.9 & 1.1 & 1.6 & 2.2 \\
Number of women & $\mathbf{2 1 1}$ & $\mathbf{1 9 8}$ & $\mathbf{2 1 4}$ & $\mathbf{1 7 4}$ & $\mathbf{4 2 5}$ & $\mathbf{3 7 2}$ \\
\hline
\end{tabular}

Note: ${ }^{+}$Percentage total may exceed 100 due to multiple responses.

Table 4.5: Percentage of women reporting the sources of information that campaigns for saving the girl child: Kaski and Tanahun

\begin{tabular}{|c|c|c|c|c|c|c|}
\hline \multirow{2}{*}{$\begin{array}{l}\text { Source of message that campaigns } \\
\text { for saving the girl child }{ }^{+}\end{array}$} & \multicolumn{2}{|c|}{ Kaski } & \multicolumn{2}{|c|}{ Tanahun } & \multicolumn{2}{|c|}{ Total } \\
\hline & Rural & Urban & Rural & Urban & Kaski & Tanahu \\
\hline Television & 85.9 & 85.7 & 80.0 & 53.2 & 83.2 & 76.1 \\
\hline Radio & 31.3 & 57.1 & 65.5 & 76.6 & 47.1 & 62.9 \\
\hline Newspapers & 26.6 & 42.9 & 25.5 & 25.5 & 26.1 & 37.7 \\
\hline Health provider/FCHV & 9.4 & 28.6 & 9.1 & 34.0 & 9.2 & 30.2 \\
\hline Meeting & 6.3 & 18.8 & 10.9 & 21.3 & 8.4 & 19.5 \\
\hline Neighbors & 3.1 & 8.9 & 3.6 & 6.4 & 3.4 & 8.2 \\
\hline Advertisement in health facility & 7.8 & 3.6 & 1.8 & 14.9 & 5.0 & 6.9 \\
\hline Family members/Friends & 4.7 & 7.1 & 1.8 & 6.4 & 3.4 & 6.9 \\
\hline Hoarding board & 7.8 & 0.0 & 0.0 & 0.0 & 4.2 & 0.0 \\
\hline Others & 4.7 & 3.6 & 5.5 & 2.1 & 5.0 & 3.1 \\
\hline Number of women & 64 & 112 & 55 & 47 & 119 & 159 \\
\hline
\end{tabular}

Note: ${ }^{+}$Percentage total may exceed 100 due to multiple responses.

\subsection{Perspectives of stakeholders on gender-focused programmes}

It was evident from the stakeholders' interviews (health care providers and programme implementers), no conspicuous difference was found with regards to the type of gender-focused programmes implemented in the two study districts. As evident from Table 4.6, in line with the national programme implementation, both the districts have been implementing scholarship programmes and programmes aimed at making schools girl friendly (i.e. distribution of sanitary pads, construction of separate toilets for girls, etc.), adolescent-friendly health services, and programmes aimed at preventing violence against girls/adolescents. In addition, the stakeholders in both the districts identified budgetary provisions for women and children, and reservation policies, which are national level initiatives. 
Table 4.6: Programmes in the study districts to raise the value of girls and women as reported by stakeholders: Kaski and Tanahun

\begin{tabular}{|c|c|c|c|c|}
\hline \multirow[t]{2}{*}{ Programmes } & \multicolumn{2}{|c|}{ Tanahun } & \multicolumn{2}{|c|}{ Kaski } \\
\hline & $\begin{array}{l}\quad 5 \\
\text { Government } \\
\text { Programmes }\end{array}$ & $\begin{array}{c}3 \\
\text { NGO } \\
\text { Programmes }\end{array}$ & $\begin{array}{l}\quad 6 \\
\text { Government } \\
\text { Programmes }\end{array}$ & $\begin{array}{c}3 \\
\text { NGO } \\
\text { Programmes }\end{array}$ \\
\hline $\begin{array}{l}\text { Allocation of } 10 \% \text { budget for women and } 10 \% \text { for } \\
\text { children }\end{array}$ & 1 & - & 1 & - \\
\hline Formation and mobilization of mothers' group & 1 & - & 1 & - \\
\hline $\begin{array}{l}\text { Programmes for public awareness to raise value of girls } \\
\text { and women }\end{array}$ & 3 & 1 & 3 & 1 \\
\hline $\begin{array}{l}\text { Implementation of national reservation policy (33\% } \\
\text { women in each field) in the district level }\end{array}$ & 1 & - & - & - \\
\hline $\begin{array}{l}\text { Programmes for skill development, capacity building } \\
\text { and empowerment of women }\end{array}$ & 2 & 1 & 1 & 1 \\
\hline $\begin{array}{l}\text { Programmes for school continuation of girls (like, } \\
\text { distributing sanitary pads during menstruation) }\end{array}$ & 2 & 1 & 1 & - \\
\hline Girls' scholarships & 1 & 2 & 4 & 2 \\
\hline Adolescent health services (focused on adolescent girls) & 1 & - & 1 & - \\
\hline $\begin{array}{l}\text { Adolescent girls' development programme (programmes } \\
\text { on violence against girls and adolescents including skill } \\
\text { development and awareness on adolescent health) }\end{array}$ & 1 & - & 1 & - \\
\hline Programmes of girl-friendly schools & 1 & - & 1 & - \\
\hline
\end{tabular}

We explored what the families and communities of their district think about these programmes. All the stakeholders in both the districts reported saying that the community has positive views on these programmes as these have contributed to raising girls' and women's awareness, helped girl's education, contributed to minimizing the child marriage practices in the village and empowered women. The following are some of the views expressed by the stakeholders:

"We visit different schools to explore and support girl students if they are facing any difficulties in their education. We ask them about their school and family environment. And we conduct discussion programmes among girls, parents and teachers to solve their problems. It is regular as we conduct every three months. It is a part of the girl-friendly programme." (Female, programme implementers, age 31, Tanahun, ID 12)

"There were occasions when girl students would remain absent during their menstruation. We conducted programmes to make them of the misconceptions of menstruation and also we distributed sanitary pads. That has created change. Most of the girls do not miss school during their periods these days." (Male, programme implementers, age 31, Tanahun, ID 14)

"We don't have any specific programmes to raise the value of girls and women. Such issues are covered under other programmes as cross-cutting issues. The issues of gender, abortion, and raising value might be included as part of other programmes. But I don't have any idea of any programmes targeted to raising women's value." (Male, programme implementer, age 35, Kaski, ID 28)

"Though it is not highly remarkable, some changes are made by the programmes. When a girl from a poor family gets a scholarship, she can continue her education. Such supports from the government are important for the general public." (Female, programme implementers, age 46, Kaski, ID 29)

"Nowadays, women have started to raise their voices against child marriage. The concepts of having certain levels of education and opportunity for employment for girls before they marry are common. These are the changes made by such programmes." (Female programme implementer, age 50, Tanahun, ID 10) 


\section{CHAPTER 5 \\ FACTORS UNDERLYING DIFFERENCES BETWEEN KASKI AND TANAHUN}

\section{Summary}

Despite the geographical proximities, some noticeable differences in some socio-economic indicators exist between Kaski and Tanahun. Differences were also observed in terms of perceived value of sons, access to USG clinics, easy access to information on sex of foetuses and demand for sex selection, between the two districts. Women in Kaski (31\%) were more exposed to family pressure to bear a son than the women in Tanahun (15\%). Such pressures were generally exerted by husbands (76\% in Tanahun, $65 \%$ in Kaski), and their mother-in-laws ( $57 \%$ in Tanahun and $72 \%$ in Kaski) respectively. More women from Kaski were exposed to USG and found out the sex of the foetus despite having higher levels of awareness about the law restricting sex determination and sex selective abortion. Urban-rural differences in foetal sex disclosure were also wide within Kaski, indicating a better access to sex determination services for urban women than rural women.

Although restricted by the law, revelation of the sex of the foetus by the doctors and providers in Kaski was more likely than in Tanahun because of the high demand for sex selection in Kaski and lack of effective regulatory mechanisms against the practice. The study has also revealed that women's parity and disclosure of the sex of the foetus positively correlated, as women after parity two are more likely to be selective regarding the sex of their next child.

In line with women's perspectives, district level stakeholders also perceived that the demand and access to USG was higher in Kaski than Tanahun. Nearly all stakeholders from both the study districts mentioned that Kaski has better access to sex selection technology and people living in this district are better informed about the sex selection procedure and services (USG) than those in Tanahun. The stakeholders in both districts identified weak enforcement of the law on sex selective abortion and poor monitoring mechanisms. They suggested that neither raids nor prosecutions took place in their districts or anywhere else in the country, and pointed to corruption within the system and the ability of powerful providers to avoid prosecution as key reasons. However, the stakeholders from Tanahun reported that their district public health office played an active role in enforcing the law, monitoring facilities and equipment, and confronting violators. To address the adverse SRB, stakeholders made certain recommendations. These include: measures to change public attitudes towards girl children; raise the value of girls; focus on girl's education and vocational skills training; ensure daughter's right to parental property; effective engagement of women in different agencies and decision making bodies of the country; and greater media involvement to increase knowledge about the negative consequences of sex selective abortion. Stakeholders suggested several strategies for empowering girls and women and raising the status of girl-child. Such strategies should focus on quality formal education, social and financial skills, and offering economic support and incentives for girls and their families. At the system and programme level, stakeholders recommended effective enforcement of the abortion law, and regular monitoring and supervision of both abortion providers and facilities.

Although both Kaski and Tanahun have geographical proximities, and are similar in several ways, the two districts are quite different from each other in terms of caste/ethnicity composition; educational attainment of the women; household wealth and women's agency. Desire to have fewer (two) children, preferably one son and one daughter, irrespective of the urban-rural residences were the common features between the two districts. We found some noticeable differences between the two study districts in terms of perceived value of sons, family pressure to bear a son, access to sex determination technology, disclosure of the sex of the foetus by health providers, and demand for discriminatory sex selection. The differences are more apparent in urban Kaski than in urban Tanahun. The factors underlying the differences are as follows. 


\subsection{Perceived value of sons}

The general belief in Nepalese society is that having sons in the family determines the status of the family and women, and also provides security to parents in old age. Families or women without sons are sometimes considered "unfortunate" or "sinful". Though our study shows the value system towards gender preference has been transforming and changing, there is still moderate levels of son preference in both districts. Our discussions in Chapter 2 showed that sons were more valued than daughters in Kaski than in Tanahun. This difference was more pronounced in rural than urban areas. More women in Kaski than Tanahun thought that a son is essential to continue the family lineage and that the presence of a son determines the status of the mother in the family.

\subsection{Pressure to bear a son}

In our study, attempts were also made to assess the level of pressure that women experienced during their pregnancy to have a son. While the large majority of respondents reported no family pressure, percentages of women who experienced pressure varied considerably across two study districts (Figure 5.1). Relatively, a higher percentage of women in Kaski (31\%) had experienced family pressure to bear a son than the women in Tanahun (15\%) (Figure 5.1). Most women who experienced pressure reported that such pressure had been exerted by their husbands (76\% in Tanahun, $65 \%$ in Kaski), and their mothers-in-law (57\% and $72 \%$, respectively) (Figure 5.2).
Figure 5.1: Percentage of women reporting experience of pressure from family members to have a son while pregnant

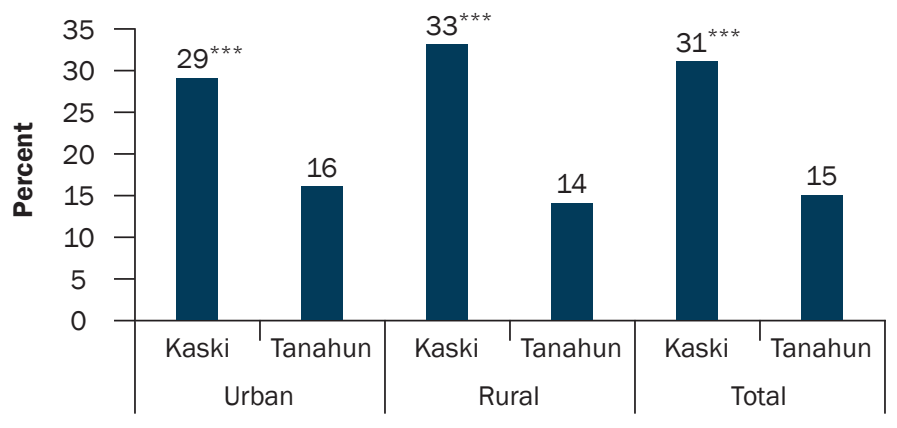

Note: ${ }^{* * *}$ indicate that differences between Kaski and Tanahun, Kaski urban and Tanahun urban and Kaski rural and Tanahun rural are significant at $p<0.001$, respectively.

\subsection{Disclosure of sex of the foetus and sex selective abortion}

The present study has shown that comparatively, women in Kaski district were more exposed to USG and demonstrated a higher tendency to find out the sex of the foetus while undergoing the procedures as they wish to limit family size to just one child or two which may be a strong driver of sex selection. We have found that a much higher percentage of women from Kaski than in Tanahun admitted knowing the sex of their foetus from the providers during the USG procedure, despite having higher levels of awareness about the law restricting sex determination and sex selective abortion. Urban-rural differences in fetal sex discloser were also wide within Kaski indicating a better access to sex determination for urban women than rural women.

Figure 5.2: Percentage of women reporting relationship with family member who pressurised her to have a son while pregnant

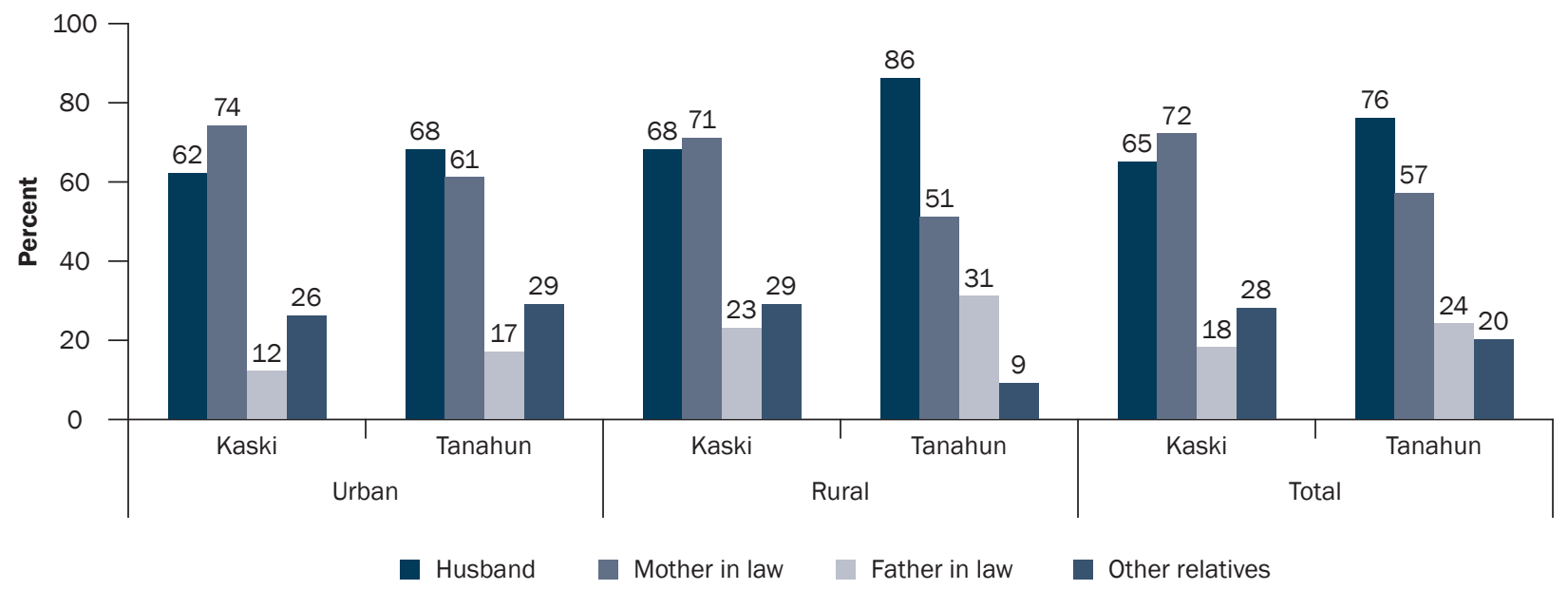


Although restricted by the law to reveal the sex of the foetus, the findings suggest that doctors and providers in Kaski were more likely to disclose the sex of the foetus to women than in Tanahun because of the high demand for sex selection in Kaski and lack of effective regulatory mechanisms against the practice. The study has also revealed that women's parity and disclosure of the sex of the foetus positively correlated as women after parity two are more likely to be selective regarding the sex of the next child. Despite this, women's reported experiences of induced abortion was also higher in Kaski than Tanahun. Although similar proportions of women from both districts who had experienced an abortion reported that their abortion had been conducted for sex selection, there was a vast difference in reporting of any familiarity with a person (self, family member, friend or acquaintance) who had undergone a sex selective abortion, with those from Kaski significantly more likely than those from Tanahun to report such familiarity.

In line with women's perspectives, district level stakeholders also thought that demand and access to USG was higher in Kaski than Tanahun. In the course of our interview with the stakeholders, we had first explained to them about the differential sex ratios in Tanahun and Kaski district-with the former district exhibiting "normal" while the latter district with "abnormal" or imbalanced sex ratios among children born and aged below 1 year, based on the Population Census. Having done that, we asked each of the providers to explain the reasons for imbalanced sex ratios for Kaski. The findings show that nearly all stakeholders from both the study districts mentioned that Kaski has better access to sex selection technology and people living in this district are better informed about the sex selection procedure and services (USG) than those in Tanahun.

\subsection{Access to health facilities and sex determination technology}

Access to health facilities (public or private health facilities such as hospitals, nursing homes, polyclinics, diagnostics centers, etc.) equipped with sex determination technology such as USG makes a difference in sex selection practices. It was evident from the study that there are fewer diagnostic centres in Tanahun than Kaski, and likewise, no approved service centers for second trimester abortions in Tanahun. Therefore, those desiring the service need to travel to Pokhara (Urban Kaski) or Bharatpur (Chitwan District) which many poor women are unable to afford. On the other hand, women in Kaski are comparatively wealthy and they have a wide range of choices of health facilities including diagnostic centers which are mostly concentrated in urban areas where they can find out the sex of the foetus and selectively terminate pregnancies carrying a female foetus with ease, despite the legal restrictions. The survey data has shown that although the use of USG during pregnancy for any reason (foetal growth monitoring, screening for abnormalities of the foetus, sex determination, etc.) was common in both the districts, the practice was more pronounced in Kaski than Tanahun (82\% versus 52\%). A higher percentage of women in Kaski than in Tanahun admitted to seeking information on the sex of their foetus. Even those who reported that their friend or family member had done so, or someone in their village, town or ward had done so were much higher in Kaski than in Tanahun.

In line with quantitative results, the qualitative study also revealed the fact about poor access to USG among women in Tanahun when compared to Kaski. The majority of the stakeholders believed that poor access to the USG technology in Tanahun, high costs of the service and poverty contributed to low levels of sex selection. In contrast, they viewed that women in Kaski were better educated than those in Tanahun, had better economic statuses, stronger son preference and wider access to facilities for USG and sex selection.

Lack of specialized training in carrying out USG among the health care providers was also identified as a reason for poor access to USG and sex selective abortion in Tanahun. A doctor in Tanahun mentioned this limitation, saying:

"I am not a radiologist. I cannot accurately detect the sex of the foetus. Therefore I don't say anything regarding the sex of the foetus to my clients." (Male, service provider, age 38, Tanahun, ID 04)

\subsection{Perceptions about factors underlying differences in the intensity of son preference}

Caste/ethnicity factor: Women from Kaski were significantly more likely than those in Tanahun to report that they had been pressured by family members to continue childbearing until they bore a son. Key informants suggested several reasons for this. Some believed that there was a concentration of certain castes in Kaski, but not in Tanahun, among whom a son was considered essential, and among whom the pressure to bear a son was particularly strong. 
In contrast, a few key informants suggested that one of the main ethnic groups in Tanahun, the Magar, accords equal value to daughters and sons, and as such, in this community, sex selective abortion is rare.

"No difference by ethnic background. Either way if they are from a high class or low class they ask about the sex of their foetuses. But what I have noticed is that Mongolian people generally don't have any problem giving birth either to sons or daughters because they don't have a male dominating culture. Mostly these issues are among Brahmin and Chhetri castes. People following Hinduism generally ask about the sex of their fetuses." (Male, health care provider, age 52, Kaski, ID 17)

Craze for sons to join the British Army in Kaski: A distinct feature of Kaski district was the aspiration of parents to make their sons join the British Gurkhas (British army). Nepal has a long history of recruitment of Nepalese youth as British Gurkhas since 1814 A.D. Traditionally, these youth are recruited from amongst selected ethnic/caste groups including the Gurung community (one of the main inhabitants of Kaski district). The location of the British Gurkha Recruitment Camp at Pokhara (Kaski district) has been an additional advantage for the youth living in this district. High salaries and higher possibilities of parents moving permanently to United Kingdom where their son would be posted in the British army are the underlying factors for recruitment as British Gurkha soldiers. Few stakeholders brought up this distinct feature during their interviews.

"There are many British people in Kaski and there is a trend of joining the British army in Kaski. Hence, the demand of the family to produce sons." (Male, programme implementer, age 48, Tanahun, ID 03)

"Maybe the Gurung community in Pokhara (Kaski) prefer to have sons. Particularly because most of the fathers are in the British Army and a son is also expected to join the British Army. A son has to follow his father's profession." (Male, health care provider, age 37, Tanahun, ID 08)

\subsection{Exposure to health care providers and community mobilization activities}

Exposure to community mobilization activities: Although the percentages of women in Kaski who had heard the messages on non-discrimination of daughters were higher than the Tanahun women, exposure to messages or campaigns about saving the girl child was low in Kaski. Although TV, radio and newspapers formed the three main sources of educational messages on gender equality and illegality of discriminatory sex selection for women in both the districts, a higher percentage of women in Tanahun and very low percentage in Kaski were exposed to these messages through inter-personal communication such as health care providers and female community health volunteers, or from the meetings they had attended, which indicates that the implementation of community based awareness programmes on gender equality was carried out in larger scale in Tanahun than in Kaski.

Access of girls to educational entitlement programmes: Despite the high level of awareness of the different educational incentives for girls (free textbooks and scholarships, etc.) the proportion of rural women (one in four) who reported that their daughter had availed these schemes/incentives was lower in Kaski than in Tanahun (two in five). No difference was apparent between the two districts on the perceived value of the scholarship. Although the scholarship was perceived to be helpful for parents and girls education, it is unlikely that access to educational entitlement schemes could have affected the desire for sons in these two districts because less than half of the respondents in both the districts viewed the scholarship as helpful in defraying the expenses related to girls, or enabled girls to complete their education.

\subsection{Law enforcement}

Despite the law against sex determination test and sex selective abortion, enforcement of the law has been weak, not only in the two districts but throughout the country. Although the government is well aware of the practice of sex selection, no effective measures have been undertaken to monitor diagnostic clinics and abortion facilities in the country. The key informants from both districts agreed that the law was rarely enforced and monitoring mechanisms were weak. They suggested that neither raids nor prosecutions took place in their districts or anywhere else in the country, and pointed to corruption within the system and the ability of powerful providers to avoid prosecution as key reasons. However, those from Tanahun appeared somewhat more likely than those from Kaski to report that their district public health offices played an active role in enforcing the law, monitoring facilities and equipment, and confronting violators. 
"There is a law on this in Nepal but it is not enforced. Anyone can do anything. They are aware about the law, but they still do it (sex determination test)." (Male, health care provider, age 39, Kaski, ID 19)

"The government is not monitoring the video x-ray centers where sex determination tests are being done; those people are not punished as per the law. There is a law but it has not been enforced." (Male, programmer implementer, age 31, Tanahun, ID 14)

"Here in Tanahun, the district health office is regularly monitoring private clinics and USG centers including their infrastructures for the services and any service that is against the law." (Female, health care provider, age 25, Tanahun, ID 7)

\subsection{District level stakeholders' recommendations for addressing unbalanced SRB}

District level stakeholders were asked for their recommendations to address unbalanced sex ratios at births. A range of suggestions were expressed which can be grouped into two level levels-community, and system and programme.

\subsubsection{Community level}

District level stakeholders provided a range of suggestions to address unbalanced SRB. Their suggestions were mostly around the need for programmes that aimed to increase public awareness to change attitudes, to raise the value of girls and reduce sex selective abortions. Stakeholders also recommended to focus on girl's education and vocational skill training; to ensure daughter's rights to parental property, effective engagement of women in different agencies and decision making body of the country; programmes encouraging parents who have girl child only and greater media involvement to increase knowledge about negative consequences of sex selective abortion and change their discriminatory attitudes towards girl child.

Need measures to increase awareness: Most of the stakeholders in both districts (21 of 29 stakeholders) recommended programmes that aimed at increasing public awareness about the abortion law and negative consequences of sex selective abortion. A few stakeholders also called for the expansion of school interventions to educate boys and girls about the abortion law, rights and negative consequences of adverse sex ratios in the country.

"To reduce the cases of sex selection and increase the value of the girl child, we have to increase programmes on public awareness. Education is the most important thing. When people are educated and aware, they develop their ability to make good judgments on what is right and what is wrong. So, if we can educate with life skill education and make people aware in all the communities, that can work most effectively." (Female, programme implementer, age 46, Kaski, ID 27)

"People should be aware about the value of the girl child and the negative consequences of sex selective abortion. So, people in the communities should know the value of a girl. They need to educate girls, prevent dowry practices, stop child marriage, and assure female's right to parental property. These issues need to be spread in communities through awareness programmes." (Female, programme implementer, age 50, Tanahun, ID 10)

"One of most important things is awareness. Awareness needs to be raised on the value of women and girls. People in our society should be aware about the equal importance of both girls and boys. They have to stop discriminatory practices in their everyday lives....this must be stopped through awareness programs." (Male, programme implementer, age 48, Tanahun, ID 03)

Need measures to change attitudes: Stakeholders also stressed the need of behavior change communication programmes that would help to raise the value of girls and changes attitudes towards gender equality. Stakeholders thought that such programmes should be aimed at reaching both urban and rural areas in more coordinated ways. Such programmes should target mothers-in-law and husbands, who need to be included as part of the "solution":

"You can imagine what happens in a desert if a plant dies. It's similar to human life. Imagine how the world will be if there are no girls. A new plant will take time to grow. Thus, it is very important to stop sex selective abortion.... . even a little knowledge sharing can save the life of a girl; the mother gets to know the value of her foetus." (Male, health care provider, age 59, Kaski, ID 16) 
Need to empower girls and women: Stakeholders suggested several strategies for empowering girls and women, and raising the status of the girl child. Such strategies should focus on providing them with quality formal education (17 of 29 stakeholders), social and financial skills, and offering economic support and incentives for girls and their families. Stakeholders also thought that it is equally important to ensure that they have access to the information about the laws on sex selection.

"The first and foremost important thing is to have a drastic change in the patriarchal system of our society. It is important to make people from urban to remote areas aware. The government should provide some economic support and free or subsidized health care services to the families having girls and such schemes should be strongly monitored." (Female, programme implementer, age 32, Kaski, ID 26)

“There should be women's voices in decision making (policy and implementation). Importance should be given to girls' empowerment programmes... The organizations and authorities that work for women and their rights should be given priority in allocation of resources. There is a problem that the programme has top priority but the budget is very low-it gets the least priority. So, both programmes and budgets for empowering women programme should get the highest priority together." (Female, programme implementer, age 50, Kaski, ID 15)

"The girls should get good educations. Moreover, education must be effective enough to make them aware about life skills. I have seen some girls who have completed 12 years of schooling but still they are not informed about common health issues particularly reproductive health related knowledge including abortion law. Some educated women remain uninformed about contraceptives even though they get married. So, the girls' education should cover the major issues of women's health and rights. Educating girls is very important." (Female, health care provider, age 40, Kaski, ID 21)

"Girls and women should be skilled and competent. The laws, policies and programmes of the state should be aimed towards empowering and developing skills of women." (Female, programme implementer, age 48, Kaski, ID 24)

"From their early childhood, girls should live in an encouraging environment created by her family, particularly by her parents. They should be offered equal opportunity in education and other ways of public exposure. Girls should have skills and proficiencies to be independent like boys. The most important thing is they should be economically independent and strong." (Female, programme implementer, age 47, Tanahun, ID 05)

"I think the Government needs to bring programmes on equal payment for males and females, change social practices on religious final death rituals ... Such things can be brought in through legal provisions and law enforcement so that a woman can enjoy equal rights and opportunities same as men." ". (Male, health care provider, age 40, Tanahun, ID 06)

Need to involve the media: Some stakeholders, mainly health care providers (seven of 12) recommended engaging national multimedia campaigns using radio, TV, including stories of happy parents with only one daughter to encourage others not to discriminate against female fetuses. They also suggested that the media disseminate information on the abortion law and make law enforcement agencies accountable to support changing attitudes about the value of girls.

"I think making the laws stronger and punishable will increase the number of sex determinations and abortions. People will go to India, Terai and Kathmandu to access services. Rather, use of the media would be better. We can raise awareness through TV programmes and paper media, and this will become a general discussion agenda in the community." (Male, health care provider, aged 39, Kaski, ID 19)

"Mass media could play a very vital role in disseminating information on these issues." (Female, health care provider, age 25, Tanahun, ID 07)

\subsubsection{Implementing laws and programmes}

At the system and programme level, most of the stakeholders recommended effective enforcement of abortion law (19 of 29 stakeholders), regular monitoring and supervision (12 of 29) of both abortion providers and facilities. A few stakeholders thought that orientation training to radiologists and abortion service providers that aimed at increasing their awareness about legal provisions of sex selection and its adverse consequence as a whole is highly needed. 
"Existing laws must be enforced effectively in practice. The other important part is prosecution. Both the sex selective abortion service seekers and the service providers must be prosecuted. This may require some acts and guidelines to support effective enforcement of the law." (Male, programme implementer, age 35, Kaski, ID 25)

"The higher authorities should monitor the service centers and other related bodies ...... A system should be developed to assess and decide on such cases on the basis of the law." (Male, programme implementer, age 40, Kaski, ID 18)

"The laws and policies must be implemented effectively. The government and responsible agencies should take action on effective enforcement of laws. The violators should be punished and the followers should be awarded. Money and power should not affect the law's enforcement." (Male, programme implementer, age 52, Tanahun, ID 01)

"The Government of Nepal should develop a monitoring mechanism. Regular monitoring is a must. It is important to understand how much the existing technology is being misused and it is also necessary to organize a community based interaction programme.... There is an utmost need todevelop and implement a strong monitoring mechanism." (Male, health care provider, age 52, Kaski, ID 17)

"The service providers should be oriented from time to time regarding the legal provisions for abortion..... Those who are referring pregnant women from other villages for determining sex of the foetus should be stopped. Posters and pamphlets must indicate that if someone is found guilty in helping determine sex, they will be punished under the legal provisions. And if someone has been punished, s/he should be highlighted in the media so that no other person dares to assist in sex selective abortion." (Male, health care provider, age 59, Kaski, ID 16)

'The laws must be enforced against the wrongdoers so that other people who have been or are doing similar things will be afraid and realize that it is illegal for real. Such news should be widely covered by the media so that would help to deter other wrongdoers." (Male, health care provider, age 38, Tanahun, ID 04)

"We service providers-both radiologists and health practitioners-should take responsibility of the ongoing situation of the increased tendency of sex selection and sex selective abortions. I had talked with one such (sex selective abortion) service providers. He thought that he was stopping people going to India for that service and stopping Nepali currency within our country. So, the service providers are not well aware of the issue. They need to be aware about its negative consequences." (Female, health care provider, age 47, Kaski, ID 23)

Interestingly, two stakeholders believed that the salaries of health care providers at the government facility should be increased to reduce sex selective abortion.

"The employed practitioners should be satisfied with the salary they get. Now, both medical service providers and radiologists are not getting good payments from their work. So, they are seeking other sources of income. They take risks for money. If the government paid them better and satisfied them with the payment of their work, they would not dare to take such challenges (sex selective abortion). So, their salaries should be increased." (Male, programme implementer, age 32, Tanahun, ID 13)

"I think that the income of doctors is very nominal in Nepal. ... That's why they try to earn money from other sources, for example, from sex selective abortion. Doctors know that they are doing wrong but since they earn very low wages, they are doing all these things. If their salaries and other benefits were increased by the government then maybe sex selective abortion would reduce." (Male, health care provider, age 40, Tanahun, ID 06) 


\section{CHAPTER 6 SUMMARY AND RECOMMENDATIONS}

The evidence gathered from the study have established the fact that despite some commonalities in son preference, the practice of undergoing USG procedures and disclosure of the sex of the foetus was higher in Kaski than in Tanahun. The recent upsurge in sex ratios at birth favoring males in Kaski was attributed to the above practice, accentuated by couples in Kaski desiring fewer children. The underlying factors for normal or "balanced" sex ratios in Tanahun are its dominant rural population, poverty and poor access to diagnostic clinics performing sex determination tests and relatively better community-based gender-focused programmes. Our study has also shown that while the district authorities in Tanahun were engaged in enforcement of the law that bars sex determination of the foetus and sex selective abortion through routine monitoring diagnostic centers and advocacy, such efforts were virtually lacking in Kaski. Women in urban Kaski demonstrated greater inclination to have induced abortions following sex determination than women in Tanahun.

\section{Recommendations}

Findings suggest that differences in child sex ratios in Kaski and Tanahun likely reflect, on the whole, such structural factors as greater purchasing power, better access to facilities, and a more deeply ingrained son preference in Kaski than in Tanahun. Though by no means conclusive, the study does indicate that programmatic influences such as advocacy and community mobilization measures, law enforcement or provision of entitlements for girls play a positive role in Tanahun, but less so in Kaski. In the absence of direct interventions, there is a distinct possibility of a worsening of the situation in Kaski, and a shift towards distorted sex ratios in Tanahun if accessibility increases. Several recommendations emerged:

- There is a need to implement national policies and programmes that aim to empower girls, promote gender equality and improve girls' overall situations. Promising approaches and programmes may include, for example, a greater focus on keeping girls in school, by providing girl-friendly education, ensuring that girls complete a secondary education, and expand the reach of the universal scholarship scheme for girls. Other efforts adopted in neighboring countries, including conditional cash transfer schemes that provide benefits to parents when their daughter achieves immunization, education and other milestones, and remains unmarried till aged 18 , may also hold promise.

- A stronger focus is needed on advocacy, public dialogue and community mobilization to inform communities about the law, change attitudes about the acceptability of pre-natal sex determination and sex selective abortion in the lines of Tanahun. More direct and focused messages are needed, through the media, through frontline workers and other interpersonal mechanisms, as well as through discourses by religious leaders and other influential individuals. These opportunities must convey the value of the girl child in general, as well as the ethics of prenatal sex determination and discriminatory selective abortion, and the long term social consequences of unbalanced sex-ratios.

- Findings have confirmed that many women face family pressure to continue childbearing till they have a son. These findings call for advocacy programmes especially in districts such as Kaski where there is a high demand for USG for sex determination purpose, those are aimed at sensitizing husbands, mothers-in-law and other family members about the value of daughters and the illegality of sex determination tests and sex selective abortions.

- More efforts are needed to raise awareness of and encourage adherence to the law, among the health care providers, including stronger monitoring mechanisms to ensure enforcement of the law and for regulating the misuse of USG. There is also a need to mobilize the communities in the monitoring and surveillance of clinics that are suspected to have violated the law by either disclosing the sex of the foetus or offering sex selective secondtrimester abortions. 
- Findings have suggested that providers themselves need to be oriented and sensitized about gender-biased sex selection in their districts. Providers at all levels, from frontline to specialists, need gender sensitization, as well as training about the law and the penalties for violating it. Health care providers must also be informed about the long-term demographic and social consequences of sex-selective abortion.

- Finally, research is needed that assesses the effect of various programmes on promoting gender equality and improvement of the status of girl child in society. 


\section{References}

Arnold F (1997). Gender Preferences for Children. Demographic and Health Surveys. Comparative Studies No. 23. Calverton, Maryland: Macro International Inc.

Bien CH, Cai Y, Emch ME, Parish W, Tucker JD (2013). High Adult Sex Ratios and Risky Sexual Behaviors: A Systematic Review. Plos One, DOI: 10.1371/journal.pone.0071580

Bongaarts J (2013). The Implementation of Preferences for Male Offspring. Population and Development Review, 39(2): 185-208.

Brunson J (2010). Son Preference in the Context of Fertility decline: Limits to New Constructions of gender and Kinship in Nepal. Studies in Family Planning, 41(2):89-98.

CBS (2002). National Population and Housing Census 2001 (National Report). Central Bureau of Statistics, National Planning Commission Secretariat, Government of Nepal: Kathmandu.

CBS (2012). National Population and Housing Census 2011 (National Report). Central Bureau of Statistics, National Planning Commission Secretariat, Government of Nepal: Kathmandu.

CREHPA (2007). Sex Selection: Pervasiveness and Preparedness in Nepal. Center for Research on Environment Health and Population Activities: Kathmandu, Nepal.

Frost WM, Puri M, Hinde PRA (2013). Falling Sex ratios and Emerging Evidence of sex-selective abortion in Nepal: evidence from nationally representative survey data. BMJ open, 3:e002612.

Fuse K (2008). Cross-national Variation in Attitudinal Measures of Gender Preference for Children: An Examination of Demographic Health Surveys from 40 Countries. DHS Working Paper, 44. Calverton, Maryland: Macro International Inc.

Gautam, K. (2013). Enhancing Quality Education for All in Nepal. Retrieved from http://www.kulgautam. org/2013/04/enhancing-quality-education-for-all-in-nepal/

Guilmoto CZ (2009). The sex ratio transition in Asia. Working Paper CEPED: 05. Centre en Population and Development: Paris.

Hesketh T, Xing ZW (2006). Abnormal sex ratios in human populations: causes and consequences. PNAS, 103(36): 13271-13275.

Jayaraman A, Mishra V, Arnold F (2009). The Relationship of Family Size and Composition to Fertility Desires, Contraceptive Adoption and Method of Choice in South Asia. International Perspectives on Sexual and Reproductive Health, 35(1):29-38.

Kim, D. S. 2013. Son-selective reproductive behavior and policy responses: Korean experience. Working group meeting on sex selection and access to safe abortion, Department of Reproductive Health and Research. WHO, Geneva, Switzerland, May 2013.

Kish. Leslie. (1949). "A Procedure for Objective Respondent Selection Within the Household." Journal of the American Statistical Association 44:380-87

Lamichhane P, Harken T, Puri M, Darney P. Blum M, Harper C, and Henderson JT. (2011). Sex-Selective Abortion in Nepal: A Qualitative Study of Health Workers' Perspectives. Women's Health Issues, 21-3S (2011) S37-S41.

Leone T, Matthews Z, Zuanna GD (2003). Impact and Determinants of Sex Preference in Nepal. International Family Planning Perspectives, 29(2): 69-75.

Ministry of Law, Justice and Parliamentary Affairs (1997). New Recommendations on Muluki Ain 11th Amendment Bill, Approved by the House of Representatives. Kathmandu.

MoHP (2002). National Safe Abortion Policy. Ministry of Health and Population, Department of Health Services, Family Health Division: Kathmandu. 
MoHP, New ERA and ORC Macro (2002). Nepal Demographic and Health Survey 2001. Kathmandu, Nepal: Ministry of Health and Population, New ERA, and ORC Macro, Calverton, Maryland.

MoHP, New ERA and ICF International Inc (2007). Nepal Demographic and Health Survey 2006. Kathmandu, Nepal: Ministry of Health and Population, New ERA, and ICF International, Calverton, Maryland.

MoHP, New ERA and ICF International Inc (2012). Nepal Demographic and Health Survey 2011. Kathmandu, Nepal: Ministry of Health and Population, New ERA, and ICF International, Calverton, Maryland.

Nanda P, Gautam A, Verma R, Thu KH, PUri M, Gian LT Tamang J, and Lamichhane P. (2012). Study on Gender, Masculinity and Son Preference in Nepal and Vietnam. New Delhi: International Centre for Research on Women.

Nepal Law Commission (2007). Interim Constitution of Nepal 2063. Government of Nepal. www.lawcommission.gov. np/index.php/en/constitution. Accessed: January 28, 2014.

NHSSP (2013). Antenatal Rural Ultrasound Programme, A Pilot Intervention in Dhading District, Nepal: Advocacy Brief. Nepal Health Sector Support Program. Available at: http://www.nhssp.org.np/pulse/Pulse\%20Rural\%20USG. pdf

National Institute of Population Studies (NIPS) [Pakistan] and ICF International. (2013). Pakistan Demographic and Health Survey 2012-13. Islamabad, Pakistan, and Calverton, Maryland, USA: NIPS and ICF International.

National Institute of Population Research and Training (NIPORT), Mitra and Associates, and ICF International. (2013). Bangladesh Demographic and Health Survey 2011. Dhaka, Bangladesh and Calverton, Maryland, USA: NIPORT, Mitra and Associates, and ICF International.

Puri M, Shah, I, Tamang, J. (2010). Exploring the nature and reasons associated with sexual violence within marriage among young women in Nepal. Journal of Interpersonal Violence, 25(10): 1873-92.

Pradhan A, Suvedi BK, Barnett S, Sharma SK, Puri M, Poudel P, Chitrakar SR, KC NP, Hulton J (2010)). Nepal Maternal Mortality and Morbidity Study 2008/2009. Family Health Division, Department of Health Services, Ministry of Health and Population, Government of Nepal, Kathmandu, Nepal

Subedi, D. (2011). 'Missing girls in Nepal: An emerging challenge'. Health Prospect (10), 34-36.

UN (2013). World Population Prospects: The 2012 Revision. United Nations, Department of Economic and Social Affairs, Population Division.

UNFPA (2012). Sex Imbalances at Birth: Current Trends, Consequences and Policy Implications. UNFPA Asia and Pacific Regional Office: Thailand.

Waldron I (1998).Sex differences in infant and early childhood mortality: major causes of death and possible biological causes. In: Too young to die: genes or gender? ST/ESA/SER.A/155. New York: United Nations. pp. 64-83. 
Annex 1: A summary of programmes and interventions

\begin{tabular}{|c|c|c|}
\hline $\begin{array}{l}\text { Programme, } \\
\text { intervention }\end{array}$ & Objectives & Activities \\
\hline \multicolumn{3}{|c|}{ Initiatives to ensure that the law is implemented } \\
\hline $\begin{array}{l}\text { Various efforts } \\
\text { to raise } \\
\text { awareness of } \\
\text { the law }\end{array}$ & $\begin{array}{l}\text { To enhance } \\
\text { adherence to the } \\
\text { law }\end{array}$ & $\begin{array}{l}\text { - Initiatives to orient radiologists and } \\
\text { medical technicians about the law } \\
\text { - NGOs and mass media have initiative } \\
\text { awareness raising campaigns against } \\
\text { sex selection }\end{array}$ \\
\hline
\end{tabular}

\section{Initiatives intended to build gender equality}

$\begin{array}{ll}\begin{array}{ll}\text { Year Against } \\ \text { GBV 2010 }\end{array} & \begin{array}{l}\text { To reduce violence } \\ \text { against women }\end{array} \\ \begin{array}{ll}\text { Gender Equality } \\ \text { Act } 2006\end{array} & \begin{array}{l}\text { To eliminate } \\ \text { VAW and gender } \\ \text { discrimination, } \\ \text { promote gender } \\ \text { equality and } \\ \text { women's }\end{array} \\ & \begin{array}{l}\text { empowerment } \\ \text { Reserves 44\% of }\end{array} \\ \text { Amendment to } & \begin{array}{l}\text { vacant groups for } \\ \text { excluded groups; }\end{array} \\ \text { Civil Service Act } & \end{array}$

\section{No specific programmes for safeguarding the rights of the girl child}

Advocacy, communication initiatives and community mobilization efforts:

National Society of Obstetricians and

Gynaecologists

Nepal Peace
Fund and Nepal
Television
Kantipur TV
and FM radio
stations

Centre for Awareness Promotion's Daughter Project

To address genderbiased sex selection and promote gender equality

To address gender- - Short videos (20 seconds) broadcast biased sex selection

To address gender- • Talk shows by experts

biased sex selection - Jingles on FM radio

Fight against the $\quad$ Raise awareness cultural preference for sons

- Organising festivals/rituals traditionally

CREHPA'S

Enable project

Safe abortion awareness and advocacy programme

Effectiveness Source

No

prosecutions

made thus far
Personal

communication with

Chairperson of Nepal

Medical Association, 2014 and NESOG, 2013.

Gender Empowerment Coordination Unit (GECU), 2013
Poster on gender-biased sex selection to be placed in hospitals and clinics

- Story based educational film aimed at ending gender-biased sex selection

- Awareness programme ANURODH and talk programmes on social effects of gender-biased sex selection daily on "no gender preference during childbirth"

- Counselling sessions for mothers and pregnant women

- Theatre programmes

- Including youth to spread messages about gender equality favouring boys to honour girls

Not available

NESOG 2013

Not available

Nepal Television, nd

Not available

Not available

CAP 2010

- Provides information about the

Not available

CREHPA, nd 


\title{
The Study Team
}

The Core Professional Team

Mahesh Puri

Principal Investigator

Anand Tamang

Suveckshya Shah

Badri Dulal

Co-Principal Investigator

Research Officer

Research Officer

\section{Field Supervisor}

Achala Shrestha

Pabitra Shrestha

Kamala Karki

Prakriti Regmi

Saraswoti Shrestha

Hemu Khadka

\section{Field Researchers}

Anustha Mainali
Beli Lama
Chandani Bajracharya
Gayatri Baniya
Gita Paudel
Jeny Pokhrel
Laxmi Basnet
Laxmi Bhandari
Maiya Koirala
Manju K.C.
Mina Dhakal
Mina Giri

\author{
Mina Shrestha \\ Nirmala Sigdel \\ Parbati Lamichhane \\ Priyanka Baidhya \\ Radha Bhattarai \\ Radhika Pokhrel \\ Sita Sapkota \\ Srijana Poudel \\ Sujita Tamrakar \\ Sunita Sapkota \\ Sushma Rai \\ Usha Kiran Pokhrel
}

\section{Project Support Staff}

\author{
Ms. Sabina Tamang \\ Mr. Dev Chandra Maharjan \\ Ms. Radhika Singh
}

Administration and Finance

Data Management Officer

Word Processor 
Printed at :

systemsvision@gmail.com 
